San Jose State University

SJSU ScholarWorks

Master's Theses

Master's Theses and Graduate Research

Spring 2010

\title{
Where's My Daddy? Effects of Fatherlessness on Women's Relational Communication
}

LaToya Marie Jackson

San Jose State University

Follow this and additional works at: https://scholarworks.sjsu.edu/etd_theses

Part of the Counseling Psychology Commons

\section{Recommended Citation}

Jackson, LaToya Marie, "Where's My Daddy? Effects of Fatherlessness on Women's Relational

Communication" (2010). Master's Theses. 3767.

DOI: https://doi.org/10.31979/etd.xy86-vnm6

https://scholarworks.sjsu.edu/etd_theses/3767

This Thesis is brought to you for free and open access by the Master's Theses and Graduate Research at SJSU ScholarWorks. It has been accepted for inclusion in Master's Theses by an authorized administrator of SJSU ScholarWorks. For more information, please contact scholarworks@sjsu.edu. 
WHERE'S MY DADDY: EFFECTS OF FATHERLESSNESS ON WOMEN'S RELATIONAL COMMUNICATION

\author{
A Thesis \\ Presented to \\ The Faculty of the Department of Communication Studies \\ San José State University \\ In Partial Fulfillment \\ of the Requirements for the Degree \\ Master of Arts
}

by

LaToya Marie Jackson

May 2010 
(C) 2010

LaToya Marie Jackson

ALL RIGHTS RESERVED 
The Designated Thesis Committee Approves the Thesis Titled

WHERE'S MY DADDY: EFFECTS OF FATHERLESSNESS ON WOMEN'S RELATIONAL COMMUNICATION

\author{
by \\ LaToya Marie Jackson \\ APPROVED FOR THE DEPARTMENT OF COMMUNICATION STUDIES
}

SAN JOSÉ STATE UNIVERSITY

May 2010

$\begin{array}{ll}\text { Dr. Priya Raman } & \text { Department of Communication Studies } \\ \text { Dr. Deanna Fassett } & \text { Department of Communication Studies } \\ \text { Dr. Shawn Spano } & \text { Department of Communication Studies }\end{array}$ 


\title{
ABSTRACT \\ WHERE'S MY DADDY: EFFECTS OF FATHERLESSNESS ON WOMEN'S RELATIONAL COMMUNICATION
}

\author{
by LaToya Marie Jackson
}

The purpose of this thesis research was to understand the relationship between father absence and women's communication styles in romantic heterosexual relationships under social cognitive theory. Two studies were conducted using a multi-method research approach in order to triangulate the results. Seven fatherless women were interviewed to arrive at a better understanding of how father absence informed their romantic relational experiences. Specifically, the topics of relationship roles, selfdisclosure, expression, and self-silencing in romantic relationships were examined in the interviews. Participants reflected on what growing up fatherless meant to them and whether or not this had any influence on the role they played (dominant, submissive, egalitarian), and how open or closed they were in their romantic relationships (from their own perspective). Open communication refers to whether or not individuals express their thoughts, feelings and needs as well as how often they express these thoughts to their partners. Questions were also asked to determine whether these women self-disclosed intimate details to their romantic partners or self-silenced themselves. An online quantitative survey $(N=131)$ examined similar research questions and tested predictions based on the results of the first qualitative study.

The results from the interviews indicated that fatherless women consider themselves to be open, able to easily express themselves, independent and even dominant in their romantic relationships; yet despite holding these characteristics, these women 
remained in dysfunctional relationships for long periods of time. Further, when selfsilencing did occur, it was because they did not want to not "push" their significant others away. There was also a tension between wanting to hold a dominant role in their romantic relationships and also being attracted to men who hold stereotypical male gender roles. Hence, there was a tension with agreeing or disagreeing with these socially constructed gender roles. In the second study, women who grew up fatherless had a significantly less happy childhood upbringing than those who had fathers. Also, in line with the results from the first study, fatherless women tended towards higher scores on self-disclosure, greater ease of expression, and lower scores on self-silencing. Significant associations were found between negative relationship with father and relational selfesteem, overall self-disclosure and overall self-silencing in romantic relationships. The respondents who had negative relationships with their fathers self-disclosed less in their romantic relationships and self-silenced more, hid their feelings more, and privileged their romantic partners in communication interactions. Taken together, findings from this triangulated study add to the nascent body of work examining and explaining the deleterious fallout from father absence on women's communication and other variables in their romantic relationships. 


\section{ACKNOWLEDGEMENTS}

I dedicate this thesis to my mother, Terry Cabral, and my grandparents/guardian angels, Fidencio y Teresa Cabral. While I discuss many of the obstacles I have faced as a fatherless woman in the context of this work, it is because of them that I have reached my academic goals. They have shaped me into the person I am today. My mother worked extremely hard as a single parent to provide for me. She has provided me with ample love-for both herself and my father, and for that I am eternally grateful. My grandparents taught me to always stay humble and true to myself, and I thank them for migrating to this country and providing me with the opportunity to obtain a higher education. Further, I also owe my academic success to the mentors that I have had throughout my academic career, beginning with Dr. David Zuckerman.

I never believed that I was smart enough to go to graduate school and as my undergraduate advisor and professor, Dr. Zuckerman taught me not only to think critically, but also supported and encouraged me to attend grad school. Rebecca and Xuan from UC Santa Barbara-you two helped me immensely throughout the grad school application process and taught me such a valuable lesson about helping others. I promise that I will continue your legacy of helping La Raza to excel and become successful in our society. Of course I cannot go without mentioning those professors at San Jose State University, who not only taught me the theory behind communication studies, but also the true meaning of being part of a community- especially Dr. Rona Halualani, Dr. Deanna Fassett, Dr. Shawn Spano, and Dr. Priya Raman, my advisor. Dr. Spano, I value your intelligence and welcoming attitude. I only regret not having the 
opportunity to take more courses with you. Dr. Fassett you have seen me throughout various stages of my graduate schooling, and I thank you for always being so supportive in my time of need. You are an excellent mentor! Dr. Raman, thank you for your optimism and for being such awesome advisor! We are an excellent team! Your patience and positive attitude will never be forgotten. You kept me going when all I wanted to do is give up. I would also like to thank my colleagues in the GTA program; my goodness, I could not have completed this program without you all! Thank you for such rich conversations, and especially for providing me comfort in knowing that I was not alone in my stress. I would especially like to thank my girl, Teresa Teng. Words cannot explain how grateful I am to have you as a colleague and friend. Thank you for your support always!

It is of great importance that I take the time to thank my participants who contributed such rich stories to my thesis. Your stories have inspired me, as I am sure they will inspire those who read this thesis. Finally, I would like to thank my support network, who always encouraged me to stay strong, would listen to both my excitement and stress throughout grad school, and always provide me with tons of love and support—Jessica Ramirez, Olivia Martinez, and Mario Lainez. Jessica, I'm so glad we were both going through our grad programs together. It was enlightening to speak to someone who was going through the very same excitement and anxiety as me. I admire you and am so proud of your accomplishments. Olivia, my BFF, you are one of a kind. Thank you for consistently providing me with words of encouragement, these words always pushed me to continue to work hard. Mario, you are such a great man! Thank 
you for being such an awesome person and always supporting me no matter what. Thank you for your patience with me, and for driving me to the bay area to attend class when it was too painful for me to do so after surgery. Thank you for being so proud of me, and listening to all of my grad school and teaching stories, and providing me with excellent words of advice. Thank you for being my rock, I love you!

In summary, I dedicate this thesis to fatherless women everywhere. While perhaps being fatherless has provided an immense obstacle in our path, we must continue to be independent, strong women. We must reach for the sky and accomplish all of our goals. We must make sure that we surround ourselves by positive male figures, especially our significant others. We must not be in negative relationships, but be with a man who treats us with love and respect. And most importantly, we must stop the cycle and make sure that the men we bear children with are great fathers, and, positive male role models for our children. Let us put an end to the negative associations related to father absence! 


\section{TABLE OF CONTENTS}

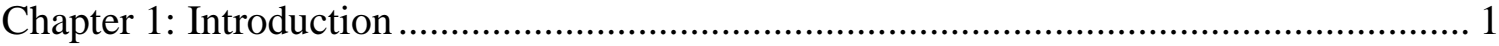

The Personal Narrative of a Fatherless Child ........................................................... 1

Chapter 2: Literature Review .................................................................................. 12

The History and Troubles Associated with Father Absence.................................... 12

The Effects of Fatherlessness on Female Development ............................................ 18

The Importance of Father-Daughter Communication............................................ 24

Communication Styles in Romantic Relationships................................................. 37

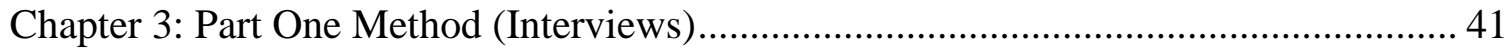

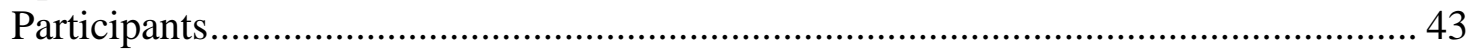

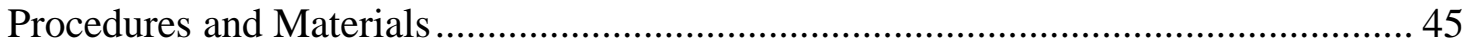

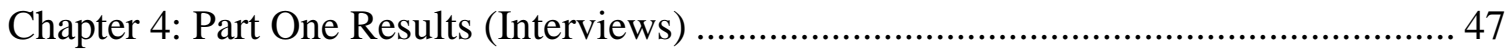

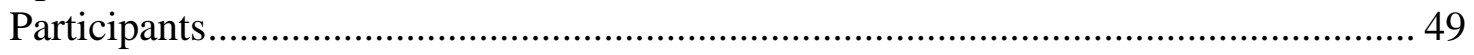

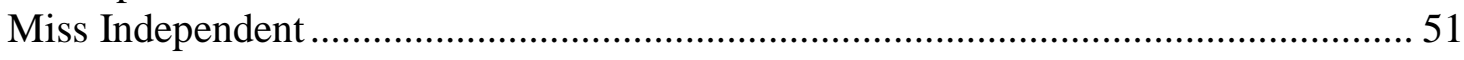

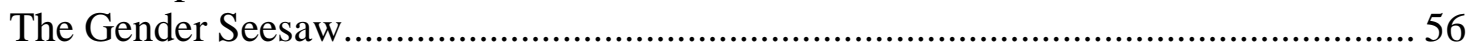

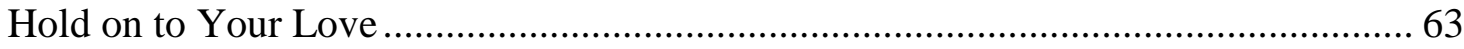

Don't Speak .................................................................................................. 70

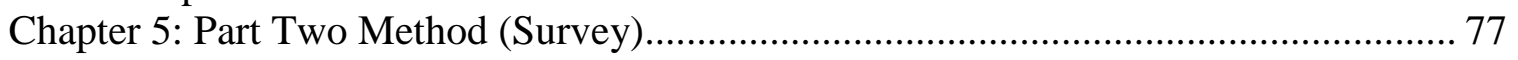

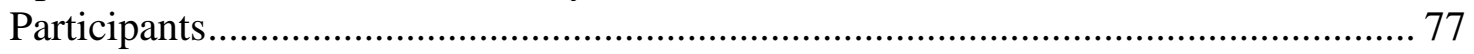

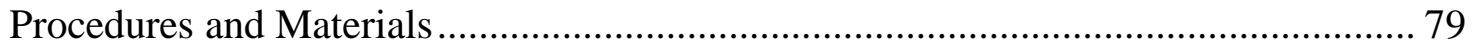

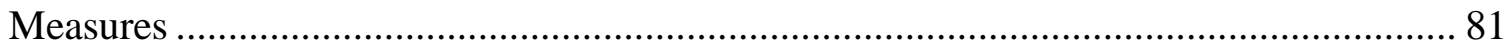

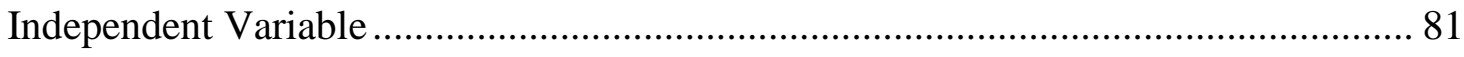

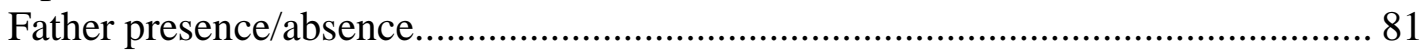

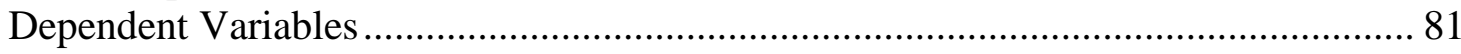

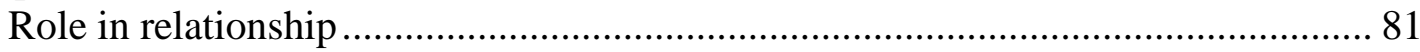

Self-disclosure

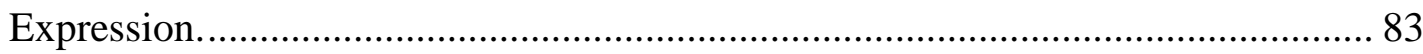

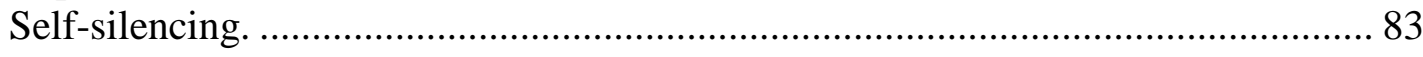

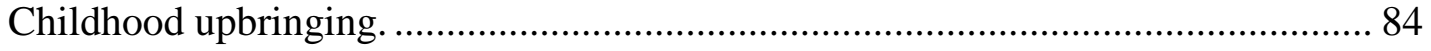

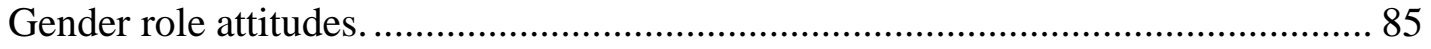

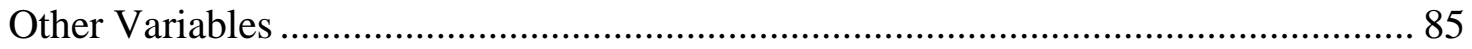

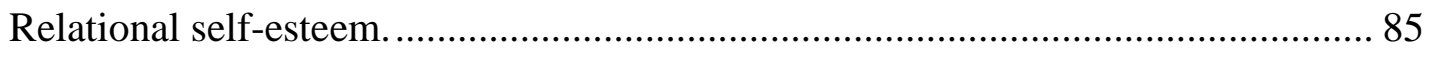

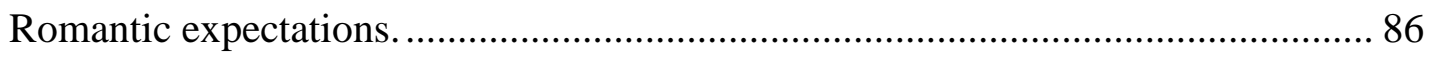

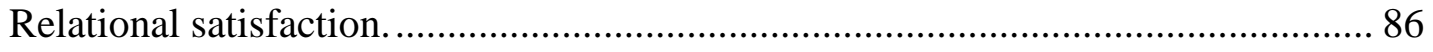

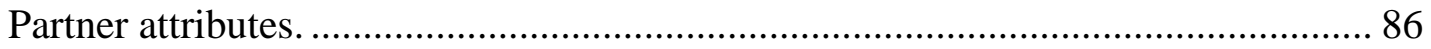

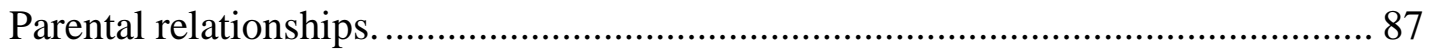

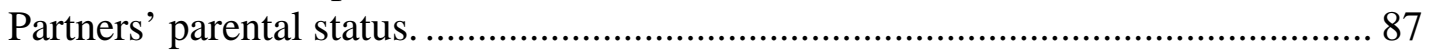

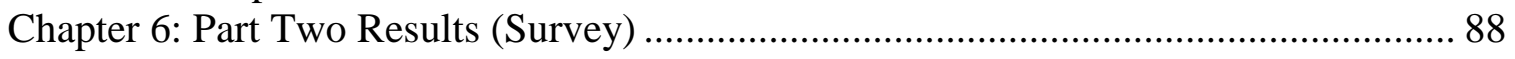

Descriptive Characteristics for Fatherless Women Only ....................................... 88

Descriptive Comparisons between Fatherless Women and Non-Fatherless Women... 89

Fatherlessness and Gender Role Attitudes........................................................... 90

Fatherlessness and Relational Self-Esteem.......................................................... 91 
Fatherlessness, Childhood Upbringing, and Parental Relationships ........................ 91

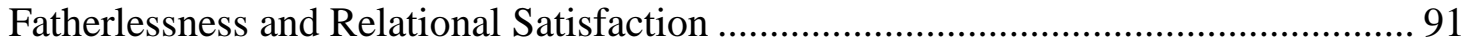

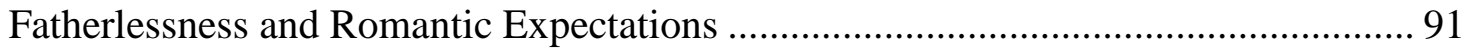

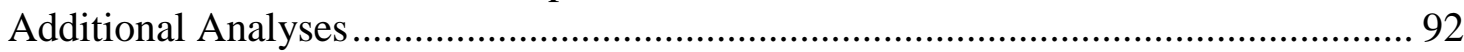

Fatherlessness and Family Household Income ....................................................... 92

The Effects of Romantic Partner's Fatherlessness on Relational Satisfaction ............ 93

Relationship with Father and Relational Self-Esteem ......................................... 93

Relationship with Father and Self-Disclosure ............................................... 93

Negative Relationship with Father and Self-Silencing ....................................... 94

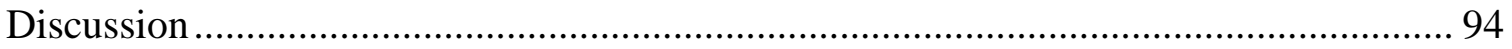

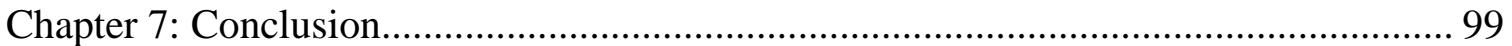

The Relationship between the Findings and the Research Questions...................... 100

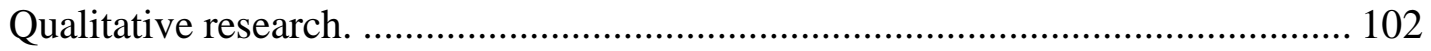

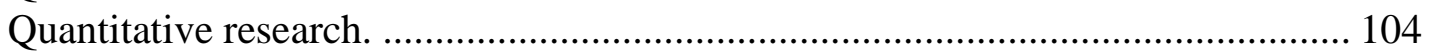

Findings from qualitative and quantitative studies. ............................................. 104

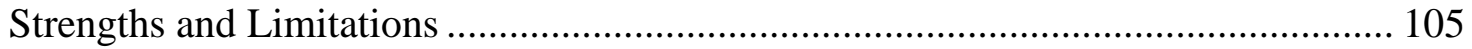

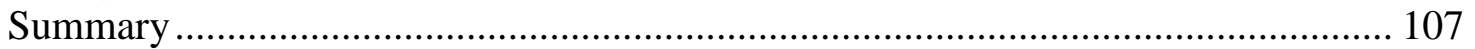

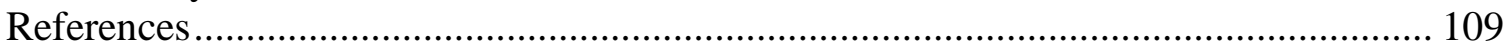

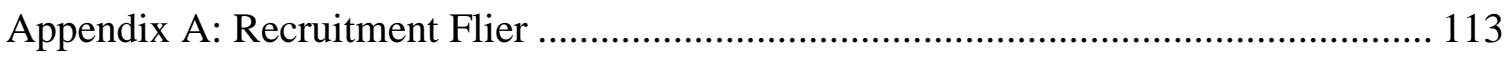

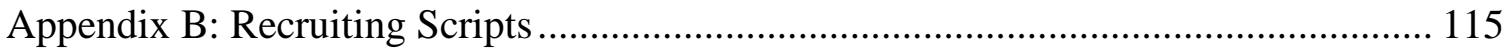

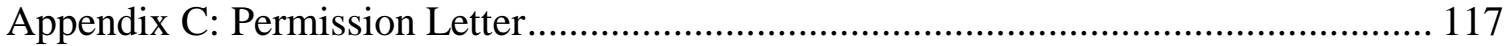

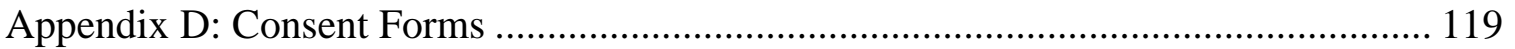

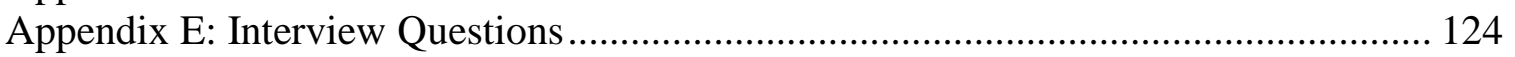

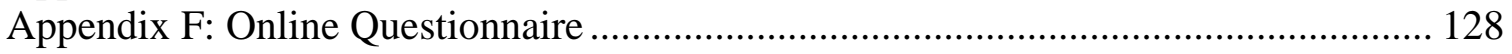

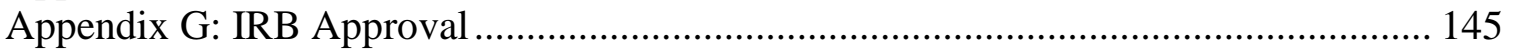




\section{LIST OF FIGURES}

Figure 1. Anxious Attachment Style (path model).................................................. 20 


\section{LIST OF TABLES}

Table 1. Correlation Matrix - All Variables..................................96

Table 2. Correlation Matrix - Relationship with Father and Other Variables.....97

Table 3. Partner Attributes..................................................98 


\section{Chapter 1: Introduction}

\section{The Personal Narrative of a Fatherless Child}

"Your daughter is one of the lucky ones," said my mother's child support caseworker. My mother was bragging about me, her daughter, who was currently pursuing a Master's degree and teaching college students. The caseworker seemed surprised to hear about the goals I had accomplished. She explained to my mother that she had seen many cases where women brought up without their fathers fall into negative life-patterns. They may drop out of school, have poor interpersonal and relational management skills, or even end up becoming single mothers themselves. Although I was fortunate enough not to fall into these categories, "lucky" was never a word I identified with as a child. I never considered myself lucky. In my adolescence and even into my adulthood, I suffered many struggles as a result of not having a father. I love my mother very much and, while I am extremely grateful to her for all of her hard work and dedication in raising me by herself, her unconditional love could not fill the void left by not having a father in my life.

\section{$* *$}

I am three years old when I first ask my mother, "Mommy, where's my daddy?" My mother responds with politeness and does not bad mouth my father, nor what I later perceive to be his devastating and decimating abandonment. She says, "You have Papi Lencho [my grandfather] and Tio Rigo [my uncle] and your cousins who all love you and who you can look at like your daddies." So, I had several fathers. Men that I "adopted" as a "daddy" and who in turn gave me unconditional love and protection. However, this 
love did not fill the emptiness of not having a relationship with my biological father.

Therefore the title of my research is "Where's my daddy?" simply because I cannot count the number of times I asked my mother this question. Further, I am certain that this is the very same question that millions of fatherless little girls have asked their mothers.

I grew up keenly aware of feeling extremely "different" in the small town of Redding, California. I felt different not just because I was fatherless, but also because I was a child of color. For me, fatherlessness and race are inextricably intertwined. My mother is Mexican-American and my father is Japanese and African-American. Therefore not only was I one of few minorities in the community where I was raised, but also a minority within my own family. I was raised by my Chicana mother and by her parents who migrated to the U.S. from Mexico in the late 1950s. My first language was Spanish, the only language spoken in my home. My traditions and strong Catholic religious beliefs derived directly from my Mexican heritage. However, my physical features derived from my African-American heritage. I had extremely curly (nappy) hair and was darker than most members in my family, and I felt "different" from them.

Both Papi Lencho and Mami Tere spoiled me with love, food, clothes and toys. I know that they did this to alleviate any hurt I experienced through the absence of my father and the color of my skin. I remember one instance when my grandfather told me in Spanish “Mija, you're not Black, you're Mexican. You don’t even look Black, you look Mexican." While this may seem horrifying to some, I know that my grandfather did 
not say this with malicious intent. He made this comment to emphasize his love for me, and to reassure me that I "belonged" and was part of the family. However, to my peers in school I was "Black". This made it especially hard and confusing the first time I was called the "N" word.

Based on my physical appearance, most people immediately believe that I am half-White and half-Black. However, the minute I begin speaking Spanish the question arises, “Are you Dominican, Cuban, Puerto Rican?” Typically once a person finds out that I speak Spanish, I am associated with Latinas who have physical features of AfricanAmericans. Hence I spent the majority of my adolescence stuck-not really belonging to one racial group or the other, trying to fit in and understand my place in this world. I grew up with a longing to be in touch with my African-American roots, and this is something that I struggle with and continue to desire. I have always felt that a huge chunk of me is missing; a part of my identity is missing that only my father can fill. This is a void that only my father can fill with his stories, his traditions and his beliefs. As long as he is not a part of my life, I will always long for those things to be instilled in me. Therefore while race is an important part of who I am, I believe that being fatherless is a more salient part of my identity. Further, the majority of the struggles I have faced in my life are linked to my fatherlessness. In overcoming these obstacles, I have become the person I am today.

My teenage years were a struggle to establish a sense of place and identity. Today I have come to peace with my story and have developed a better understanding of who I am. However, I find that, even as a scholar, I revisit questions that troubled me as 
a child. I am drawn towards exploring the effects of father absence on children, specifically their abandoned daughters. In my case, "his" rejected daughter. I find bits and pieces of my own story reflected in the research in this domain. For instance, similar to other fatherless women (e.g., Barras, 2000), I had several men that I "adopted" as fathers. I found that a father instills not only his beliefs in his children, but specifically shapes his daughter's femininity, a huge part of her identity (Blankenhorn, 1996; Calvin, 1993; Krohn \& Bogan, 2001; Mackey \& Coney, 2000). More notably, this influence (or lack thereof) is reflected in the daughter's own romantic relationships. Perhaps the abandoned daughter searches for a man who will protect her. Or she lacks the skills or the judgment to make successes of her relationships. Or perhaps this perception is colored by my own history.

I think back to my own romantic relationships and can quickly summarize them as: Cheater, Commitment-phobe, Cheater, Liar, and Cheater. If it was a messed up relationship, I was likely in it. I will admit that I was a bit surprised when I found that there is a direct link between being fatherless and the likelihood of being in dysfunctional romantic relationships. That is, fatherless women are more likely to be single mothers, engage in promiscuity, and end relationships quickly in fear of abandonment (Aquilino, 1996; Atkins et al., 1994; Blankenhorn, 1996; Calvin, 1993; Krohn \& Bogan, 2001). This is not to say that all fatherless women are or will be in a dysfunctional relationship, however I have personally known quite a few who have fallen into these categories, including myself.

I've heard that women tend to date and go onto marry men who resemble their 
fathers. Many of my girlfriends have agreed that their significant others have had the same personal characteristics as their fathers. I, on the other hand have never been attracted to a certain "type" of man. The men I have dated have varied in physical appearance, ethnic background, personality and religious background. Nonetheless, I always blamed my past significant others for walking all over me, cheating on me, and being noncommittal. However, in retrospect, I realized that I had allowed this to happen. I was afraid of being abandoned by my partner, and, for that reason, I did whatever it took to keep that person in my life. I have always naturally been passive in relationships. I have kept thoughts and feelings to myself in fear of losing or upsetting that loved one. I always tried my best to avoid confrontation and arguments, even if that meant selfsilencing my true feelings and needs. I did whatever I thought I needed to do in order to keep that male presence in my life.

Calvin (1993) explains that fatherless women tend to cling to their partners in a suffocating manner in fear of these men abandoning them as their fathers once did. On the other side of the spectrum, fatherless women are also known for breaking off relationships quickly before their partners can abandon them. I fall into the first category. More importantly, as a communication scholar, my questions are not so much psychological but communicative. I wondered if other fatherless women also express their feelings less or suppress their feelings in romantic relationships for fear of abandonment. The cognitive psychology literature undoubtedly shows that there are many psychological factors associated with father absence (Aquilino, 1996; Atkins et al., 1994; Blankenhorn, 1996; Calvin, 1993; Krohn \& Bogan, 2001); however in the 
communication studies field, there are limited articles on father-daughter communication, and further, on how father absence affects (if at all) how a woman communicates with other men in her life. Nonetheless it is apparent that children must learn how to behave and interact from a particular source, and this first source of socialization typically is the child's parents. Hence, does the absence of one of these parental figures, here specifically the father, affect the daughter's communication style?

Since this research topic is fairly new in the communication studies discipline, my thesis is an exploratory study. As such, there may be more than one theory that fits the framework for this thesis. For example, theories of adolescent development state that relationships formed in childhood can affect future sense of self both cognitively and affectively (Botta \& Dumlao, 2002). Similarly, social construction theory is also focused on relationships and interactions between people. Social constructivist scholars believe that a person's ideology is a social intervention, and meaning is developed through interactions between people. Further social constructionism is based on relationships and "personhood becomes a matter of how people are talked about, the social practices they engage in, and the particular relationships they find themselves in...the ways in which someone is identified, talked about, and treated all contribute to creating a particular identity for the individual" (Raskin, 2002, p. 10). This theory believes that "reality is socially constructed, based on people's definitions" (Cheung, 1997, p. 332). Both social construction theory and theory of adolescent development are well-known theories, however my focus for this research included not just how identity is constructed but also focuses on potential deleterious outcomes in the absence of a father's modeling positive 
behaviors and communication. Will a child be able to exemplify these positive behaviors and be able to be openly expressive to her romantic partner? Although social cognitive theory has primarily been used in the context of the mass media, it focuses on modeling and has also been used when it comes to gender roles.

Hence, the theoretical framework for this study is Bandura's social cognitive theory. This theory suggests that "people are self-developing, proactive, self-regulating, and self-reflecting, not just reactive organisms shaped and shepherded by environmental events or inner forces. Human self-development, adaptation and change are embedded in social systems" (Bryant \& Oliver, 2009, p. 94). People are not just products of social systems, but also the producers of them.

People gain understanding of causal relationships and expand their knowledge by operating symbolically on the wealth of information derived from personal and vicarious experiences. They construct possible solutions to problems and evaluate their likely outcomes, without having to go through a laborious trial-anderror process (Bryant \& Oliver, 2009, p. 95).

For the purpose of this research, the experiences as referred to by Bandura are the personal experiences between a father and a daughter or the lack thereof.

As a daughter, it is essential to engage in various personal and meaningful experiences with a father. These experiences teach us as individuals how to adapt to certain social situations. However, it is equally important for a father to be able to model positive behavior for his daughter to follow. Dail and Way (1985) discuss social cognitive theory (derived from social learning theory) and state that "individuals learn a great deal through imitation and, in social situations, may learn quite rapidly simply by observing the behavior of others" (p. 492). This is also known as modeling, and it 
presumes that direct observation is the most powerful stimulus for modeling to occur. According to Bandura's theory, "humans have evolved an advanced capacity for observational learning that enables them to expand their knowledge, and skills rapidly through information conveyed by the rich variety of models...virtually all behavioral, cognitive, and affective learning from direct experience can be achieved vicariously by observing people's actions and its consequences for them" (Bryant \& Oliver, 2009, p. 98). While such modeling can occur through the socialization of schools and communities, the likelihood is that this modeling is based on what is directly observed in the household by children. "Much social learning occurs either designedly or unintentionally from models in one's immediate environment" (Bryant \& Oliver, 2009, p. 98).

One part of social learning is to understand and perform gender roles. The femininity of a woman has been socially constructed to be a salient part of her identity and her role as a female. In turn, society puts an emphasis on the responsibility the father has in shaping his daughter's gender role. For instance, when the child is born, there is such clothing that reads "daddy's little girl” or "daddy's princess" or "team daddy." Imagine never being able to be included in this interaction of the two genders. A daughter may feel like she loses out on a host of life experiences. Bandura and Bussey (1984) claim that sex or gender roles are promoted through social influences that conduct gender labeling and structure activities in a way to teach children these roles. On the other hand, Bandura and Bussey (1984) also found in their study that children tend to emulate same sex behavior or modeling; that is, sons tend to imitate their fathers and 
daughters tend to imitate their mothers. Other scholars, however, have found that the father is also a model for the daughter to follow, shaping both her femininity and masculinity (Blankenhorn, 1996; Endres, 1997; Horan et al., 2007; Krohn \& Bogan, 2001). For example, his involvement and love builds her confidence, independence, and sense of love-worthiness.

Therefore, while theory of adolescent development and social construction theory could be considered pertinent for this thesis study, the focus of social cognitive theory and this research is on modeling, specifically the modeling of behaviors. Fathers model to their daughters how to manage conflict, and how to be independent. They model to them what it is to be loved and how to trust. They can also model positive behavior when interacting with their wives (the mother of their child). Based on this vicarious learning, children from a two-parent household can adapt these experiences to their own personal romantic relationships. Yet, would this assertion hold truth in a single parent home in the absence of the father?

As divorce rates are rising, so is single parenthood and father absence. According to the U.S. Census Bureau in 1998, approximately thirty percent of children under eighteen in this country lived with a single parent. Of this percentage, eighty-four percent lived with their single mothers. These compelling statistics make it imperative to study the communicative and psychological problems arising from father absence.

Most of the research framing the present project was from sources outside of the communication studies field in disciplines such as child development, psychology and counseling (Aquilino, 1996; Atkins et al., 1994; Carlson, 2006; Ellis, et al., 2003; 
McCormick \& Kennedy, 2000; Pollock, et al., 2001). The majority of these articles were studies using quantitative approaches, since psychology and counseling are primarily positivist disciplines. Although I consider myself an interpretive scholar, I do believe that the evidence provided by these quantitative studies will assist me in creating a framework for my own research. My thesis work will not only fill an apparent gap in the field, but also specifically describe and demonstrate the effects of fatherlessness on women's communication styles in romantic heterosexual relationships.

For the purposes of this study, father-daughter relationships are the communication and interaction between a father and a daughter. Additionally these relationships will be viewed based on a heterosexual dyad where both the father and mother take an active role in raising the child, and not a same-sex couple.

Further, this study will use a multi-method multi-paradigmatic approach from both interpretive and positivist worldviews to triangulate the data. In this particular case, I also feel that, just as it is important to gain a rich and deep understanding of the experiences of fatherless women, it is equally important to explore whether these experiences are generalizable to other fatherless women. Thus, the first step is to identify and describe the problem, judge its applicability to other fatherless women, followed by making larger society aware of such problems so that we can collaboratively create a solution. Four primary areas will support this study based on a review of previous literature: history and problems associated with father absence, the effects of father absence on female development, father-daughter relational satisfaction and communication, and communication styles in romantic relationships. The literature 
review follows in Chapter Two. 


\section{Chapter 2: Literature Review}

Research on fatherlessness and its effects on family dynamics is fairly new in the communication studies discipline. The current research is based mostly in fields such as counseling and cognitive psychology, both of which are positivist in nature. Therefore the articles used to create the framework for this thesis study are predominantly from a quantitative approach. In this chapter the review of the literature encompasses four broad topics. First, the historical and societal factors hypothesized to lead to father absence are examined. Second, a review of the injurious effects of father absence on female identity development is provided. Next, the importance of father-daughter communication is examined highlighting potential effects on daughters' communication strategies within their romantic relationships. Finally effective communication strategies in romantic relationships are discussed. The chapter concludes with the research questions to be addressed by this thesis.

\section{The History and Troubles Associated with Father Absence}

According to Barras (2000), four out of ten children in the United States are fatherless. Consequently, scholars have long sought to understand the historical and social factors that contribute towards father absence. For instance, Barras (2000) isolates one major historical event that occurred in American society, i.e. the feminist movement, and links it to father absence. According to Barras (2000), the feminist movement of the 1960s "spurred the death of the traditional male and created massive confusion about the

present and future role of men in American society" (Barras, 2000, p. 45). Women began to form a "we don't need them [men]" state of mind. Barras (2000) describes feminists 
as wanting to remove a double standard by sleeping with whomever they pleased and having children out of wedlock, therefore proving to "the man" that she can serve as both father and mother to her child. Women were irate about the inequality between the genders and wanted liberation. While this may be a somewhat logical explanation, the link between fatherlessness and the feminist movement is tenuous at best.

It was 1987 when my father stopped communicating with my mother and me. So while the feminist movement may have an association with fatherlessness, it did not play a specific factor in my life. My mother did not want to stick it to the man by pushing my father away, but rather wanted what was best for me. He was in and out of my life and she wanted a stable environment for her first-born. "Either stay in her life or stay out," she asked of him. He chose to stay out.

Similar to my experience, by 1996, $60 \%$ of African American, $19 \%$ percent of Caucasian and $30 \%$ percent of Hispanic children were living in father absent homes. The fathers of these children and my father decided to stay out of our lives. We were abandoned — our fathers were gone. Barras (2000) states that “...death puts an end to fathers. Abandonment puts an end to fatherhood...death is more personally final, but departure is more culturally lethal...” (p. 51). While fatherlessness oftentimes entails children who are fatherless due to bereavement, the focus of this paper is more towards children who are fatherless due to abandonment. The literature reveals that abandonment has a more harmful effect on the adolescent due to the fact that a child whose father has 
passed on understands that this was not the choice of the father. On the other hand, women who are fatherless as a direct result of abandonment may have a sense of "I was not good enough for my father to stick around."

Growing up, I never pointed the finger towards others for the abandonment of my father. However I did place the blame on myself: "I must have not been cute enough, that's why he left me!" or "I must have not been lovable." Oftentimes, and, to this day, I continue to ask myself the same questions over and over again, "Why did he leave me? How could any father abandon his child?" Previously, I discussed fatherlessness and its association with the feminist movement; Kristol (1994) discusses another social pathology that explains why fathers may choose to abandon their children. According to the author, fatherless families have strong links to Welfare programs and low socioeconomic status. Kristol (1994) notes that a beginning salary in the United States ranging from $\$ 6.00$ to $\$ 7.00$ an hour cannot support a family as well as the Welfare program can. Therefore a male may opt out of supporting his children/family to prevent the possible loss of his "manhood" by not making enough money to support his family. However, in order to reassert his manliness, the male will continue to father more out-ofwedlock children. This proves that while he may not be man enough to support a child, he is man enough to procreate. Notably, Kristol's (1994) research highlights the role household income or poverty may play in the relationship between fathers and their children. This theme is further amplified in the following study.

In more recent times, DeBell (2008) looked at the number of American children living in fatherless homes and what effects fatherlessness has on these children. This 
study found that approximately 19 million children in the United States are fatherless. DeBell (2008) terms fatherlessness a "social disaster" and elucidates how the deleterious effects of fatherlessness are intertwined with income and gender roles. In line with other scholars, DeBell (2008) finds that "income is relatively strongly associated with child well-being, and children living with two parents benefit from higher average household income and lower poverty rates than children in other family arrangements. There is evidence that when welfare states provide resources to single-parent families, children improve academically" (p. 429). Further, the modeling of gender roles or the absence of models has more negative fallout as a result of father absence. According to DeBell (2008), mothers traditionally tend to be the nurturers and fathers the disciplinarians in the home. However, if the biological father is no longer in the picture, it becomes difficult for the single mother to exemplify both of these roles to her child. Thus the child is not exposed to a gamut of parental guidance and role-playing behavior.

The negative effects of father absence manifest themselves in several other ways in fatherless children. Overall, fatherless children are less physically healthy and more likely to have attention deficit hyperactivity disorder (ADHD) than children living with a biological father. Fatherless children are also more likely to not enjoy school, repeat a grade, receive lower grades and be expelled or suspended from school (DeBell, 2008).

On the other hand, single mothers tend to be extremely more involved in the child's school activities than both biological parents. "Your daughter is one of the lucky ones," said my mother's child support caseworker. My Mom is a great disciplinarian. I never repeated a grade. I rarely received lower grades. I was never expelled from 
school. Perhaps I was "lucky" because I was able to make a positive outcome out of my life despite my fatherlessness. Nonetheless, while to others I was successful, emotionally and psychologically I was a mess.

It was 1997, and I was suffering from depression. I could not find an explanation as to why I felt so down. I did not eat. I would lock myself in the room and cry for countless hours. I read letters that my father wrote to my mother and cried. I cried hoping that he would magically sense my tears and come back to me. Now I understand how Craig's absence created a psychological burden on me. Researchers note father absence is directly related not only to a child's poor academic performance, but also to early sexual activity, poor interpersonal relationships and negative self-image, particularly in female cases (Aquilino, 1996; Atkins et al., 1994; Blankenhorn, 1996; Botta \& Dumlao, 2002; Carlson, 2006; Ellis, et al., 2003).

Aquilino (1996), for example, discusses how the life paths of children and parents are intertwined by examining historical data pulled from various national surveys. This data demonstrates the direct linkage between father absence and the life course of young adults, including school completion, home leaving, and entry into the labor force. This study highlights how transitioning to single parenthood, including stepparent and nonparental living arrangements, has been linked to lower probability of high school completion, academic performance and behavior problems, earlier movement toward residential independence, increased likelihood of child bearing and earlier marriage and cohabitation. Thus there seem to be strong links between father absence and children's relational choices too. 
Atkins et al. (1994) support Aquilino's (1996) argument that the lives of children and parents are intertwined. These authors discuss the role of family influences on sexual behavior in Latino and White adolescents. Atkins et al. (1994) found that "adolescent sexual attitudes are influenced by the frequency and type of communication that occurs within a family" (p. 974). The authors became interested in this topic because around that time period there were more than one million teen pregnancies annually, one in seven teens had contracted one or more sexually transmitted diseases and, in 1993, eleven thousand individuals between the ages of 13 to 24 had contracted AIDS.

Finally, Krohn and Bogan (2001) provide some compelling statistics about children in fatherless homes. These authors found that, in 1997, $63 \%$ of youth suicides, $90 \%$ of all homeless runaway children, $71 \%$ of all high school dropouts, and $85 \%$ of youths in prison grew up in fatherless homes. Further, fatherless daughters are 164\% more likely to become single parents as opposed to daughters who grow up in traditional households. More recent data demonstrates that more than 400,000 teen births annually in the United States are by unmarried mothers (Crary, 2008). Additionally, Crary (2008) agrees that "teen births do have substantial, widespread negative effects especially for the children of teen mothers...the children are more likely to be in foster care, less likely to graduate from high school...the daughters are more likely to have teen births themselves, the sons are more likely to be incarcerated" (Crary, 2008, p. A3).

There is no question that fatherlessness is a serious issue that not only affects the fatherless child, but society as a whole. Additionally, with the likelihood of fatherless daughters becoming single parents themselves, this epidemic is cyclical and gains more 
mass and momentum every cycle. These statistics demonstrate the many psychological and social problems associated with father absence, and hence the importance of studying this topic. These studies further support why research is needed in the communication studies field particularly since fatherlessness is linked to various negative factors in the female child's life. Thus, the next section shall discuss the negative consequences specifically faced by women who are fatherless.

\section{The Effects of Fatherlessness on Female Development}

A father plays a distinctive role in shaping a daughter's sexual style and her understanding of the male-female bond. A father's love and involvement builds a daughter's confidence in her own femininity and contributes to her sense that she is worth loving (Blankenhorn, 1996, p. 11).

Blankenhorn (1996) further associates a women's sense of love-worthiness to her independence in later relationships. If a woman has a good relationship with her father, she is less likely to be on a quest for male approval or seek male affection through promiscuous sex. This research highlights fatherless women as at a greater risk for early sexual activity, adolescent childbearing, divorce, and lack of sexual confidence. In summary, Blankenhorn (1996) argues that:

because they [fatherless women] are deprived of a stable relationship with a nonexploitative adult male who loves them, these girls can remain developmentally 'stuck,' struggling with issues of security and trust that wellfathered girls have already successfully resolved... When a girl cannot trust and love the first man in her life, her father, what she is missing cannot be replaced by her mother. Nor can it be replaced by money, friends, teachers, social workers, or well-designed public policies aimed at helping her. She simply loses (p. 10).

Therefore, without having a father to model to her what it is to be loved and how to trust, the daughter loses out and can experience issues of security and trust in her romantic 
relationships. Hence a woman's early experiences with her father have a link to what her experiences will be with other men in her life.

Why don't guys ask me out? I feel so unattractive. The boys at Anderson High circa 1998 are attracted to the blonde girls with blue eyes - the White girls. I definitely don't fit that criteria! I wish I was prettier/smarter/hotter...the list is endless. I was full of insecurities and my biggest insecurities were rooted in my African-American features and crooked teeth. Ironically, these were the very features given to me by my father, a father I did not know. So I felt doubly rejected - not just by my father but by most of the boys around me. The summer of 1998 (after what felt like a lifetime) I finally met a boy—Joaquin. He did not speak to me of love, only the cold language of "hook-ups" and "kicking it." I was drawn to him. I just want to be loved and feel attractive...even if I had to share him with his girlfriend. A couple of years later when he had a child with that girlfriend, I continued to stick around. I was infatuated with this man; or perhaps infatuated with the idea that he could be attracted to a Black girl with nappy hair and buck teeth.

My experience with Joaquin clearly demonstrates that I was clueless about how to deal with men. I allowed myself to be the other woman just because it was my first romantic interaction with a male. Since he was the first romantic relationship I had been in, I wanted to hold on tight and never let go of him. I was afraid of his abandonment. As Calvin (1993) states “Numerous studies have shown that a woman's early relationship 
with her father influences the ways she'll deal with all men—in both her career and personal life" (p. 161). According to this author, abandoned daughters are more likely to experience career problems such as inertia, lack of ambition and being easily intimidated by male authority figures. This woman may also create a fantasy image of her father and spend years searching for a person to fulfill that fantasy through intimate relationships. Calvin (1993) further discusses the notion that fatherless women tend to cling on to their significant others almost in a suffocating manner in fear of being abandoned just as they were abandoned by their fathers. Correspondingly, Christiani (2003) agrees that fatherless women tend to have an anxious attachment style in romantic relationships, which means that they are less inclined to leave a relationship despite any relational problems and its relative value (see Figure 1 for a path model). After dating Joaquin, I continued to exemplify this anxious attachment style in my future relationships.

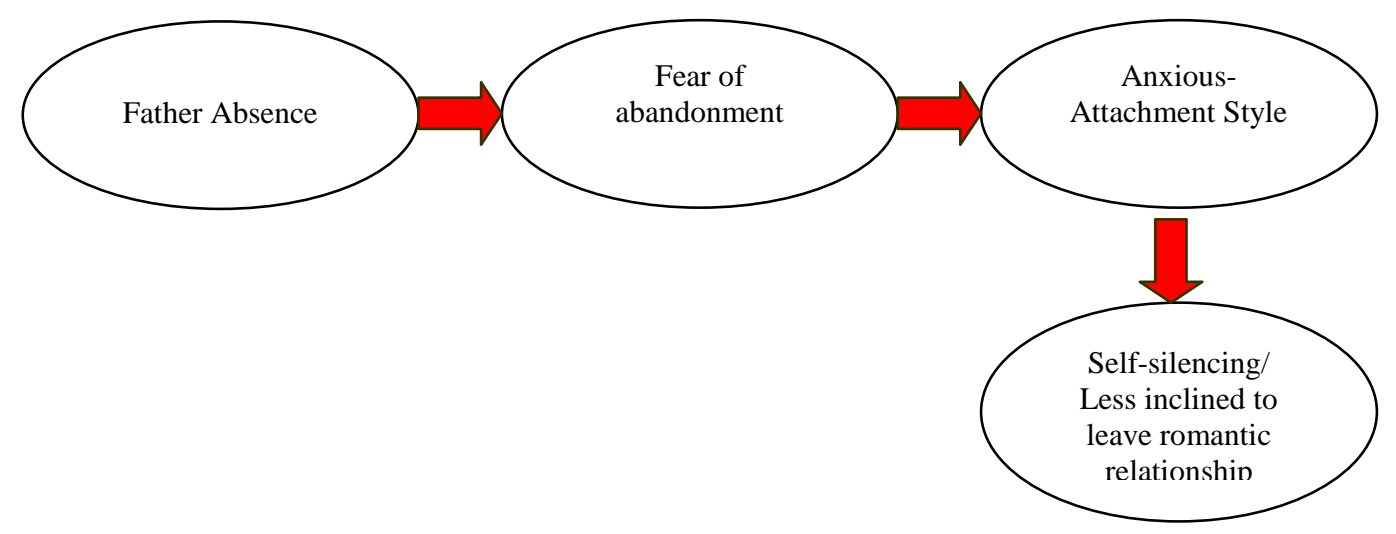

Figure 1. Anxious Attachment Style (path model). 
Picture it: Sacramento State University, 2001. It is my first week of college and I feel great! There is so much diversity and there are so many people who have similar physical characteristics as me. For the first time ever, I feel like I belong somewhere. I walk on campus and guys are hitting on me...I'm actually getting hit on! I meet Caleb and we immediately connect. Our friendship quickly turns into my first "real" relationship. I am in love and he becomes "my first." Seven months after meeting him, and three months after officially dating him, Caleb decides that things just aren't working out any longer. I was shocked! After the break up, I started off strong. “I don't need him!" Next thing I knew I was on the floor in his dorm room. "Please don't leave me! I can change! We can make this work." I was literally on my knees crying, begging him not to leave me. The picture is extremely vivid in my head, and I believe it was one of the weakest moments in my life. Nonetheless, just days after the break up, Caleb had a new girl. I came into Sacramento State feeling confident about myself, but my experience with Caleb threw that confidence right out the door.

**

Christiani's (2003) study found that fatherless women on average tend to have longer lasting relationships (although not necessarily positive) than other women, and this definitely held truth in my case. I continued to see Caleb whenever he chose to see me and on his terms for up until a year after the break-up. I thought I had learned from that relationship, but my next relationship was very similar to the first. 
Perhaps the word relationship does not adequately describe what I had with this next man because he and I were never officially together. He was my Mr. Big-the notorious bachelor and noncommittal antagonist on the series Sex and the City. He consumed four years of my life and all of my time, energy, will-power, and brain-power. "I'm not ready for a relationship," he would say. "How can I make you happy if I can't even make myself happy?" Mr. Big had a point. Regardless, as much as he told me that he was not ready to commit, I still stuck around hoping he'd have a change of heart. And very similar to my situation with Caleb, I found myself begging again. However this time I was not begging for a man not to leave me, but begging for him to love me and commit to me. "Why can't you just love me? Why won't you just be with me?" My previous relationships gave me the strength to leave this non-committal person. I was strong enough to leave and never physically go back to him. Although I must admit that mentally I always did look back and wonder a lot of “what-ifs.” He truly was my Mr. Big!

The narratives above describe my experience as a fatherless woman. I was clingy and felt a need for that male presence in my life. The minute I had a man in my life, my greatest fear was his abandonment. However there is also the possibility that a fatherless woman may engage in promiscuity and end relationships quickly so that her lover does not have a chance to abandon or reject her. Krohn and Bogan (2001) found that women who had little contact with their fathers had greater difficulties forming lasting relationships with men. These women would either shy away from men altogether or become sexually aggressive. However, the women who had fathers in their lives were 
able to interact with males by following the father-daughter relationship model. Mackey and Coney (2000) explain this phenomenon as being associated with the father's absence during his daughter's formative years. According to these authors, the father's absence negatively effects the development of the psycho-sexuality of his daughter. The authors further elaborate:

The suggestion is that this early influence lends itself to an easier achievement of a successful pair-bond by his daughter-grown-to-maturity. Thus, it is suggested that the early and consistent contact between a daughter and her biological and social father serves to set her psycho-sexual template, which--years later-influences her reproductive tactics. In this instance, it is the number of partners that is the focus. An out-of-wedlock birth effectively precludes such contact between herself and her biological and social father. It is suggested here that, without such contact, the girl's psycho-sexual template is forged more diffusely and becomes less selective (Macky \& Coney, 2000, p. 349).

If a father had been present, the child would be less likely to engage in promiscuous sex, which could possibly lead to that woman being a single parent herself. Further, Krohn and Bogan (2001) argue that in their study fatherless women suffered from apprehension and demonstrated inadequate skills in relating to men. In the case of the fatherless woman, a mother's attitude and behavior towards her child is equally important because it affects the way her child adjusts to such a situation. However, oftentimes the mother is the breadwinner and has less time for her child.

The previously mentioned studies indicate that, as a result of being fatherless, women carry on the emotional baggage onto their romantic relationships. However, the question remains as to why? McCormick and Kennedy (2000) found that women who are fatherless due to divorce or abandonment reported lower self-esteem than women who grew up in a traditional household. More specifically, children who reported being 
fatherless as a result of divorce reported lower self-esteem, acceptance in childhood, and acceptance in late adolescence by their fathers. On the other hand, children who were fatherless due to abandonment reported feeling less acceptance in late adolescence by their fathers. Further, women overall reported less independence-encouragement by their fathers in late adolescence than men. Therefore, if a fatherless woman experiences low self-esteem in her formative years, it is likely she will carry this onto her romantic relationships. The fatherless woman may find difficulty learning the concept of independence since her father was not around to model this for her. Further, she may never truly feel accepted by her significant other since she never felt a sense of acceptance by her father. The above studies indicate the extreme importance of the father figure on the female's identity. The focus next shifts to the significance of fatherdaughter communication and whether it affects women's communication styles in romantic relationships. In the next section the importance of father-daughter communication for each individual in this dyad is examined.

\section{The Importance of Father-Daughter Communication}

The interpersonal theory of adolescent development elucidates how a father is crucial in shaping the identity of the daughter (Botta \& Dumlao, 2002). This theory suggests that the interpersonal relationships that a child forms growing up can affect his or her sense of self. Further a dysfunctional family environment can create a negative self image, which can then contribute to self directed hostility and the development of poor interpersonal relationships as an adult. Additionally it was found that a daughter's relationship with her father as an adolescent relates to self-esteem more so than her 
relationship with her mother. The deleterious effects of negative or low self-esteem manifest themselves in strained interpersonal relationships.

With regard to communication within the family, Botta and Dumlao (2002) explain two dimensions of communication related to family communication patterns. The first refers to conformity orientation, which is the degree to which parents create an environment that emphasizes consistent attitudes, values and beliefs between family members. Secondly, the authors compare conformity orientation to conversation orientation, which refers to supportiveness, open communication and an independence of thoughts and feelings between family members. Theoretically, children exposed to consistent and open communication will be better adjusted socially and emotionally than children exposed to closed (non-modeled) and inconsistent communication. The following descriptive examples from four studies further support the concepts and theory presented by Botta and Dumlao.

In order to have a better understanding about the relationship between a father and his daughter or a mother and her son, Horan, Houser, and Cowan (2007) explored gender roles in parent-child dyads. These authors conducted a study on the role played by parents in the gender development and sex typing of their children. These scholars define sex typing as "where a person feels controlled by their gender role and thus pressured to behave in a stereotypically masculine or feminine way" (Horan et al., 2007, p. 363). Horan et al. (2007) utilized Bandura's social cognitive theory as their theoretical framework for this study. This theory suggests that gender roles are modeled and reinforced by a parent to his or her child. The researchers hypothesized that 
"communicated gender role messages will differ based on the sex composition of the parent-child dyad" (Horan et al., 2007, p. 365).

Horan et al. (2007) found various outcomes as to whether children were encouraged to communicate in a more masculine or feminine demeanor by their parents. Six hundred and thirty five undergraduate students participated in this research, using a modified version of the Bem Sex Role Inventory. The study found that the gender role messages communicated by parents were dependent on the sex of the child. That is, parents encouraged their children to communicate in a more masculine or feminine manner depending on his or her sex. Further, "parent sex had a larger effect on the communication of feminine-gendered messages than did child sex in this study" (Horan et al., 2007, p. 368). For the purposes of this study, feminine gendered communication refers to being soft-spoken, sympathetic, compassionate, and cheerful. Masculine gendered communication refers to the socially constructed masculine styles of selfreliance, dominance, aggression, competitiveness, and ambition. However, the authors found that fathers do not relay feminine gendered messages to their sons or their daughters. It was found that fathers more than mothers stress strong gender identities with their emphasis on masculinity. Although other scholars have found that the father does shape his daughter's femininity, this article argues that fathers do not just encourage their daughters to communicate in a feminine manner, but rather in a masculine style (i.e., to communicate with self-reliance, dominance, aggression, competitiveness and ambition). Yet, this masculinity is encouraged and emphasized by a father towards his son more so than towards his daughter. Undoubtedly the role of the father is crucial in 
shaping the gender identity of his child, and, further, perhaps it is the lack of learning this masculine communication style by the father that makes it difficult for a fatherless woman to express herself to a male partner in her romantic relationships.

Just as a supportive environment and open communication between a father and child can contribute to a positive self image for that child, Endres (1997) found that daughters take on their fathers' communication style and, as closeness between father and daughters increase, so does similarity in style. Further, he found that, as a result of a poor relationship with a father, the daughter transfers all of her negative experiences to her romantic relationships with men. Most of the groups in this study accepted that their experience with their fathers shaped how their current relationships are with men. Additionally, these daughters also found themselves in relationships with men like their fathers. Endres (1997) states "clearly daughters' lives are shaped by their perceptions of their fathers: of how he communicates with her; of what they do together; of who she thinks she is" (p. 335). However, researchers should also focus on how father absence shapes women's lives and romantic relationships when they do not have that initial interaction with a male figure.

Punyanunt-Carter, in her 2005 study, discusses the myriad motives behind communication and parental/child satisfaction in father-daughter relationships. The results indicated that daughters communicated mainly with their fathers for affection, relaxation, pleasure and inclusion, and those who communicated for these motives had fathers who communicated for the same exact motives. The results also indicated that the strongest motive for daughters was affection while the strongest motive for fathers was 
pleasure. Daughters were also satisfied when their fathers expressed feelings of love to them and when there was communication between the two. "The least satisfied fatherdaughter relationships are ones in which daughters do not obey or communicate with their fathers" (Punyanunt-Carter, 2005, p. 299); fatherless women who do not have communication with their fathers certainly fall into this category.

The absence of a father throughout his daughter's childhood can affect her selfconcept into adulthood. This is proven in another study by Punyanunt-Carter (2007). She examined "how attachment theory affects perceptions of satisfaction in fatherdaughter relationships" (p. 105). The author uses attachment theory (Bowlby, 1969) to understand how a person's first relationship(s) or attachment bonds can have an effect on the person later on in his or her life. There are three types of attachment styles for adults: secure adults, avoidant adults and anxious/ambivalent adults. She found that daughter communication satisfaction was significantly related to father relationship satisfaction and vice versa. Secure individuals develop close relationships with others easily and do not worry about being alone or being emotionally hurt. Avoidant individuals are untrusting of others, independent and prefer to stay away from relationships. Anxious and ambivalent individuals are perceived as non-committal in relationships. Undoubtedly father-daughter communication shapes the self-concept and future relationships of these daughters; however fatherless daughters receive the shorter end of the stick by not having that figure in their lives to help develop attachments, social skills and identity. 
Based on the prior research, women communicate with their fathers for love and affection, and, the most satisfied daughters are the ones who have communication with their fathers. The following study demonstrates how women maintain relationships with their fathers. Punyanunt-Carter (2006) examined the influence of attachment styles on father-daughter relationship maintenance behaviors (positivity, openness, assurances, networking, sharing tasks, conflict management and advice). The results indicated that daughters in all attachment styles typically used assurances, conflict management and positivity to maintain their relationships with their fathers. As a relationship maintenance strategy, fathers in all three attachment styles mainly used assurances, conflict management, shared tasks, positivity and advice. Finally the results indicated that fathers were significantly more likely than daughters to use all relationship maintenance behaviors. Overall, Punyanunt-Carter (2006) found that attachment styles did not influence the usage of relationship maintenance behaviors for both daughters and fathers. Nonetheless, relationship maintenance behaviors did exist, demonstrating the importance of maintaining the relationship for both parties.

The previous studies discussed the importance of maintaining a relationship. However, just as it is important to be able to maintain a relationship, it is equally important to be able to resolve conflicts in the relationship. Further, it is important to be skilled at conflict resolution. Dumlao and Botta (2000) describe conflict as "communication that shows a struggle between two interdependent parties over goals they perceive to be incompatible or resources they perceive to be scarce" (p. 174). These authors state that conflict management is associated with relationship satisfaction and that 
children grow to understand how conflicts work and how to handle them based on what they experience at home. "Moreover, Family Communication Patterns [FCP] have been shown to influence long-term orientations to communication, including what information is focused upon and how a person learns to process incoming information, even after the individual leaves the family setting" (Dumlao \& Botta, 2000, p. 175). These authors once again refer to the Family Communication Pattern as their theoretical framework for this study that suggests that communication patterns develop from experience in interactions rather than personality characteristics. There are two dimensions to this theory: conformity and conversation orientation; where families can score high or low on either one of these dimensions. Further, laissez-faire families are parent-child relationships that score low on both dimensions (where they neither conform nor converse). Therefore children learn how to socially interact by other means outside of the home. Conflict styles are based on five styles, which are: avoiding, accommodating, confronting, compromising, and collaborating.

The results from the study indicated that children tend to emulate various conflict resolution styles based on whether their fathers are protective or not. Children who had laissez fathers had a lower accommodating and collaborating style than those children raised by a non-laissez faire father. However these children did not have a higher avoidance style. Further, "individuals with protective fathers had a higher avoidance conflict style and accommodating conflict style, and a lower confronting style and collaborating conflict style than those whose fathers were not protective" (Dumlao \& Botta, 2000, p. 182). Pluralistic fathers, those fathers who score high on conversation 
orientation and low on conformity orientation, had children who exemplified avoidance style, collaborating style and confronting style. In conclusion, the levels of conformity and conversation encouraged by a child's father also encouraged his or her styles of managing conflict. Collaborating and accommodating were the strongest and most consistent styles of conflict management exemplified by the father. Both collaborating and accommodating are key elements in sustaining a relationship. Therefore, if a father cannot or does not exemplify this to his child, who is to say that he or she will be able to manage conflict in romantic relationships? If a father cannot demonstrate to his child how to collaborate and discuss a conflict with his or her significant other, a child may be more prone to avoid the conflict and self-silence his or her thoughts or feelings.

The previously discussed articles demonstrate that parents undoubtedly create a framework for their children to follow when it comes to interacting and communicating with others. Harp, Webb and Amason (2007) used Bandura's social cognitive theory to study family interactions. These scholars agree that "rules for interaction are established in the family and reinforced by parents and siblings, ultimately creating normative behavior. [Further] parents typically serve as children's first communicative role models; thus, the interactions with parents may have the great impact on a child's communicative development" (Harp et al., 2007, p. 2). The goal of this specific research was to determine whether the communication patterns that children exemplify when in conflict with their parents is also used when in conflict with their romantic partners as adults. For this study, family communication patterns are used in the same context as discussed by Botta and Dumlao (2002) as conformity orientation and conversation orientation. These 
patterns in a parent child interaction can have two outcomes: either this family communication pattern is strictly used in a family context, or the family communication pattern can be so widely adopted that these children will make it applicable to any personal relationship. Therefore the family communication pattern could either prompt some sort of conflict behavior in a romantic relationship or it could be nonexistent. Additionally, families high in conformity focus on harmony and unity amongst family members and do not encourage individuality. Families low on conformity represent the direct opposite and emphasize individuality. Conversation-orientation is based on either encouraging the family to speak out about any irrelevant number of topics versus only speaking when absolutely necessary.

There were various measures used to understand the conflict management styles endured by the participants. To this end, Harp et al. (2007) used Thomas and Kilman's (1974) Conflict Mode Instrument to identify the five conflict management styles of: competing, accommodating, avoiding, collaborating and compromising. The sample consisted of one hundred and sixty college students and seven-point Likert scales were used to measure the family communication pattern and the conflict management styles. These researchers found that participants from two-parent households scored higher on fathers' conversation orientation than those participants who grew up in a single parent household. Further, participants from two parent households also reported higher collaborating with father scores and higher compromising with father scores than participants from single parent households. This is of course, because the father figure is not an active participant in the life of the child. Further, "four of the five conflict with 
mothers scores correlated significantly with comparable scores for romantic partners. In contrast, only two of the five conflict with fathers scores correlated significantly with comparable scores for romantic partner, i.e., competing and compromising" (Harp et al., 2007, p. 21). The authors go on to explain that this may be perhaps because the mother traditionally holds the more nurturing role in the household. "Mothers' [conformity orientation] was associated with two mother-child conflict scores (i.e., avoiding and compromising), perhaps indicating that mothers' desire for children's conformity stimulates and directs children to avoid and/or compromise with her" (Harp et al., 2007, p. 23). However let us look at this in the context of a fatherless child.

If a single mother is raising a child, she may raise her to conform to certain situations with a romantic partner and avoid certain situations. Further, without the father in the picture, a fatherless child could lack the conversation orientation taught to her by her father as well as the key elements of collaborating and compromising with her romantic partner. Research indicates that collaborating and compromising are both two key elements to maintaining a healthy romantic relationship (Pollock, Die, \& Marriott, 2001). Harp et al. (2007) describes compromising as the result of using a combination of assertive and cooperative behaviors showing both a concern for one's own goals as well as for the other's perspective and thus ultimately protecting the relationship. The parties engage in give and take with each party giving up something to acquire a concession from the other party" (p. 10). However, if the father does not teach or transfer the conflict management style of compromise to his daughter, how is she supposed to model 
this in her romantic relationships? Further, will she eliminate the concern for her own goals and take on only those of her romantic partner?

"Get out from under the table LaToya!" My mother yelled this at me the day she introduced me to the man who is now my step-father. I did not like the idea of my mom dating, and, for that reason, I got under the table at the restaurant and would not come out. I wanted her all to myself. Therefore, although my mother dated, I rejected any notion of her being in a relationship or interacting with a man that was not my father.

Kline, O’Neil, and Fay (2005) believe that “children may form their views about love and intimacy from observing how their parents relate to each other, from the attitudes that their parents hold about love and intimate relationships, or from how their parents relate to them" (p. 1). This seems simple enough and this concept coincides with Bandura's theory that children model what they directly observe in the home. The goal of these scholars was to examine what role family communication has on the love attitudes of young adults. These authors used love attitudes as their theoretical framework for this study as well as the view of family communication orientations as discussed by Botta and Dumlao (2002): conformity and conversation orientation. The theoretical framework of love attitudes suggests that there are six ways of loving: Eros, Ludus, Storge, Pragma, Mania, and Agape (Kline et al., 2005). Further, an individual can express one attitude of loving while still having the others present. 
There are six primary love attitudes, or ways of loving, and more than one attitude can be held at any given time. For instance, eros is an intense passion towards one another that is physically centered. Ludus is the attitude of love as a game played with multiple players/partners. The individual who falls in the storge category believes that love develops from a friendship; whereas the individual who falls in the pragma category believes that love is realistic and calculated rationally. Mania suggests that love is an emotional rollercoaster with its ups and its downs. Further the person with the mania attitude sees love as, at times, obsessive and unpredictable. Finally, someone with an agape attitude sees love as selfless and typically puts the other person first.

The purpose of Kline et al. (2005) research was to understand whether parents' love attitudes had any influence on their child's love attitudes. Fathers had more of an influence on the love attitudes of their children than mothers. This was found when two hundred and thirty six participants completed a questionnaire. These participants were college undergraduates, and they also had their parents fill out the questionnaire. Seventy-three percent of the parents reported to be married to the father of their child. The Love Attitudes Scale and Family Communication Patterns Scale were used to measure the variables. The scholars found no correlation between a mother's love attitude and that of their young adult children; however, there was a correlation between a father's love attitude and the love attitudes of eros, ludus, and mania in their young adult children. More specifically fathers and daughters had positive correlations between their ludus, pragma and mania love attitudes. Taken together, "fathers' love attitudes appeared to have a more pervasive influence on young adults' love attitudes, influencing 
four of the six styles in some way, compared to mothers' whose love attitudes affected just one of the young adults' love attitudes" (Kline et al., 2005, p. 15). Further, fathers with a high conversational orientation were likely to have daughters with higher pragma love attitudes. Fathers who reported high openness had children with higher agape love attitudes. Those fathers who reported providing support to their children had lower storge love attitudes; and those who reported providing advice had lower eros love attitudes. Hence it was found that the father plays an essential role in shaping his child's love attitude. While the love attitudes of ludus, pragma and mania may not be the most healthy love attitudes, they are aspects of love held at any given time by an individual. However if these love styles are not exemplified by the father, how are these love attitudes learned by children? The authors found that parents are the leading source for children to learn about love. Therefore if a father is not a part of his daughter's life, she may not fully understand what the concept of love is nor feel a sense of being completely loved. And how is she supposed to learn how a man is to love a woman if she never saw her father love her mother?

The Love Attitudes, as described above, demonstrate how truly complicated love and relationships can be. As a result, romantic relationships are growing more difficult to maintain due to communicative problems that arise. However, my research seeks to understand whether women who are fatherless are able to employ communication styles that are typically modeled by a father figure. Research demonstrates that women abide by the male-female relationship model taught to them by their fathers (Krohn \& Bogan, 2001). However, fatherless women do not have that person to teach them this. This 
could result in even greater difficulty in maintaining a romantic relationship, and, as a result, an increase in separation and divorce. As a study on a fairly new topic in the communication studies discipline, this research will fill an apparent gap in the field by examining not the psychological factors of fatherlessness, but rather the communicative aspects. The final section of this literature review focuses on the communication styles employed by couples in order to maintain a successful romantic relationship.

\section{Communication Styles in Romantic Relationships}

I have shed a lot of tears in my past relationships; nonetheless, I must admit that those relationships have trained me to become a more open person in my current relationship. In my prior relationships, I embodied a persona that just wasn't me. I was not myself and self-silenced not only my wants and needs, but also who I was. I am typically a very loud and outgoing person, yet I rarely exemplified this behavior with my romantic partners up until now. In my current relationship I have learned to be much more open. I am open about who I am and also about vocalizing what it is that I want, need or feel. I still find that I am not completely open with Romeo, but I pick and choose what to disclose to him. Sometimes I continue to self-silence certain thoughts, feelings or needs. Perhaps I self-silence them in fear of abandonment or perhaps I self-silence them to avoid an argument. The truth of the matter is that I am fearful of self-disclosing too much to my romantic partner. I am fearful because this is my first romantic relationship that is not dysfunctional where I feel truly loved, supported, and appreciated as a woman. I am also fearful because of my "daddy issues;" because I am scared of losing the first solid romantic relationship that I have had with a man. I am scared of being abandoned 
by my partner just as my father abandoned me. Yet, it is that very self-silencing that leads to future relational problems. So although I struggle with speaking my mind, I work very hard at overcoming this obstacle on a daily basis.

I face these struggles due to being fatherless because a father has a crucial role in shaping not only the daughter's identity, but her communication styles as well. Many agree that communication is the key to a successful relationship. Yet daughters raised in a fatherless home may not necessarily learn the communication styles they can use to establish a successful romantic relationship. However, the question remains as to what communication styles lead to a happy or successful relationship?

Pollock, Die, and Marriott (2001) found that couples that shared egalitarian marital roles rather than traditional roles exemplified better marital communication. These are roles in which both spouses are equals. Additionally, Johnson (1997) states that openness is what constitutes a good relationship. This includes being open to others and also being open to listen to the ideas, thoughts and feelings of others. Openness is also known as the communication style of self-disclosure. Johnson (1997) defines selfdisclosure as "revealing to another person how you perceive and are reacting to the present situation and giving any information about yourself and your past that is relevant to understanding your perceptions and reactions to the present" (p. 241). Further this author goes on to claim "healthy relationships are built on self-disclosure" (Johnson, 1997, p. 242). While I agree with the previously mentioned authors that two people must be open and honest with one another to maintain a healthy relationship, I also believe that this takes time and practice. 
I have grown quite a bit from my first high school relationship to my current relationship. With each of my previous relationships, I have learned what works and does not work in a relationship, and I have also learned how to be open, honest and to just be me. Scholars state that self-disclosure is a communication style needed to maintain a healthy relationship, however so is expression. McKay, Davis, and Fanning (1995) describe the importance of four categories of expression: observations, thoughts, feelings, and needs. Self-disclosure and expression are two key elements out of the many communication styles needed to maintain a healthy relationship. However, with the issues of identity faced by fatherless women and the lack of a father figure to follow the male-female relational model, these communication styles may be difficult to exercise. Therefore if these women are not self-disclosing or expressing themselves, they are self silencing. Uebelacker, Courtnage, and Whisman (2003) describe this theory as a process in which women seek a conflict-free relationship and therefore silence their thoughts, needs and actions. Self-silencing theory is based on the idea that women find relationships of central importance, and further find their sense of self in a relationship. In summary, women will self-silence themselves in order to maintain that close relationship. Self-silencing would be considered a communication block, and Corey and Corey (2002) describe communication blocks as making it difficult to have "I-thou encounters," which is when each person in the intimate relationship is open both with each other and him or herself and further expresses what he or she thinks and feels. Lastly these authors state that individuals "carry many of the patterns they established in their childhood into their transactions as adults" (Corey \& Corey, 2002, p. 361). Hence 
fatherless women may be more prone to encounter communication blocks such as self silencing and less prone to self disclose and be open with their romantic partners. Based on these concepts and on the research found in the review of the literature, the following research questions shall be explored in my thesis:

Research Question 1: How do fatherless women describe their experiences with their role in romantic relationships?

Research Question 2: How do fatherless women describe their experiences with self-disclosing in their romantic relationships?

Research Question 3: How do fatherless women describe their ease of expression in romantic relationships?

Research Question 4: How do fatherless women describe their experiences with self-silencing in their romantic relationships? 


\section{Chapter 3: Part One Method (Interviews)}

My thesis research involves a multi-method approach. More specifically, both qualitative interviews and quantitative surveys were used to understand how participants construct the experience of father absence and further to examine the same research questions with a quantitative focus. The purpose of the interviews was to comprehend and gain a deeper understanding of what it means to grow up in a fatherless home from the perspective of the participants. Further, the goal was to understand the role (if any) that fatherlessness plays in women's romantic relationships. The purpose of the survey was to test whether the patterns found in the interviews applied to a larger sample of fatherless women. Further the survey helped compare fatherless women and women who were brought up by their biological parents on variables such as ease of expression, selfsilencing, and self-disclosure. If a negative association does exist between fatherlessness and women's communication styles in romantic relationships, the ultimate intention is to make larger society aware that fatherlessness does not only contribute to psychological problems, but also to aspects that are relevant to the communication studies field.

As an interpretive scholar, I am fascinated with understanding communication phenomena in depth and describing the experiences of fatherless women. I am a strong believer that reality is constructed through social experience and that the knowledge that these women have is based on their subjective meanings and experiences. Further as the researcher in this study I feel inextricably connected to my participants as a fatherless woman myself. Nonetheless while I may not completely connect with the epistemological and ontological assumptions of the positivist paradigm, I find that using 
quantitative methods is a useful addition to this thesis study. I feel the need to not only understand the experiences of fatherless women, but also distinguish whether or not these experiences are applicable to other women. I feel that by implementing a multi-method approach, solutions can jointly be created to address the problems associated with father absence. The following scholars further support my notion of the importance of using a multi-method research approach. According to Louis (1982) for thirty years there have been two paradigms of knowing that govern social science methods.

The first stresses the need to apply research design and analysis principles derived from the hard sciences, and emphasizes the desirability of experimental or quasiexperimental design and statistical analysis of multiple cases. The second paradigm argues that social phenomena are essentially different from those observed by the hard sciences and that, in order to understand them adequately, we must understand how they occur and what they mean to members of the social structure (p. 7).

While this article is extremely outdated, these two paradigms continue to exist and are dominant in the social sciences. Although the controversy has decreased between qualitative and quantitative researchers as to whose methodology is "right", the controversy has not been completely extinguished. However, Wong (2002) argues that a "heavy dependence on a single method in research can make the findings subject to the problem of methodological bias" (p. 247). Wong (2002) explains that a multi-method approach could help because the strengths of one approach can aid the weaknesses of the other. The two methods can complement one another.

Louis (1982), who discusses the commencement of multi-method research being conducted as early on as the 1960s and 1970s, explains the various positive dimensions of this approach. According to this scholar, researchers began to use a multi-method 
approach to further strengthen an analysis, point out interactions that should be researched further, and to discuss inexplicable findings that cannot be explained by one single method. Louis (1982) further argues that using a multi-method approach can eliminate the bias discussed by Wong (2002) and also allows for cross-site analysis. It is because of this that government agencies lean more towards using a multi-method approach. Of course using a multi-method approach can be a lot of work; however it is my belief that the end result makes it worth it. Therefore for the purpose of this thesis I will be using this approach. My interest is to understand the members of the social structure of fatherlessness, while also finding out whether the experiences of these women are applicable to multiple cases through the use of surveys and statistical analysis. Chapters Three and Four shall focus on the qualitative study. Chapters Five and Six address the quantitative study. Finally, Chapter Seven contains the general discussion of the quantitative and qualitative results, limitations and future directions for research, and the conclusion.

\section{Participants}

A convenience sample of seven participants were recruited for interviews based on contacts I had already established. These women were personal acquaintances of mine who I have known for at least six months. It was my belief that interviewing my "girlfriends" would allow for a rich, open and honest conversation of the fatherless experience. Further, I found that these conversations served as an opportunity to get to know these women on an entirely different level. While some of these participants were aware of the research being conducted and volunteered to participate, others were 
approached (in person or over the phone) and asked to participate in research that will be beneficial for the communication studies field. Please see the attached recruiting script (Appendix B). The majority of these participants are located in Sacramento, CA while some reside in the Bay Area. Further, these participants are women over the age of eighteen who were raised in a fatherless home due to abandonment. Hence, for the purpose of this research the conceptual definition of a fatherless woman shall be a female who has had limited to non-existent contact with her birth father since childhood due to abandonment on his behalf. Finally, the interviewees have been in at least one romantic heterosexual relationship. While a weakness with this sample is that I know these women on a personal basis which made it difficult for me to maintain the role of observer, the strength is that these women were prone to answer the questions more openly and honestly since they have an already established relationship with me. The participants were offered snacks (such as juice, water and muffins) during the interview portion of this study.

This research was a minimal risk for the participants. These participants did not undergo any type of harm; however discussing what it meant to grow up fatherless and recalling failed relationships was emotionally burdensome for some of the participants. Therefore the risk was the emotions that go along with discussing and recalling upsetting events. On the other hand, some of the participants stated that they benefitted from discovering new things about themselves and/or their relationships. Ultimately all of the participants are at a benefit by participating in research that is fairly new to the discipline, and highlighting members of an underprivileged group. 


\section{Procedures and Materials}

Prior to conducting the interviews and then recruiting additional participants to complete the survey instrument, a human subjects application was placed on file and approved by both San Jose State University and Sacramento State University's IRB committees since participants were recruited from both universities. Once these committees approved the methodology (see Appendix G), I began the interviewing process. However, prior to being interviewed, the participants were given a consent form as well as time to review and sign it (please see Appendix D). A signature was obtained before conducting the interviews. Upon obtaining a signature from the participant, she was given a copy for her records. Please see the attached consent form (Appendix D).

The interviews were held at a mutual location agreed upon by the participants and me. The hope was for the location to have a comfortable and open environment for the participant. As previously mentioned, to ensure the confidentiality of the participants they were asked to complete a consent form prior to commencing the interviews. The participants were asked a list of open-ended questions related to the research questions (see Appendix E). A total of seven participants were interviewed. The interviews were then transcribed and analyzed for common or recurring themes. However prior to analyzing the transcriptions, I emailed them individually to the corresponding participant to be certain that everything was captured correctly from the perspective of that participant. Criteria as outlined by Lindlof and Taylor (2002) were used to create the interview questions. I also explored what effects (if any) other factors such as relationship with the mother, relationship with another male figure that is not the 
biological father, etc. have on fatherlessness and self-silencing, expression, and self disclosure. Further the interview questions were open-ended followed by various probes (Appendix E). A weakness is that the answers to these questions are based on the perspective of the participant and memory, which may not necessarily be accurate. However this research's strength is that a mixed method approach is being utilized which will provide a set of two analyses that likely will overlap.

A digital tape recorder was used to record the interview portion of this research. This involved a minimal risk of discomfort for the participants as some felt uncomfortable being recorded and fearful that I cannot be trusted and that confidentiality will not be maintained. However, I was certain to reassure the participants that all information will remain confidential. While the interviews were taped for the purpose of transcribing and analyzing the data, all recorded tapes were locked up in my household, accessible only to me and only used for the purpose of the approved research. Lastly pseudonyms were used to refer to the various participants in the script of the thesis. 


\section{Chapter 4: Part One Results (Interviews)}

As previously discussed, my interest in this research topic derives from my fatherless upbringing. Throughout my collegiate years I noticed many negative patterns in my romantic relationships; however I always referenced those patterns to my inexperience as a romantic partner (which in part was the explanation!). It was not until I began reading up on fatherlessness that I realized that I fell into the many categories discussed in the literature. Particularly, I had a tendency to remain with romantic partners regardless of how poorly I was treated, or how unhappy I was (Calvin, 1993). I have a fear of abandonment. I further realized that this fear of abandonment also contributed to how I communicated in my romantic relationships. I self-silenced many of my thoughts, feelings and needs because I was fearful that my partner would abandon me, as my father once did. Although I have grown a lot, and am extremely more open with my current romantic partner, I wondered what role other fatherless women hold in their romantic relationships and how open/closed/vocal they are with their romantic partners.

Social cognitive theory states that learning is interactive. In other words, individuals' interactions are based on what has been modeled to them, or what they observe. Therefore, I envisioned that fatherless women would self-silence in their romantic relationships. I believed that they would self-silence themselves because their father did not model to them how to interact, and overcome problems with the opposite gender. I also believed that they would self-silence because of their fear of abandonment. However, upon engaging in dialogue with father-absent participants, I found that 
fatherless women encountered many tensions in their romantic relationships. It is important to note that these tensions could be explored further in our discipline using a relational dialectic framework. Relational dialectics has been mainly used to explore the tensions (push and pull if you will) people experience in both family relationships, and non-marital romantic relationships. "Central to the relational dialectics perspective is a commitment to understand salient contradictions, simultaneously united-yet-opposed themes" (Braithwaite \& Baxter, 2006, p. 33). Therefore, this theory emphasizes "the importance of studying contradictions as they are locally situated" (Braithwaite \& Baxter, 2006, p. 34). There were several contradictions or tensions that were found in the present research between the romantic role of fatherless women and gender roles, as well as between communication openness and relational length. These contradictions shall be explained in greater detail in the context of the findings.

I interviewed seven fatherless women in a period of a month. During this period of time I found myself comforted, as I could relate with many of the experiences expressed by these women. It was a time frame where I experienced a lot of self-discovery, and also new discoveries, and admirations, for the women I interviewed. The participants were women that I have currently known from nine months to eight years. I predicted that by knowing these women on a personal level, they would be extremely open and honest with me, and it resulted in just that. My participants and I found ourselves crying and laughing together; and I found myself doing a lot of nodding. Many of the stories provided to me by these women overlapped with one another, while others were extremely different from each other. Nonetheless, each participant provided me with a 
rich and unique take on what it means to be fatherless from their perspective, and how fatherlessness has played a role in their romantic relationships.

While many interesting discoveries arose throughout the interviews, I will focus on four major themes that stood out to me. I named these themes after song titles that came to mind upon analyzing the data. The themes are as follows: a) Miss Independent: the tension between gaining independence as a result of being fatherless, and experiencing hardships in their romantic relationships due to being fatherless, b) The Gender Seesaw: the tension between fatherless women holding a dominant role in a romantic relationship, and being attracted to men who hold stereotypical male gender roles, c) Hold On To Your Love: fatherless women as having an aggressive and open communication style, yet remaining in difficult relationships, and, d) Don't Speak: fatherless women as holding back thoughts and feelings in order to not push their significant other away. Miss Independent and The Gender Seesaw address my first research question. Whereas, Hold On To Your Love and Don't Speak address research questions two, three and four. Throughout the remainder of this chapter each theme will be discussed in full detail, and specific examples will be provided to support these themes. These examples were presented by the participants during the context of the qualitative interview. However, prior to exploring these themes, I will first reveal the demographic background of these participants.

\section{Participants}

Seven women were approached and recruited as participants for qualitative interviews. These women are personal acquaintances of mine and for the purpose of this 
thesis pseudonyms shall be used in place of their names (Wanda, Mona, Miranda, Samantha, Tracy, Cindy and Debbie). I made an attempt to be inclusive of women from various ages, ethnic backgrounds and familial backgrounds. At the time of the interview, two participants were between 18-22 years old, three participants were between 23-27 years old, one participant was between 28-32 years old, and one participant was between 33-37 years old. One participant is African-American, two participants come from an Asian background, two participants are of Hispanic/Latina descent, and two participants are multi-racial. Since the focus of this research is on fatherlessness, it was of extreme importance for my participants to discuss their upbringing.

For the purpose of this research, I defined a fatherless woman as a woman who has had limited to nonexistent contact with her birth father. For instance, three participants have had contact with their birth father within the last year, two participants have not had contact with their birth father between 1-5 years, one participant has not had contact with her birth father in over six years, and one participant has never had contact with her birth father. Therefore, when asked about their upbringing, five participants referred to being raised solely by their birth mother, one participant discussed being raised by her mother and other relatives (e.g. grandparents), and one participant discussed being raised by her mother and stepfather. When asked if they have any male role models who they look up to as a father figure, two participants described have a relationship with a stepfather and looking up to him as a father, two participants discussed having a relationship with a mentor and looking up to him as a father, one participant discussed looking up to her grandfather as a father figure, and two participants 
did not have a male figure whom they looked up to as a father. Hence, these women all fit the criteria of being fatherless according to my definition, and based on the rich conversation I had with each of these individuals, I have found four common themes (Miss Independent, The Gender Seesaw, Hold on to Your Love, and Don't Speak).

\section{Miss Independent}

Undoubtedly throughout all seven interviews with my fatherless friends, there was a common theme of struggle. Each woman in one way or another has faced a hardship as a result of being fatherless. Nonetheless, while these obstacles can often times be extremely difficult to overcome, and even traumatic, I am a strong believer that these hardships make a person stronger. I believe that something positive always comes out of something negative. Although it is extremely difficult to be a fatherless woman, especially in a society that to this day continues to put an emphasis on the nuclear family, there are also things gained from being fatherless. When posed with the question of whether or not anything was gained as a result of being fatherless, all seven participants referred to independence and strength.

Wanda discussed her independence and described her strength as a fatherless woman as being both physical and mental:

"Definitely because I really do everything by myself...like if something is broken, I fix it. I don't wait for nobody. I move the shit if it's I don't know how many pounds, I'll move it by myself. I'll take a fucking dolly and move it...you know? I have this strength in me and it's not physical it's just mental, that I can just do anything really and I gained a lot because I don't need any kind of man. I hope, I don't."

Similarly, Mona also discussed not needing to rely on a man in her life, "And to be a strong woman, I learned that from my mom and grandmother: To not rely on a guy for 
anything."

Some of the participants discussed how difficult it is to rely on others, even if they want to. Miranda stated,

"I know I'm very independent. I really don't rely on anybody. I've never, you know, liked being in a situation where I have to, where I depend on other people. I'm very self-reliant."

Samantha also considers herself to be a self-reliant person,

"I gained a huge sense of having to take care of myself. Like if you were to put, blindfold me and drop me off in the middle of our country right now with a gas card and keys to a ride like I would find my way. Like I'm very, I'm not afraid...um I'm definitely a self-starter... so I gained a lot of independence, like I very much do take care of myself. It's almost hard to let him take care of me [referring to her significant other]."

Tracy agreed with my other participants by saying, "The major thing is independence.

It's being more independent, not to rely on anybody." Cindy and Debbie also referred to independence and strength when answering this interview question. Cindy said, "Um, I feel that I gained independence because of that...." Debbie answered, "I think being fatherless helps you become more independent and make you more of a strong woman." Therefore, based on the answers from these participants, these women have gained a sense of independence and strength as a result of being fatherless. I found it interesting that each of these participants unanimously gave the same answer to this question. I too consider myself to be a very independent person, however I have never quite thought about my independence in the context of being fatherless. Nonetheless, while these women spoke about the positive aspects of being fatherless, they had much more to say about the negative aspects when asked if anything was lost as a result of being fatherless. Wanda and Samantha described missing out on having the father as the protector 
of the home. Wanda explained,

"I do because...the protector of the home and...the only protector I had was my mom, but it wasn't physical [protection]; it was just like...physical...that's the only thing I lacked. And that's what I look for in relationships."

Samantha agreed with Wanda,

"I missed out on...I think that a man can have a certain sense of security that a mother can't provide, but there's just, I don't know, there's just that thing you don't...you don't have... and having, you know, your dad is your protector. Your dad is the one that defends your honor and does all that."

My participants also felt that part of being the protector of the home includes the father having "the talk" with a boyfriend.

"The talk" is traditionally known in heterosexual American society as when a father interrogates his daughter's boyfriend, to see if he is worthy or good enough for her. Wanda stated, "...I feel like you know the father talks to the novio [boyfriend in Spanish] kind of thing? I never had that." Miranda agreed,

"And, um, I missed out on, I feel like I missed out on the, um, whole like dating thing where my dad's all protective of me with the guys and stuff. And you know? Making, I'd like have to like bring my boyfriend to meet him and they're all scared of him and they know better to mess with me cause my dad'll kill them. I missed that [chuckled]."

Tracy gave a similar answer, "like, I wish that my father could meet my boyfriend type thing. You know, bring my father, my boyfriend home to dad." While these participants clearly were proud of their independence and strength, there was a common reference to the father as someone who should provide safety and security for the family. There is a tension between being independent, yet still needing that man as a form of protection; and this is why a father figure needs to be around, to protect his daughter. Blankenhorn (1996) clearly states that a father builds a sense of security in his daughter. Hence, if a 
father is not around to provide this security for the woman, this could result in an insecure woman.

While studies show that a father provides a sense of security for his daughter, a father is also a model for his daughter. Miranda, Cindy, Samantha and Tracy described missing out on a father as a role model and how this has contributed to their insecurities. Miranda explained:

"Yeah. I missed out on a lot. Not having a dad to teach me, um, certain social skills...I know that emotionally I just really missed out on that stability. Having the stability, and um, being focused and knowing who you are as you're growing up, when you're a young lady. Because I really didn't know who I was until I decided to find out who I was...the biggest thing, um, was not having a dad to explain to me, uh, men. How to deal with men. Um, and how to look through their words and their ways and their conniving games to get sex. Because when I was young, um, that was the only way I knew how to get attention from men was to have sex with him and so I did have a lot of partners when I was young...And then even later when I actually really started like to grow up in my late, uh, twenties did I realize that it was a problem. I had a problem. Um, by acting out like that and looking for something that was never really there. Trying to, um, fill a void, with physical love that was, it was never gonna happen."

Cindy found her negative patterns to also be related to her fatherless upbringing.

"If he would have been around more I feel like I probably wouldn't have lost my virginity at such a young age. I probably wouldn't of you know started dating at such a young age when...you can't really call it dating I guess but fooling around [chuckles] you know. And I feel like I kinda just valued myself more cause I didn't at all and I think that that was really important and now that I'm older you know I realize it and I wish I hadn't done all those things, but if he was around it probably would have been different."

Samantha agreed with Cindy and Miranda,

"Um...having a man in my life that I could, that models what I think is good. I mean I've had plenty of models for what I think is not good...Um...I missed out...I missed out on having that role model...Y You just don't have it um and that's been...having that relationship and having that that model for what a good man is...that's been huge." Tracy stated, "Um, I think I missed out on just like, just the father-daughter talks. And, you know, teaching me." 
In the interviews, these four women explained that the lack of this male role model has been a leading contributor to many of their hardships. Particularly, these hardships were experienced in their romantic relationships.

Wanda, Samantha, Tracy, Cindy, and Debbie described how being fatherless has specifically affected their romantic relationship. Wanda stated,

"It's weird because even with my dad...the things in the past...like I suppress them and start forgetting them and so they don't hurt as much and I think that's what I did with Phillip... all the things that he did, I started suppressing them and the anger started going away and that's why I kept forgiving him and kept letting him in my life even though he hurt me so much."

Similar to myself, Wanda has an anxious attachment style (Christiani, 2003), in which it was difficult for her to leave her romantic partner, despite the dysfunctions of the relationship. Samantha, also had many negative experiences in her romantic relationships,

"I had never had a positive... honestly this is my first positive relationship with a man. So...not including my brother; but I haven't had any close, positive relationships with men my entire life. So...none of my romantic relationships. None of my relationships with my two fathers. I haven't had a positive experience."

Tracy discussed not knowing how to communicate in her current romantic relationship,

"So me and him in a relationship is okay, but I really don't know how to communicate to a guy like that because I've never really had the training. Like I've never had: oh you shouldn't talk to a guy like this or you know if a guy's like this that means that you know he wants a little bit more attention or something. Or guys are just gonna naturally do that, you know. I've never known that and I've never had like any guys in my life to you know like express that to me."

Cindy also experiences difficulty in expressing herself in her romantic relationship:

"But the big issue I think in my relationship with him is I-I um get really violent when I get really mad and my brother's like that and my dad is like that. 
They...that's all I've seen you know growing up; when I was younger that's what I saw...I think, well I guess one thing I'd like to say is that trust was like a really big thing I guess you know for men. Um when I was with my ex boyfriend in high school like I was just you know I felt like I couldn't trust him 100\% and I think that's how I felt when I first got with Julius, because you know I was so jealous...that's been one thing that I've always had trouble with... being able to trust a man you know and being able to have him...knowing that I could have him there and that he' $d$ be there for me and that I could count on him. Um and I guess that's probably just been the hardest thing dealing with you know being able to trust a male figure..."

Finally, Debbie admits having difficulty in her relationships due to her fatherless upbringing, "Um...it was very difficult I think. He said that I had issues because of my dad and I think it was true because I had trust issues but he also had issues too..."

Undoubtedly, I would say that my girlfriends are all strong, independent women. Since I have known each of them personally, I know that they have overcome extreme hardships. They were forced into the role of independence as a result of being fatherless. Further, I believe that each hardship that they have experienced has made these women stronger. Yet, my participants find difficulty between holding an independent role, and wanting to be taken care of in relationships. These women continue to struggle with insecurities about what their role should be in their relationships. They want to be independent, yet do not know quite how to act because they have never consistently interacted with a male figure. They have always taken care of themselves, and do not know how to trust a man to take care of them. They want to be independent, yet also protected. Nonetheless, no matter how independent and strong these women let off to be, during the interviews there was a common reference to traditional gender roles.

\section{The Gender Seesaw}

Throughout the entire interview process the participants consistently referred to 
the role of gender. Particularly, these women referred to traditional gender roles held by males and females. I believe that it is important to note here that gender roles are socially constructed, and the women that I interviewed are all minorities, who come from ethnic backgrounds where these stereotypical gender roles are reinforced. With that being said, literature discusses the father as a role model for his daughter. Many of my participants discussed not having a father to model for her how to behave in a relationship, or what a good man should be. Nonetheless, when it comes to their romantic relationships, the majority of my participants clearly stated that they hold a dominant role in their relationships. Yet, I noticed that these women had trouble with identifying themselves with one particular role. For instance, Wanda stated

"I'm a caretaker... I think in my heart I'm submissive, but if the person even tries to... like if I' $m$ the way I want to be, I'm kinda submissive, but if someone tries to tell me that he wants me like that, I totally take the dominant role and I just kinda do the opposite. I become very dominant and am just very... Both. Yeah."

Samantha also considers herself to play both roles:

"But yeah...no uh I think um...I can be dominant and it takes the right person to...I can dominant if the other person... if I can take control of the whole thing, I will and I discovered that I don't like it. In my last relationship, I was totally the dominant person. Like I took initiative for everything. I planned everything. I organized and controlled everything and I, it wore me out. And so in this relationship we're much more egalitarian and I even allow myself to be more submissive sometimes, which is scary at first cause you're like 'are you sure you're going to do that right? Cause I usually do that and I know how to do it right. So...if you mess up like you might not wanna do that.' But I let him really...I let him be dominant at points. I think it's definitely a balance. I mean I have my areas where I'm more dominant. There are certain areas in the relationship where he is. And we're very much...it's a very balanced, very balanced... Uh... so yeah I think it is very much egalitarian balance, but I have a tendency towards dominance."

There were also tensions in Debbie's answer, 
"Um I think I was submissive at first and then I became the dominant one at the end [laughing]."

Samantha refers to the stereotypical male gender roles in her response,

“Oh, yeah, we're equal. Definitely. Um, there's times when I'm submissive and there's times when I'm more dominant. Um, but I think in general, he's the, he's, he's the man. [chuckle] He is the man and I let him be that and that's one of the things that I really like about him. It's that he does take the role of the man. He's in control. He's in charge and, um, and I respect him for that."

Based on the answers above, it was almost as if my friends had a game of tug-o-war taking place in their minds, and one team is holding dominant roles in their romantic relationship and the other team is holding submissive roles.

While some of the participants gave conflicting responses to the interview question, Tracy and Cindy referred to strictly holding a dominant role in their relationships. Tracy stated,

“Um, financial-wise I guess you could say I'm more dominant because I've been supporting him for almost over a year now...Like, he'll get help from his, his aunt like every now and then. Like, $\$ 25$ or whatever. But pretty much I'm the more dominant one. I'm the one that pushes him..."

Cindy also considers herself dominant in her romantic relationship:

"Um, I guess I would have to say the dominant. I mean I don't really like him telling me what to do [laughing], and he knows it. And even if he tells me like he didn't want me going to Puerto Rico, but I was like "I'm going! I already bought my ticket! What are you going to do? Nothing!" [laughing] But if he does something I don't like and I tell him "you better not do that!" he doesn't do it, he really doesn't. And if he does do it, there's hell to pay [both laughing] later...there really is so I'm just very like don't mess with me and things that I don't like I don't know I like to have the upper hand. I don't like knowing that somebody has, kinda controls me...some control over me..."

Although these women in one sense or another consider themselves to play dominant roles in their relationships, there is a tension as to what role they want to play. They 
discuss wanting to be submissive, yet not wanting to be controlled. I believe that this derives from being taught independence in their single parent household. They want to be dominant because they want to be in control. They have never been cared for by a man, yet there is this wanting or need to be submissive and hold those "wifey" gender roles. There were also tensions when my participants discussed male attributes. My participants referred to themselves as independent and dominant, yet they also discussed wanting or being attracted to a man who will protect them, and hold traditionally masculine roles. During the interview, my participants were asked to describe the type of man they are attracted to, as well as discuss their current romantic relationship. The findings are outlined below.

Wanda, Samantha and Tracy described how their gender plays a role in their romantic relationships. Wanda explained her role in her past relationship,

“...because he doesn't have family here, like family family. So I think I really...I was his family and he was my family. We just kinda fulfilled that for each other and it was just very comforting. And I really took care of him, I think [crying]....I still care for him a lot, but I kinda took the role of caretaker with him. Like if he got sick, I was on him. Like it was very, like mother-child thing. Like I really felt like I needed to take care of him because he was very lonely, not lonely, but with the family he has...I felt bad for him in that way."

As previously discussed by Wanda, she chose to hold this role in this situation; whereas if forced into that role she resisted, and no longer wanted to be submissive, but rather take on a dominant role. Similar to Wanda, Samantha also used to reject traditional female roles in her previous relationships, until she entered her current relationship. "All of the traditional wifey things that I never thought I wanted to do, I want to do.” Tracy discussed implementing these submissive roles in order to please her significant other, 
"You know, I know that I'm supposed to treat them right. You know, like I try to do my best like you know as I would you know if he was my husband. You know, cook for him, you know, make sure his needs are met basically and everything."

Tracy explains that these are the things she learned to do for a man despite not having a father in her life. Now that I have discussed the experiences that my participants explained feeling when it comes to their particular gender roles in romantic relationships, next I will summarize how these women referred to gender in the context of the men they are attracted to or date.

I posed the question to my participants as to what type of male they are attracted to; and surprisingly four participants referred to gender roles. Wanda responded, “Basically a man man, like a man's man. Somebody who can do the handy work...a man's man." Mona explained that prior to her current relationship she use to be attracted to bad boys,

"I don't know if that makes sense at all because he was unpredictable and didn't answer to anybody, not even me. But he would always make me feel like you know; he needed me or something like that, even though he didn't show it."

Miranda has also been attracted to bad boys, "He's strong. He knows he's the man and stuff and, um, in the past I've been attracted to real bad boys too." Lastly, Samantha responded to what kind of man she is attracted to,

“...I've been treated as though they are my protector. I mean I can think of a situation with every single guy I've been with where they have stepped up to the plate to defend my honor in some way...that's just the type of person. And so that's how I've been treated. Um...I think they tend to treat me...like put me in that wifey role and at times before I've resisted and this time I don't because I feel that he is fully the man that I expect him to be so I don't have a problem, I like it."

Not only did my participants refer to being attracted to a "man's man," many of them 
also described being attracted physically to men who can protect them. Some of these fatherless participants discussed being attracted to men who not only have the mental characteristics of a "man's man," but also the physical.

Wanda, Miranda, Samantha and Cindy discussed being attracted to men who are tall. Miranda and Cindy specifically mentioned men who are over six feet tall. Three participants also referred to being attracted to men who are built big. Therefore, not only do these women want a sense of security from their men emotionally, but also physically. This refers back to my participants missing out on a father figure as a protector, and now they are attracted to men who hold the traditional male role of the protector of the home. There is consistent conflict between my fatherless participants wanting to be independent and dominant (which are roles that go against the social construction of femininity in our society), and being attracted and wanting a man who is a "man's man" and a protector of the home. Further, as an independent woman, there is difficulty in letting this man take control and reverting to traditional female roles (even submissiveness). I definitely find it difficult to revert to traditional female roles, and many times I resist these roles.

"You need to learn how to cook!" my mother says when she finds out that I'm living with my boyfriend. "If you want to hold the role of esposa [Spanish for wife] and live with your boyfriend, then you should cook! What are you going to do, have your suegra [Spanish for mother-in-law] cook for you?" But, Romeo told me that it's okay that I don't cook, and that he accepts me for who I am. At times, I feel that I should try. I feel that I want to be domestic, but part of me resists. Perhaps it is laziness. Perhaps 
something is wrong with me. But, I'd much rather be the breadwinner and have Romeo stay home and cook and watch the kids. There is nothing wrong with that right? I have this debate in my head pretty frequently. I especially feel this way when I walk through the door with fast food in my hand for Romeo and me. Romeo's mom looks at me. I feel her eyes telling me, "How dare you not cook for my son? What kind of wife will you ever be?" She has never said anything to me, but I sense it. I want to cook but I have to work on my thesis, and grade papers, and work. These are just excuses, I know. But I really do want to make a nice meal for my Romeo, but I resist. I resist when he asks me to make him breakfast. I resist when part of me wants to get up and make dinner and the other part wants to just lie in bed and watch TV. What is wrong with me? But, why should I even have to cook? Romeo already told me it's okay that I don't. Why do I experience these tensions? I experience the very same conflict discussed by my participants.

My interviewees while independent cannot help but to feel insecurities as a result of being fatherless. As fatherless women we are not only looking for a man to fulfill the role of our father, but specifically a man's man to justify our role as women. We have tensions and insecurities finding this role within ourselves, since our father was not around to teach this to us; and our mothers had to play both gender roles of father and mother. Further, as long as we have a romantic partner to fulfill this role, we will stay with this man despite the dysfunctions of the relationship. Five of my participants were in romantic relationships during the time of the interview, and two were not. Three of my 
participants discussed being in relationships where they were treated poorly, and five of my participants described their past relationships as difficult, or dysfunctional.

\section{Hold on to Your Love}

It has been said that communication is the key to a happy relationship. Johnson (1997) states that openness is what constitutes a good relationship. This includes being open to others, and also being open to listen to the ideas, thoughts and feelings of others. Openness is also known as the communication style of self-disclosure. Johnson (1997) defines self-disclosure as "revealing to another person how you perceive and are reacting to the present situation and giving any information about yourself and your past that is relevant to understanding your perceptions and reactions to the present" (p. 241). Further, this author goes on to claim, "healthy relationships are built on self-disclosure" (Johnson, 1997, p. 242). When I reflected upon my previous unhappy relationships, I recalled my self-silencing. I self silenced many of my thoughts and feelings in order to please my significant other, and hence maintain that romantic relationship. I wondered if other fatherless women self-silenced themselves. After interviewing my seven participants, I found that these women are open, and at times even communicate aggressively in their romantic relationships.

The majority of my participants identified with having an open communication style with their romantic partners. I thought that I would find the opposite since research demonstrates that fatherless women tend to have an anxious attachment style (Calvin, 1993; Christiani, 2003). This means that fatherless women have a fear of abandonment, and hence hold onto their partner in almost a suffocating manner, and are less inclined to 
leave a romantic relationship. Therefore, I predicted that if fatherless women want to maintain this relationship and keep their significant other happy, perhaps they self-silence their thoughts, feelings and needs. I posed many questions to my participants that reflected communication openness, and I was intrigued by the responses that I received.

Six participants described themselves as open in their romantic relationships. Six participants stated that they do not keep secrets from their romantic partners. Wanda explained that she feels as though she can't lie,

“Yes, I do. No...I'm very open, I don't keep secrets. I don't even really lie... because I have really bad guilty conscience and I really can't lie. I'd rather admit it rather than lie. I'm very honest with them... Like I don't really...like if I feel something is bothering me, I'll tell him. If something makes me happy, I'll tell him. Like I told him how I felt lonely..."

Samantha discussed being open in her romantic relationship due to her own insecurities:

"Um...but in general on the day to day stuff, I'm really...I'm really really open. I can a lot [interviewer laughs]. Um...I almost think I over talk things sometimes cause I'm so cautious about things not going wrong that I'm like 'hey you know I noticed that such and such that you haven't really like made eye contact with me lately,' and he's like 'what are you talking about?' [interviewer laughs] and I'm like 'well I just want to make sure that everything is okay with us,' and he's like 'we're fine.' I'm like 'okay.' So...kinda like because of that lack of security. That lack of... you know when you play the trust game and you fall back and wait for somebody to catch you? I've had so many bad experiences with somebody not catching me [chuckles]...metaphorically and knocking my head on the ground that sometimes I found myself looking back to see if he's there. And he is so patient with me about it that you know sometimes he's frustrated like 'God! We're getting married. What are you saying?' Um...but I do I question things pretty openly and I think I'm getting you know instead of being confrontational about it, I approach it in a more humble way like 'hey I know this might sound completely psycho but I need to talk to you about something'. And he's like 'oh my God, what?' And it's something really small. He's like 'no, it's fine.' And sometimes I feel like I need to know you're not going anywhere. I need to know that you're in it for the long haul. Like I need that reassurance. So I'm very...I have no problem asking for that. Um and I think sometimes I ask for it in round about ways like asking about little things like the example I gave cause I' $m$ like...I'm almost like testing you like 'are you sure? Are you sure you're going 
to be there?' And sometimes I.... and I've done this in the past. I've always done it, and I had to learn to stop doing it with him cause I can see how it drives someone crazy. Not that I would drive anyone crazy [laughing]. But I would test people to see if they were going to stick around. And it's almost like my diva attitude and he kind of showed me like 'Hey you don't have to do that. I'm going to be here. You don't have to be a psycho. Like you don't have to be a diva. I see that you are. I recognized that. I accept it, but don't take it overboard to see if I'm going to put up with it cause I'm here.' And so um sometimes that's my way of asking for it is by pushing and anta--...almost antagonizing or just kinda being... being a diva about it and then looking back to see if he still loves me. Like do you still love me? I'm being a psycho bitch right now [both laughing]. And I stopped doing that with him cause I realized, I didn't have to. But it's like...you're not really asking for it, you're just testing the person. You don't need to test somebody...you know what I mean? So..."

I found Samantha's response to my interview question especially interesting because insecurities also surface in my romantic relationship. I seek attention from Romeo all the time and need him to reassure me that he loves me, and is by my side. Towards the beginning of my relationship with Romeo, I had many trust issues that I brought into my relationship based on past experiences. Whereas in previous relationships I was more timid and submissive, I vowed to myself to be open in my relationship with Romeo, and true to myself. I have overtly stated things as they are, and, perhaps, been a little too true to who I am, to the point where my mentality is "this is me take it or leave it!" I curse. I'm loud. I tell things the way they are. I am not domestic and if you don't like it, then too bad. However, when there is the slightest sign that things are going wrong in the relationship, or that it could come to an end, this is where my insecurities come to surface.

All seven of my participants unanimously stated that they do express their observations, thoughts, feelings and needs in their romantic relationships. All seven of my participants unanimously described themselves as aggressive during their arguments 
with their romantic partners. Wanda stated,

"Well now...I'm aggressive [laughing]. Passive...I'm only passive if...I really won't hold back now. To a man, like to my romantic partner, I really don't hold back. Even if we're in a public place, it doesn't matter...Yeah, aggressive."

Mona also considers herself to be aggressive during her arguments with her romantic partner:

"I'm a bitch! I am a biatch! I'm a brat. I admit this. I pull off the silent treatment first. Most of our arguments aren't that big. It's just bickering. He'll say something and I'll be like 'I don't like your tone' or 'I don't like your attitude.' I just pull the silent treatment and he does not respond well to the silent treatment. He's not very nice. I'll hold back at first and then he'll ask 'what is wrong with you?' and then finally, depending on my mood and how tired I am I either release. I talk so much... I should know better, but I'll say exactly how I feel when I feel it and I won't hold back and it's probably not the most productive or constructive, but it is how I feel."

Samantha again referred to her insecurities in arguments:

“Um...you know I would say in my current relationship I don't. I don't hold back anything. I mean I can't... if we're getting married, I can't afford to. You know at this point you know you can't. Um...I think in my past relationships and when we first met um like issues of abandonment... if we were to get an argument and the other person were to just like get up and leave, I couldn't take it. It would drive me crazy. Cause I would feel like how could you walk away from this argument? How can you...it's almost like telling me you don't care. And I hate to say that typical like "I didn't have a daddy, so I feel abandoned," but that is what it is! It is exactly what it is. I mean I think when we first met we got into an argument and he left me...we were living separately and he got up and left and I flipped out. I was like 'don't you ever do that again! Like the next time you leave, you better leave for good! I don't do that.' There's one thing... and then you know there would be times when I would get up and leave and it's almost like I wanted to beat him to it. Like I'm going to leave before you leave! I've never been broken up with cause I could not, there's no way I'd be able to take that. I've never had someone break up with me. I always break up with the other person first. And so while I'm so afraid of that, that I would rather abandon the other person than be the one...I hate being the one left standing. And that's the area that I struggle the most with."

Cindy also described herself as aggressive with her partner: 
"I would definitely say aggressive. I'm definitely not passive and I'm not passive aggressive because I like to tell people straight up if I don't like something, especially when it comes to my boyfriend. I always let him know what is bothering me right away even if it causes...even if it's the smallest little thing and I know it's going to cause an argument, I still have to let him know. It just... and I get really aggressive. You know I get very loud and I start yelling right away. I raise my voice right away to try to get my point across... Um I fully express them, which is part of the reason why I get really angry because I feel like he's not listening and I'm telling him exactly how I feel and then it kinda just turns into a 'you're making yourself the victim' 'no, you're making yourself the victim, I'm just telling you how I feel.' But I definitely always tell him exactly what I'm feeling [laughs]."

Further, six participants stated that they frequently express their feelings and needs to their romantic partners; and six participants stated that they reveal intimate details about themselves within the first two years of their romantic relationships. Therefore, it is very apparent that my participants have an open communication style with their romantic partners. They do not self-silence themselves, and are extremely direct in arguments, as well as when it comes to their thoughts, feelings, and needs. Hence, based on this openness in their romantic relationships, it would seem that these women would have extremely healthy relationships based on what research constitutes as a healthy relationship (Corey \& Corey, 2002; Johnson, 1997; McKay, Davis \& Fanning, 1995). Nonetheless, the majority of these participants described having been in a difficult or dysfunctional relationship.

Wanda, Mona, Miranda, Samantha and Debbie described their past relationships as difficult or dysfunctional. Wanda described a relationship she was in for approximately two-in-a-half years.

"Like fifteen times we broke up or something...He never defended me, he never stood up for me, he never defended or gave me the place that I was supposed to be given as his girlfriend... I kinda moved to his side and became, just really 
disrespectful. I started talking like very vulgar with him, like if I didn't feel something was right. Like it was very dysfunctional. Respect was out the door. We fought a lot. We fought a lot, a lot a lot....but that whole time, we really loved each other. We built a bond...I don't know how... So the respect was out the window from the beginning, and then trust issues came about when...there was an incident there where his ex girlfriend showed up and he totally disrespected me by...I felt like...by...first of all he left me alone to talk to her, and he was just talking to her the whole time and that was the first time in my life where I've been in a place where I don't know nobody...And I was very, very angry. He went into the house and he was saying some things to me and I said some things to him and he threw beer at me, in front of his cousin Norma... So from there... and then he left. I don't know where he went, and I don't know with who, and I don't know what...because I woke up like at 4 in the morning and he still wasn't there....But anyways the incident in February really shocked me. I didn't think it was going to happen to me. He didn't hit me, he was pushing me and he charged me. And he threw me a couple of times, not threw me, but just rush me and push me so that I fell, and it was like three times that that happened. And he like held me hostage ...it was just traumatizing. And so that really killed it for me, I thought. But then a couple of months later he came back like he always does and...I don't know...And it's just something so unacceptable to me and it happened to me and I accepted him back... So to wrap it up, a love and hate relationship that's what it was. We just got use to it and that's how it was and it was normal to us, where it was very dysfunctional to other people."

Similarly to Wanda, Samantha also described her past relationship as dysfunctional and also abusive.

"I was in a relationship before this for six years and that relationship was very...it was emotionally, mentally and sometimes physically abusive...And it's just weird because I had been in this relationship for six years before and never felt that you're the one thing. I mean I thought maybe, but I was dealing with all the things I didn't want to deal with you know what I mean? Somebody that wasn't consistently affectionate. Somebody that was very much self-centered. Somebody that was very... all the things that made me think 'oh typical man'...I really feel that the six year relationship, prepared me for this one cause we really beat each other up. Not physically, but we really let each other have it you know, let it all hang out."

Miranda described being in more than one abusive relationship.

"My son's father, I believe he had mental health issues and that was an abusive relationship. Um, not at the beginning, but it just escalated into that with all the disappointments that I, that I experienced in that relationship. Um, the 
relationship after that, um, was verbally abusive."

These are just a few stories that my participants shared with me. My heart reached out to these women. I felt a sense of disappointment, and sadness, not only because no individual should go through such pain, but particularly because these are women who are close acquaintances of mine, and this was even more disheartening. Further, after listening to these women's stories, I couldn't help but feel a sense of confusion. I could not understand how such strong and independent women could remain in such difficult relationships for awfully long periods of time. All of my participants described having an open communication style in their romantic relationship, and yet they were in extremely unhealthy relationships. Five out of the seven women interviewed described being in an unhealthy relationship. This is just bizarre to me.

There is a tension between being open in their relationships, yet remaining in difficult or dysfunctional relationships. However, I came to realize that this is where the anxious attachment style comes into play. People can be open and honest in their relationship, yet continue to put up with disrespect. A woman can tell her significant other how she feels, but if either party doesn't take action, nothing will change. While these women have the qualities of strength, independence, openness and even aggressiveness (because I would say that when you have a rough life, you have to learn to be aggressive to get ahead in this society), their own insecurities have prevented them from taking action. This action does not mean speaking up and telling your partner how you feel or what you need, but it means leaving a relationship that is verbally or physically abusive. Further, it means not making the sacrifice to remain in an unhappy 
relationship in order to have a protector in your life to fill the void of not having a father. The next section will reflect how an anxious attachment style has caused these women to hold back certain thoughts and feelings in order to not push their significant other away.

\section{Don't Speak}

Overall, my girlfriends described themselves as very open with their romantic partners. However, there was also conflict within this category. Many of my participants described being open when it came to expressing their thoughts, feelings and needs to their romantic partners, however, this was to an extent. The participants explained that if they felt they were pushing their partner's buttons or pushing him away, this is when they would self-silence or hold back thoughts, feelings and needs. Miranda discussed her communication with her partner being more so on his terms,

"We don't have arguments [laughter]. Cause he does not, he will not engage with me...But, like, I think if he does something to make me mad it's hard for me to come out and I guess, say it or something. But eventually I'm gonna get around to it. It has to come out at some point. And so I do, I just pick the right time and place to tell him."

Tracy specifically discusses not wanting to push her partner away,

“Um, I fully express them to a limit [laughter]. I don't try to make him really, really upset, but I'll express the way I feel until I see, like the line is drawn to where like, okay I don't really want to push you out, but I want you to know how I feel."

I posed the question as to whether there are topics or situations when my participants feel as though they do hold back when communicating with their significant others. Six participants stated that there are certain topics or situations when they do hold back. Four participants described holding back when it comes to their significant other's family issues. One participant described not wanting to disclose things about her past to her 
significant other, specifically about previous romantic partners. Three participants

discussed not wanting to push their significant others away. Miranda explained:

"Um, in the past with him, um I've held back because I knew that he, I knew that I, the way that I wanted to express it or I knew that the way that it would end up coming out would be in a manner that was not accepting to him. And so I've, I did hold back. Um, there was a period in the relationship where I really held back a lot. But, after exploding, I told him I couldn't do that...Um, and if I do get mad at him, it's like I have to remove myself from him and so I can calm down. So I'm I am able to talk to him like that. I recognize that that's what I have to do now and so that's what I do. I just don't say what I really think I guess. I thought that I didn't really hold back cause I've been trying to make myself, um, express, be more expressive to him, but um, yeah there are times when I hold back I guess."

Tracy also does not want to push her significant other away.

"I try to hold back on the job situation, him not having a job. You know, I mean that's really hard to do, but I do try to hold back because I won't want him to like, just leave me because like I'm I'm acting like a money, you know, money like gold digger or something...I don't wanna push him away like my mom pushed me away either [chuckle]."

Debbie mentioned that she held back in order to save her relationship.

"Um...I think...I think when you try to please them too much cause you want to save your relationship. It gets to a point when you can't deal with it so then you tell them through yelling and anger."

All seven of my participants described self-silencing themselves in their romantic relationships, and feeling as though they cannot tell their significant other how they're feeling or what they need in one form or another. However, two of my participants specifically described self-silencing because of their significant others being noncommittal. Miranda explained:

"Um, we had a rocky start and he pretty much like just shelved me for a minute. It's like he wanted to be with me, but he wasn't sure because we had a rocky start...And so there was a time when he would call me, but he would never come see me or, like, it was our relationship was on hold, pretty much. And I wanted to 
talk to him, um, a lot during that time. And I couldn't, I wouldn't cause I understood where we were with it, and I knew we weren't like serious even though I wanted to be. Um, I held back a lot and that was difficult. I cried a lot."

Debbie also felt as though she self-silenced herself a lot at the beginning of her relationship. She explained that part of this was due to the fact that this was her first relationship.

"Um, I think at the beginning because it was like my first relationship so I didn't know really what to act and then you don't wanna disappoint them either so you continue to do the things and then when he was the one trying to act like we weren't together that was just like slap in the face. But at the beginning since I didn't know how a relationship was suppose to be and like whatever I catered to him and was very submissive, but later yeah...A lot at the beginning."

Therefore, while these women felt as though they have open communication styles in their romantic relationships, there were certain situations where they felt as though they needed to hold back or self-silence themselves.

In every relationship there is a time when a person must compromise, which in turn could at times lead to holding back. However, as explained by these women this form of self silence is more so related to insecurities and wanting to please their partner rather than compromise. The experiences of these women are that they want to be open and honest, yet are afraid of abandonment. Thus, they remain in dysfunctional relationships, or just hold back in order to not push their partner away regardless of the circumstances of the relationship. Nonetheless it is understandable why the lives of these women have been constructed in this manner. There was not a male figure in their lives to model what a good man should be, therefore they may consider these dysfunctional relationships to be "normal." Further, if the way we understand the world is socially constructed, and there is not a person in your life to provide a model for what a good 
relationship is, these women are left out in the cold.

All seven of my participants described receiving either no information whatsoever, or negative information from their mothers about relationships and men. More specifically, three participants stated that nobody spoke to them about relationships and men, whereas four participants stated that their mothers spoke to them about relationships and men and provided them with not necessarily the best advice. Samantha and Miranda stated that their mothers would say negative generalized comments about men such as: “Well men just aren’t consistent. Men just aren’t considerate. You know how men are!" or "To be a gold digger...to use men for their money." Cindy stated that her mother advised her to not have sex until she is married, and that women are suppose to go to the altar as virgins, whereas men can do whatever they want until they are married. Mona stated,

"She'll say 'never rely on a man for money, you have to be an independent woman...' So we would talk about that too. We would talk about how that played out, her relationship with my father. And she would always tell me, 'not all guys are like your dad, so don't think they are all bad'...Yeah so we talk, especially now. She will share insights about everything. She confided in me now more so than ever."

Typically a mother has her daughter's best intentions at heart. I know that my mother always offers me advice thinking about what is best for me. I am sure that the mothers of my participants want nothing but the best for their daughters, and therefore want their daughters to be independent, and not controlled by a man. Many times the advice of mothers is based on previous situations they have encountered. Therefore, it is logical for a fatherless woman to be confused and have such meaningful experiences as described by my participants. 
There are struggles when there is not a father in the home to model how a daughter should interact with a man, or to provide her with a sense of security. We want to be independent, strong, self-reliant, and not rely on a man (as possibly taught to us by our mothers), yet will also be on a search for a man to give us a sense of security and protection that we never received from our father. It is inevitable, our relationships with our parents construct us into the people we are in this world. Although these struggles can lead to difficulty in our romantic relationships, I must also admit that they have also led us to question gender roles as they are constructed by society, and this is definitely a positive aspect of father absence, as gender roles should not be set in stone.

In summary, research questions were explored through qualitative interviews. During this dialogue, participants described their experiences as fatherless women. In response to research question 1 , they explained that they considered themselves to play a dominant role in their romantic relationships. Ease of expression, communication openness, self-disclosure and self-silencing were also discussed to address research questions two, three and four. Participants associated themselves with being open and expressive with their romantic partners. Nonetheless, while independent and dominant in their romantic role, the participants also claimed that they were attracted to men who hold stereotypical male gender roles. Further, while open in their communication style with romantic partners, the majority of the participants described being involved in a dysfunctional romantic relationship (either present or past) for a long period of time. Based on these findings, quantitative research questions and hypotheses were created to explore whether these experiences are encountered by a larger sample of fatherless 
women. Therefore, based on the qualitative analysis, the following research questions and hypotheses were explored in the quantitative study:

RQ1: What role do fatherless women play in their romantic relationships?

RQ2: How do fatherless women self-disclose in their romantic relationships?

RQ3: How do fatherless women express themselves in romantic relationships?

RQ4: Do fatherless women self-silence in romantic relationships?

The intent of the research questions above was to determine if there are similar findings as encountered in the qualitative study with a larger population of fatherless women. Additionally, research questions were created to compare fatherless women to women who grew up in intact homes. Therefore for the purpose of comparison, the following research questions were explored:

RQ5: Do fatherless women differ in their romantic relationship roles compared to women from intact families?

RQ6: Are there differences in self-disclosure in romantic relationships between fatherless women and women from intact families?

RQ7: Do fatherless women express themselves differently in their romantic relationships compared to women from intact families?

RQ 8: Are there differences in self-silencing in romantic relationships between fatherless women and women from intact families?

Upon analyzing the qualitative results and based on the research in the body of the literature review, I felt confident making the following predictions: 
H1: Fatherless women hold more traditional gender roles than women who grew up in intact families.

H2: Fatherless women have lower self-esteem in their romantic relationships than women who grew up in intact families.

H3: Fatherless women have a less happy childhood than women who grew up in intact families.

H4: Fatherless women are less happy in their romantic relationships than women who grew up in intact families.

H5: Fatherless women have less idealistic romantic expectations than women who grew up in intact families. 


\section{Chapter 5: Part Two Method (Survey)}

\section{Participants}

Based on the analysis from the open-ended interview questions, an online survey instrument was created on Survey Monkey (Appendix F) and disseminated between October 2009 and February 2010. One hundred and thirty one women (18-65 years old; $M=27.58, S D=8.17$ ) answered the online questionnaire. The survey was completed by both fatherless women (33.6\%) and women who grew up in a home with both biological parents (66.4\%). As previously stated, for the purpose of this research the conceptual definition of a fatherless woman was a female who has had limited to non-existent contact with her birth father since childhood due to abandonment on his behalf. Participants raised in a "traditional, intact" household were conceptually defined as women who were raised in a household in which both the mother and father cohabitated and took an active role in raising the child. Additionally, father-daughter relationships were viewed based on a heterosexual dyad where both father and mother took a role in raising the child and not a same-sex couple. Both sets of participants (fatherless women and women who grew up in an intact household) were over the age of eighteen and ideally would have had at least one romantic heterosexual relationship.

Since the focus of this study was on heterosexual romantic relationships of fatherless heterosexual women, two participants were excluded from the study's analyses as they identified themselves as lesbian. $93 \%$ of the remaining respondents identified as straight and $6 \%$ identified with being bisexual. Thus the final analysis sample had an $N$ of 129 women. 
Most respondents were Hispanic/Latina (44\%). The remaining respondents were White (25\%), Multiracial (12\%), Asian or Pacific Islander (11\%), African-American (4\%), and $4 \%$ identified themselves with other ethnic groups. The majority of the respondents were Christian (81\%). The remaining respondents claimed other religious backgrounds such as Agnostic or Buddhist (12\%), Atheist (5\%), and Muslim (2\%). A majority of the participants reported higher education qualifications: $38 \%$ had a Bachelor's degree, $31 \%$ had some college, $21 \%$ had a graduate degree, $5 \%$ had a postgraduate degree and 5\% had completed high school or received a G.E.D.

The reported household income for the participants while they were growing up was: $\$ 60,000$ and over (26\%), \$15,000-25,000 (18\%), \$25,000-35,000 (16\%), \$35,00045,000 (15\%), $\$ 45,000-60,000(14 \%)$, and less than $\$ 15,000(10 \%) .66 .4 \%$ of the respondents were brought up with their biological father while $33.6 \%$ were fatherless. Out of this percentage $49 \%$ of the women were fatherless due to divorce, $23 \%$ were fatherless due to abandonment, $7 \%$ were fatherless due to bereavement, and $21 \%$ stated other reasons (e.g. father was incarcerated, living in another country, mother did not know him, etc.) $98 \%$ of the respondents were raised by their biological mother and $2 \%$ were motherless. $14 \%$ of the participants were raised by a person other than both their biological father and mother. These were people such as stepparents, grandparents, foster parents, and nanny/babysitters.

With regard to their relationship status, $32 \%$ of participants reported as dating one person exclusively, $30 \%$ were in married or committed relationships, $21 \%$ reported being single, $8 \%$ dating casually, $6 \%$ living with their partner, and $4 \%$ were divorced. Overall, 
participants reported an average of 4.97 years $(S D=5.49)$ for the length of their current relationship. Of the participants who currently were in a relationship, $27 \%$ stated that their partners were fatherless and $8 \%$ reported that their partners were motherless. For participants who were currently not in a relationship, it had been an average of 1.58 years $(S D=1.38)$ since their last relationship. The average length of their previous relationship was 1.44 years $(S D=2.13) .32 \%$ of participants reported being in one relationship, and a similar number reported at least two relationships. $24 \%$ reported as being in three relationships, and $7 \%$ reported as being in four or more relationships. $6 \%$ reported as never ever being in a relationship.

\section{Procedures and Materials}

Approval from the Institutional Review Board (IRB) at San Jose State University was secured prior to beginning this study (please see Appendix G). Upon analyzing the qualitative interviews, the online questionnaire was slightly modified to complement the interviews. This modification was resubmitted to the IRB committee for re-approval. The online questionnaire was available via Survey Monkey from October 2009 through February 2010 (Appendix F). Each participant completed a questionnaire at her convenience. The consent form was also available online and an online signature stamp was required prior to allowing the participants the opportunity to take the online questionnaire (see Appendix B and D).

Each participant that completed the survey was directed to another optional survey where an email address could be submitted to be entered into the drawing. This method served to ensure the anonymity of the participants, as the answers to the survey 
were not connected by any means to the email addresses. I analyzed the surveys for recurring themes of fatherless women being less open and self disclosing and more selfsilencing; while seeking out themes of women who grew up in traditional households having more open communication patterns in their romantic relationships. Participants were recruited by posting fliers on campus with a $\mathrm{url}$ of where the survey could be found (Appendix A). There was also an email sent out with a recruiting script to various Communication Studies students and to members of Lambda Sigma Gamma Sorority Inc. Additionally, signs were posted in classrooms, public domains, and dorm areas on San Jose State University campus in attempts to recruit women who meet both of the criteria of growing up fatherless and in a traditional household (Appendix A). Originally participants from Sacramento State University were also supposed to be recruited, however this study did not pass CSU, Sacramento IRB protocol. While college students are a limited sample, San Jose State University is very diverse in nature and thus it was hoped that this would contribute to increasing the generalizability of the study by being inclusive of a plethora of demographics. Further, I also recruited participants by posting the same advertisement on the list serve for Lambda Sigma Gamma Sorority Inc. throughout the state of California. Please see the attached permission letter (Appendix C). Finally as an incentive, the participants were entered in a drawing for a $\$ 100$ gift certificate for a store of their choice.

The questionnaire was divided into three sections - demographic variables, questions pertaining to childhood upbringing/family background, and questions pertaining to the respondents' current or past relationships. Most measures were Likert 
scales, and all reliabilities are reported as Cronbach's alpha. All items from the scales were measured on a 5-point scale from 1 "Strongly Disagree" to 5 "Strongly Agree" or on a 7-point scale where 1 was "Strongly Disagree" to 7 "Strongly Agree." Items were reverse-coded where necessary prior to creating the scales. Additionally, exploratory factor analyses were carried out individually for all scales to make sure that items in each scale loaded on a single factor. Please see Table 1 for a correlation matrix for all independent and dependent variables. Additionally, please see Table 2 for a correlation matrix examining the relationships between relationship with father and the other main variables in the study. Finally, correlation analyses were run to identify potential control variables (age etc). None were found, therefore no variables were controlled for in the statistical tests.

\section{Measures}

\section{Independent Variable}

Father presence/absence. This variable was measured by the question "Were you raised by your biological father?" Approximately $34 \%$ of the sample reported being fatherless and $66 \%$ grew up in a home with both biological parents.

\section{Dependent Variables}

Role in relationship. Respondents were asked to indicate the role that they typically played in romantic relationships, and asked to indicate whether this was egalitarian (62\%), dominant (19\%), submissive (15\%), and more than one role (4\%).

Self-disclosure. Johnson (1997) defines self-disclosure as "revealing to another person how you perceive and are reacting to the present situation and giving any 
information about yourself and your past that is relevant to understanding your perceptions and reactions to the present" (p. 241). This variable is more so focused on a woman self-disclosing more intimate details about herself rather than her thoughts, feelings and needs as in the dependent variable of expression. Self-disclosure was measured by using a modified version of the Revised Self-Disclosure Scale created by Wheeles (1978) and found in the book Communication Research Measures by Rubin, Palmgreen and Sypher (2008); this scale included 22 items $(\alpha=.87, M=4.92, S D=.77)$. Items were for example "I am not always honest in my self-disclosures". Responses were measured on a 7-point Likert scale where 1 is "Strongly Disagree" and 7 is "Strongly Agree." Therefore, the higher the score, the more the participants self-disclose to their romantic partners. However, an exploratory factor analysis (principal axis factoring, Varimax rotation with Kaiser Normalization) revealed the presence of three different factors. Items in the scale loaded on three different factors, that were termed post hoc: frequency of self-disclosure, veracity of self disclosure, and valence of self disclosure.

The first subscale was frequency of self-disclosure. This scale had 7 items $(\alpha$ $=.88, M=4.93, S D=1.14$; e.g. "I do not often talk about myself"). Responses were measured on a 7-point Likert scale where the higher the score, the more frequently the participants self-disclose to their romantic partner. The next subscale was veracity of self disclosure. This refers to how sincere or honest participants are in their self-disclosures. Seven items were measured on this scale ( $\alpha=.86, M=5.2, S D=1.09$; e.g. "I always feel completely sincere when I reveal my own feelings and experiences”). Once again, the 
higher the score the more sincere my participants are in their self-disclosures to their romantic partner. Lastly is the subscale of valence of self-disclosure. This refers to whether the participants had positive or negative self-disclosures about themselves to their romantic partner. There were four items on this scale $(\alpha=.75, M=4.72, S D=$ 1.12; "On the whole, my disclosures about myself are more negative than positive"). The higher the score, the more positive the self-disclosures.

Expression. McKay, Davis, and Fanning (1995) describe the importance of four categories of expression: observations, thoughts, feelings, and needs. Therefore expression is a variable that focuses less on the intimate and more on "generic" thoughts, feelings and needs. For instance this variable focuses more on a need such as "I am not afraid to voice my needs to my significant other" rather than a more intimate detail as "This happened to me as a child." Eleven items were taken from a scale found in Rubin, Palmgreen and Sypher (2008) to measure the dependent variable of expression $(\alpha=.89$, $M=3.89, S D=.66$ ). Responses were measured on 5-point Likert scale where the higher the score, the more expressive participants are in their romantic relationships.

Self-silencing. As defined by Uebelacker, Courtnage, and Whisman (2003) selfsilencing is conceptually defined as a woman who silences her thoughts, needs, and actions to her romantic partner. Self-silencing was measured by using a slightly modified scale created by Jack (1991) found online and which was also used by Uebelacker, et al. (2003). Since there were some questions that were double-barreled, the scale has been slightly modified. However, an exploratory factor analysis (principal axis factoring, Varimax rotation with Kaiser Normalization) revealed the presence of five different 
factors. Items in the scale loaded on four different factors that were termed post hoc: hiding of feelings, privileging others, hesitancy and selflessness.

Overall self-silencing included all 32 items $(\alpha=.91, M=2.45, S D=.54)$ on a 5point Likert scale where the higher the score, the more my participants self-silence in their romantic relationships. The first subscale refers to hiding of feelings. There were five items on this scale ( $\alpha=.83, M=2.13, S D=.79)$ and the higher the score, the more participants hide their feelings in their romantic relationships. One of the questions on this scale was "Often I look happy enough on the outside, but inwardly I feel angry." The second subscale refers to privileging others, specifically a romantic partner. One of the questions on this scale was "I try to bury my feelings when I think they will cause trouble in my close relationship." There were four items on this scale $(\alpha=.82, M=2.42$, $S D=.87)$. The higher the score, the more participants privileged their romantic partners' feelings above their own. The third subscale was hesitancy. One of the questions on this scale was "I don't speak [about] my feelings in an intimate relationship when I know they will cause disagreement." This scale had three items $(\alpha=.75, M=2.35, S D=.83)$. The higher the score on the 5-point Likert scale, the more hesitant participants were to be open in their romantic relationships. The last subscale was selflessness. One of the questions on this scale is "Caring means putting the other person's needs in front of my own." There were four items on this scale ( $\alpha=.68, M=2.98, S D=.79)$, however this scale had slightly low reliability.

Childhood upbringing. Three different scales were created to assess this variable. One scale focused on childhood upbringing with such questions as "Growing 
up, my family members were very close to each other" or "Growing up, there were never any substantial problems in my house." This scale was assessed with six items ( $\alpha=.89$, $M=3.52, S D=.96)$. The next scale focused on the respondents' parental relationships and was assessed using two different scales for the two sub-strategies of relationship with father and mother. Originally the scale for Relationship with Father had ten items, however only nine items were retained to improve reliability $(\alpha=.86, M=3.11, S D=$ .87). The Relationship with Mother scale had eight items ( $\alpha=.84, M=3.83, S D=.73$ ). These scales had such questions as "I communicate with my father on a daily basis" or "my personality is similar to my mother's." Responses were coded on a 5-point Likert scale, with higher scores reflecting a more positive childhood upbringing or a more positive relationship between the respondent and her father or mother.

Gender role attitudes. Gender Role Attitudes was assessed with ten items $(\alpha=.76, M=2.33, S D=.58)$. This scale had such questions as "When a man and a woman are on a date, it is OK for the woman to pay for the date" or "a woman's marriage should come before her career." This variable was also measured on a 5-point Likert scale where 1 is "Strongly Disagree" and 5 is "Strongly Agree". For this scale the higher the score, the more the respondent agreed with traditional gender roles.

\section{Other Variables}

Relational self-esteem. This scale was created for prior research by Raman and Halford (2009). Relational self-esteem focuses on how the respondent sees herself in a romantic relationship and what she believes is her worthiness of being loved. Relational self-esteem or perceptions of oneself in a romantic relationship had ten items ( $\alpha=.90, M$ 
$=3.61, S D=.77)$. Responses were measured on a 5-point Likert scale with such questions as "I am confident about myself as a romantic partner" or "I am better in romantic relationships than most other people." Hence, the higher the score the more positive my participants consider themselves to be as romantic partners.

Romantic expectations. Romantic expectations focuses on what an individual expects from his or her romantic partner. This scale was based on Segrin and Nabi's (2002) work. Romantic expectations originally had twelve items, however one item was dropped to improve reliability ( $\alpha=.79, M=3.61, S D=.77)$. This scale was also on a 5point Likert scale and has such questions as "I expect that my partner and I will trust each other entirely" or "I expect no jealousy between my partner and me." Hence, the higher the score, the higher the idealized expectations in a romantic relationship.

Relational satisfaction. Relational satisfaction was measured by a scale created by Steuber (2005). This variable is focused on how satisfied an individual is in his or her romantic relationship. This scale was measured with eight items ( $\alpha=.88, M=5.86, S D$ $=1.07$ ) on a 7-point Likert scale. The higher the score, the more satisfied my participants are in their romantic relationships.

Partner attributes. Nine items were used to measure liking of male/partner attributes. The purpose of these items was to determine if the respondents had a certain "type" of romantic partner that they commonly are attracted to. This included such questions as "I like my man to be dangerous (a bad boy)" or "I like my man to be my protector; I should always feel safe by his side." Please see Table 3 for means and standard deviations for all items. 
Parental relationships. Nine items evaluated participants' relationship with their father $(\alpha=.86, M=3.11, S D=.87$, e.g. "I have a strong positive relationship with my father"). Eight items evaluated participants' relationship with their mother ( $\alpha=.84, M=$ $3.83, S D=.73$, e.g. "I communicate with my mother on a daily basis"). Both sets of items were 5-point Likert scales.

Partners' parental status. As reported earlier, of the participants who currently were in a relationship ( $\mathrm{N}=90), 27 \%$ stated that their partners were fatherless and $8 \%$ reported that their partners were motherless. 


\section{Chapter 6: Part Two Results (Survey)}

\section{Descriptive Characteristics for Fatherless Women Only}

RQ1: What role do fatherless women play in their romantic relationships?

Results indicated that $62 \%$ of fatherless women hold an egalitarian role in their romantic relationships, $21 \%$ hold a dominant role in their romantic relationship, $12 \%$ hold a submissive role, and $5 \%$ hold more than one of the above mentioned roles.

RQ2: How do fatherless women self-disclose in their romantic relationships? For fatherless women overall self-disclosure had a mean of $4.76(S D=.84)$, frequency of self-disclosure had a mean of $4.53(S D=1.27)$, veracity of self-disclosure had a mean of $5.01(S D=1.11)$, and valence of self-disclosure had a mean of $4.99(S D=1.22)$. This was on a 7-point Likert scale where the higher the score the more the women selfdisclose. The results indicated that fatherless women are above the mean when it comes to self-disclosing. Hence, they do tend towards higher self-disclosure.

RQ3: How do fatherless women express themselves in romantic relationships?

The results indicated that ease of expression had a mean of $3.82(S D=.75)$ on a 5-point Likert scale. Once again the higher the score, the more expressive the participants are. Based on these results fatherless women are above the mean, leaning more towards ease of expression.

RQ4: Do fatherless women self-silence in romantic relationships? Overall selfsilencing had a mean of $2.47(S D=.59)$, hiding of feelings had a mean of $2.31(S D=$ $.75)$, privileging of others had a mean of $2.42(S D=.89)$, hesitancy had a mean of 2.50 $(S D=1.07)$, and selflessness had a mean of $2.97(S D=.75)$. These items were on a 5- 
point Likert scale where the lower the score the less the participants' tendency to selfsilence. These numbers indicated that fatherless women do not self-silence themselves in romantic relationships.

\section{Descriptive Comparisons between Fatherless Women and Non-Fatherless Women}

RQ5: Do fatherless women differ in their romantic relationship roles compared to women from intact families? Results from a chi-square analysis revealed no significant difference in the roles played by fatherless and non-fatherless women in romantic relationships $\chi^{2}(3)=.44$, n.s. Egalitarian roles were favored by the majority of both fatherless women and women who grew up with a father in the household $(N=24,53$; $62 \%, 62 \%)$, as were dominant roles $(N=8,16 ; 21 \%, 19 \%)$, and submissive roles $(N=5$, $14 ; 13 \%, 16 \%)$. Roughly equal percentages of both groups of women identified with more than one role $(N=2,3 ; 2 \%, 3 \%)$. However, more fatherless women identified themselves as being dominant in a relationship as compared to submissive.

RQ6: Are there differences in self-disclosure between fatherless women and women from intact families? Results from independent samples $t$-test analyses indicated that overall self-disclosure does not differ between fatherless women $(M=4.76, S D=$ $.84)$ and women who grew up with their father in the household $(M=5.00, S D=.74)$, $t(119)=1.58, n . s$. However, results did indicate that fatherless women $(M=4.53, S D=$ 1.27) significantly self-disclose less frequently than women who grew up with their father $(M=5.12, S D=1.03), t(119)=2.71, p<.05$. There were no significant differences between the two groups on veracity of self-disclosure. However, differences 
on valence of self-disclosure approached significance $(p=.09)$. Fatherless women make more positive self-disclosures than non-fatherless women to their partners.

RQ7: Do fatherless women express themselves differently compared to women from intact families? Results from an independent samples $t$-test indicated that ease of expression did not differ between women who are fatherless $(M=3.82, S D=.75)$ and women who grew up with a father in the home $(M=3.93, S D=.63), t(119)=.79$, n.s.

RQ8: Are there differences in self-silencing between fatherless women and women from intact families? Results indicated that overall self-silencing does not differ between women who are fatherless $(M=2.47, S D=.60)$ and women who grew up with a father in the home $(M=2.42 S D=.51), t(119)=-.46, n . s$. There were no significant differences on any of the self-silencing subscales. However hiding one's feelings approached significance $(p=.09)$. Fatherless women tend to hide or suppress their feelings more than non-fatherless women.

\section{Fatherlessness and Gender Role Attitudes}

Results from an independent samples $t$-test indicated that gender role attitudes do not differ between women who are fatherless $(M=2.29, S D=.59)$ and women who grew up with a father in the home $(M=2.35, S D=.59), t(123)=.48, n . s$. These findings indicated that fatherlessness was not related to gender role attitudes. Thus H1 was not supported. For the purpose of exploration differences on two items from the male attributes scale were tested. These items were "I like my man to be a nice guy who always treats me well," $t(123)=2.29, p<.05$ and "I like my man to be a nurturer, in touch with his feminine side, $" t(123)=2.15, p<.05$. In both cases women from intact 
households scored significantly higher than fatherless women on these items, thus lending some amount of indirect support to H1. Lower scores would indicate a preference for more "traditional" qualities in men.

\section{Fatherlessness and Relational Self-Esteem}

Results indicated that relational self-esteem does not differ between women who are fatherless $(M=3.56, S D=.82)$ and women who grew up with a father in the home $(M$ $=3.64, S D=.74), t(122)=.53, n . s$. Fatherlessness was not related to relational selfesteem and thus $\mathrm{H} 2$ was not supported.

\section{Fatherlessness, Childhood Upbringing, and Parental Relationships}

Results indicated that women who grow up fatherless $(M=3.06, S D=.85)$ have a less happy childhood upbringing than those who had a father $(M=3.74, S D=.95)$, $t(127)=3.99, p<.05$. As hypothesized, H3 was supported. Fatherlessness significantly and negatively impacted childhood upbringing.

\section{Fatherlessness and Relational Satisfaction}

Results indicated that relational satisfaction does not differ between women who are fatherless $(M=5.67, S D=1.21)$ and women who grew up with a father in the home $(M=5.94, S D=1.03), t(76)=.98$, n.s. Fatherlessness was not related to relational satisfaction and thus H4 was not supported.

\section{Fatherlessness and Romantic Expectations}

Results indicated that differences in romantic expectations approached significance in the hypothesized direction. Women who are fatherless $(M=3.83, S D$ $=.58$ ) tended to have less idealized romantic expectations than women who grew up with 
a father in the home $(M=4.02, S D=.48), t(122)=1.91, p=.06$. Thus H5 was not supported. However, this test was borderline significant. Presumably, since the number of participants was low, power to detect these effects was low too.

\section{Additional Analyses}

For exploratory reasons a series of chi-square tests and Pearson's bivariate correlation analyses were run to detect whether or not fatherlessness and relationship with father was associated with other variables measured in the study. It was found that fatherlessness is associated with household income and also plays a role in relational satisfaction, except that in this case partner fatherlessness was examined. There was also an association between having a negative relationship with a father ("I have a negative relationship with my father.”) and poor relational self-esteem, and low scores on overall self-disclosure, and overall self-silencing. However, before discussing these findings it is important to note a limitation with this cross-sectional study. There are limitations to drawing causal claims from this data since correlational findings do not imply causality (Rindfleisch, Malter, Ganesan, \& Moorman, 2008).

\section{Fatherlessness and Family Household Income}

Analysis revealed that fatherless women were significantly unlikely to have a high household income while growing up compared to women who grew up in intact households, $\chi^{2}(5)=20.19, p<.001$. The majority of fatherless women reported their family income being less than $\$ 15,000(N=10,23 \%)$. Eight fatherless participants (19\%) reported the income being between $\$ 35,000-45,000$. Thirty women who were 
brought up in an intact home (35\%) reported having a household income of $\$ 60,000$ or more, while only four fatherless participants (9\%) fell in this category.

\section{The Effects of Romantic Partner's Fatherlessness on Relational Satisfaction}

Results indicated that women who have romantic partners who are fatherless are less satisfied in their romantic relationship themselves, $t(76)=-3.27, p<.05$. This is extremely interesting because this could potentially signify that fatherless men have difficulty being in a relationship, and perhaps also encounter difficulties communicating with their romantic partner. These findings could also be a reflection of the fatherless male lacking a father to model to him how to communicate with a significant other. This fascinating association could be explored further in a study in the communication studies discipline.

\section{Relationship with Father and Relational Self-Esteem}

For all women, results indicated a significant negative association between relationship with father and relationship self-esteem, $r(122)=-.30, p<.001$. The respondents who have a negative relationship with their father have lower self-esteem in their romantic relationships.

\section{Relationship with Father and Self-Disclosure}

Results indicated a significant negative association between relationship with father and overall self-disclosure, $r(119)=-.27, p<.001$. Significant associations were found for frequency of self-disclosure, $r(119)=-.26, p<.001$, and veracity of selfdisclosure, $r(119)=-.25, p<.001$. The respondents who have a negative relationship 
with their father self-disclose less and are less truthful in their self-disclosures in romantic relationships.

\section{Negative Relationship with Father and Self-Silencing}

Results indicated a negative and significant association relationship with father and overall self-silencing, $r(119)=-.29, p<.001$. With regard to the sub-scales, negative associations were found between relationship with father and hiding feelings, $r(119)=$ $41, p<.001$, privileging the other, $r(119)=-.24, p<.01$, and hesitancy, $r(119)=-.20, p<$ .05. Respondents who have a negative relationship with their fathers self-silence more, hide their feelings more, and privilege their romantic partners more.

\section{Discussion}

The core purpose of this study was to determine whether or not the patterns found in the qualitative interviews applied to a larger population at hand. Overall, the qualitative and quantitative findings overlapped with each other. This is discussed in greater detail in Chapter Seven. It was found that fatherless women do have a less happy childhood as opposed to women who grew up in an intact home. Findings also demonstrated that fatherless women self-disclose less frequently than women who grew up in an intact home. Hence, fatherlessness was associated with childhood upbringing and self-disclosure. However, results indicated that fatherlessness was not related to the variables of: gender role attitudes, self-silencing, ease of expression, relational satisfaction, and romantic expectations. However, correlation analyses revealed strong, negative, and significant associations between relationship with father and relational selfesteem, overall self-disclosure and overall self-silencing. Therefore findings indicated 
that having a positive relationship with a father influences his daughter's communication as well as her self-esteem in romantic relationships positively. In other words, if a daughter has a negative relationship with her father, she will likely have a negative relationship with her romantic heterosexual partner and a negative view of her own abilities. Thus it is not just the condition of father absence but the quality of the relationship with the father that matters. The final chapter compares the results of the qualitative interviews and quantitative surveys, and discusses the strengths, limitations, and future directions for this thesis study. 
Table 1

Correlation Matrix - Main Variables

\begin{tabular}{|c|c|c|c|c|c|c|c|c|c|c|c|c|c|c|c|}
\hline & $\mathrm{CU}$ & GRA & $\mathrm{RS}$ & PS & IRE & $\mathrm{EE}$ & OSD & FSD & VSD & VaSD & OSS & $\begin{array}{l}\text { SSH } \\
\mathrm{F} \\
\end{array}$ & $\begin{array}{l}\text { SSP } \\
\mathrm{O} \\
\end{array}$ & SSH & $\begin{array}{l}\text { SSS } \\
\mathrm{F} \\
\end{array}$ \\
\hline $\begin{array}{l}\text { Childhood Upbringing } \\
\text { (CU) }\end{array}$ & - & $.27^{*}$ & $.27^{*}$ & $.18^{*}$ & $.18^{*}$ & .14 & .09 & .07 & .15 & -.03 & -.06 & $.30^{-}$ & -.07 & -.06 & .05 \\
\hline $\begin{array}{l}\text { Gender Role Attitudes } \\
\text { (GRA) }\end{array}$ & & - & .13 & .08 & $.22^{*}$ & -.10 & -.09 & -.07 & -.10 & -.09 & $.18^{*}$ & .00 & .01 & .14 & $\begin{array}{l}.37^{*} \\
*\end{array}$ \\
\hline $\begin{array}{l}\text { Relational Satisfaction } \\
\text { (RS) }\end{array}$ & & & - & $.28^{*}$ & $.34^{* *}$ & $.42^{* *}$ & $.42^{* *}$ & $.29^{*}$ & $.46^{* *}$ & -.10 & -.18 & $.60^{-}$ & -.15 & $-.23^{*}$ & .19 \\
\hline $\begin{array}{l}\text { Perception of Self as a } \\
\text { Romantic Partner (PS) }\end{array}$ & & & & - & $.27^{* *}$ & $.48^{* *}$ & $.52^{* *}$ & $.41^{* *}$ & $.41^{* *}$ & $.33^{* *}$ & $.60^{* *}$ & $.57^{* *}$ & $.54^{* *}$ & $.40^{* *}$ & $.21^{*}$ \\
\hline Idealistic Romantic & & & & & & & & & & & & - & & & \\
\hline Expectations (IRE) & & & & & - & $.28^{* *}$ & $.27^{* *}$ & .13 & $.34^{* *}$ & -.04 & $\begin{array}{c}-.08 \\
-\end{array}$ & $\begin{array}{c}.34^{* *} \\
-\end{array}$ & $\begin{array}{c}-.04 \\
-\end{array}$ & $\begin{array}{l}-.12 \\
-\end{array}$ & $.20^{*}$ \\
\hline Ease of Expression (EE) & & & & & & - & $.65^{* *}$ & $.61^{* *}$ & $.57^{* *}$ & -.01 & $.62^{* *}$ & $.57^{* *}$ & $.40^{* *}$ & $.67^{* *}$ & -.14 \\
\hline Overall Self-Disclosure & & & & & & & & & & & - & - & - & - & \\
\hline$(\mathrm{OSD})$ & & & & & & & - & $.83^{* *}$ & $.84^{* *}$ & $.35^{* *}$ & $.68^{* *}$ & $.71^{* *}$ & $.44^{* *}$ & $.58^{* *}$ & -.17 \\
\hline Frequency of Self- & & & & & & & & & & & - & - & - & - & - \\
\hline Disclosure (FSD) & & & & & & & & - & $.54^{* *}$ & .07 & $.56^{* *}$ & $.56^{* *}$ & $.32^{* *}$ & $.56^{* *}$ & $.21^{*}$ \\
\hline Veracity of Self- & & & & & & & & & & & - & - & - & - & \\
\hline Disclosure (VSD) & & & & & & & & & - & .10 & $.57^{* *}$ & $.70^{* *}$ & $.36^{* *}$ & $.51^{* *}$ & -.05 \\
\hline Valence of Self- & & & & & & & & & & & - & - & - & & \\
\hline Disclosure (VaSD) & & & & & & & & & & - & $.30^{* *}$ & $.25^{* *}$ & $.31^{* *}$ & -.02 & -.12 \\
\hline Overall Self-Silencing & & & & & & & & & & & & & & & $.56^{*}$ \\
\hline$(\mathrm{OSS})$ & & & & & & & & & & & - & $.74^{* *}$ & $.82^{* *}$ & $.69^{* *}$ & \\
\hline Self-Silencing Hiding & & & & & & & & & & & & & & & \\
\hline Feelings (SSHF) & & & & & & & & & & & & - & $.58^{* *}$ & $.52^{* *}$ & .14 \\
\hline Self-Silencing & & & & & & & & & & & & & & & $.34^{*}$ \\
\hline Privileging Other (SSPO) & & & & & & & & & & & & & - & $.45^{* *}$ & \\
\hline $\begin{array}{l}\text { Self-Silencing Hesitancy } \\
\text { (SSH) }\end{array}$ & & & & & & & & & & & & & & - & $.23^{*}$ \\
\hline Self-Silencing & & & & & & & & & & & & & & & \\
\hline Selflessness (SSSF) & & & & & & & & & & & & & & & - \\
\hline
\end{tabular}


Table 2

Correlation Matrix - Relationship with Father and Other Variables

Relationship

with Father

Childhood Upbringing

$.51^{* *}$

Gender Role Attitudes

.02

Relational Satisfaction

.19

Perception of Self as a Romantic Partner

$.38^{*}$

Idealistic Romantic Expectations

.14

Ease of Expression

$.28^{* *}$

Overall Self-Disclosure

$.27^{* *}$

Frequency of Self-Disclosure

$.26^{* *}$

Veracity of Self-Disclosure

$.25^{* *}$

Valence of Self-Disclosure

.06

Overall Self-Silencing

$.30^{* *}$

Self-Silencing: Hiding of Feelings

$.41^{* *}$

Self-Silencing: Privileging Others

$.24^{* *}$

Self-Silencing: Hesitancy

$.20^{*}$

Self-Silencing: Selflessness

.06

${ }^{*} p<.05,{ }^{* *} p<0.01$ 
Table 3

Partner Attributes

Partner Attribute

Mean $(S D)$

I like my man to be dangerous (a bad boy). $\quad 2.45(1.03)$

I like my man to be a nice guy who always

treats me well.

$4.45(.64)$

I like my man to be me protector; I should

always feel safe by his side.

I like my man to be a nurturer; in touch

with his feminine side.

I like my man to be a man's man; he

should hold all of the traditional male

$3.00(1.11)$

gender roles.

I like my man to be tall.

$3.96(.83)$

I like my man to be short.

$1.83(.87)$

I like my man to be big built.

I like my man to be skinny.

2.50(.92) 


\section{Chapter 7: Conclusion}

When I wrote my personal statement for my application to graduate school, I recall writing that I wanted to focus my research on multicultural identity. My focus quickly changed upon taking an interpersonal communication class my first semester in the graduate program. I was fresh in the graduate program, fresh into a new relationship, and still pretty bitter about my past relationship. It was also a time when my father was constantly on my mind. It was that summer that my mother had told me the "true" story about my father. Throughout my childhood and into my adulthood, my mother never spoke negatively about my father. However that summer I came to learn about a more negative side of this man. He and my mother did love each other very much. Nonetheless, I found out that my father not only left my mother and I for a sport-basketball, but also for another woman-he was a cheater. Perhaps during that semester in graduate school I was seeking therapeutic relief through research and writing. Nonetheless as I write this last chapter of my thesis, I know that I chose the perfect topic to research.

I am 27 years old and I have "daddy issues.” I struggle with not knowing who my father is, and as a result, I struggle trying to figure out who I am in this world. I further struggle with my identity in romantic relationships. Upon interviewing seven fatherless women, I felt enlightened to know that other women encounter similar meaningful experiences as me. However, I also felt very distraught by the fact that both these seven women and I have had to deal with such hardships. Nonetheless, it is extremely important to listen to and understand our stories. In the first chapter of my thesis I 
discussed my own personal narrative that has driven me to be passionate about this topic. In this concluding chapter, I will discuss the placement of theory in this study, the relationship between the findings and the research questions, and the strengths and limitations of this study.

\section{The Relationship between the Findings and the Research Questions}

As discussed in Chapter One, I chose social cognitive theory as a more applicable theoretical framework for this study. This theory proposes that,

people gain understanding of causal relationships and expand their knowledge by operating symbolically on the wealth of information derived from personal and vicarious experiences. They construct possible solutions to problems and evaluate their likely outcomes, without having to go through a laborious trial-anderror process (Bryant \& Oliver, 2009, p. 95).

Thus, if a father is not present to be able to offer his daughter those personal and vicarious experiences she may be unable to construct solutions to problems, particularly problems with her heterosexual romantic partner. This could result in a fatherless woman going through the "laborious trial-and-error process" to really be able to understand what a healthy romantic relationship entails; just like in the case of the fatherless participants in both the qualitative and quantitative studies. Although a mother could explain to her daughter what constitutes a healthy relationship, this is not the same as simply observing how a father treats a mother as well as how he interacts with you as a child. Responses given by participants during the qualitative interviews, explicitly demonstrates why social cognitive theory is an apt framework for this research.

During the interviews, fatherless participants described missing out on a father as a protector of the home. Further, they discussed not having a male role model to instill a 
sense of security in them. In line with social cognitive theory, four out of seven of the participants described missing out on a man to model positive behavior, certain social skills, as well as ways to relate to other men. For example, Samantha specifically stated, "Um having a man in my life that I could, that models what I think is good. I mean I've had plenty of models for what I think is not good." One participant referred to not knowing how to communicate with her significant other, because she never had a father to interact with and teach her these skills. On the other side of the spectrum, one participant recalls her father modeling negative and abusive behavior in the home, and, described herself as abusive in her romantic relationship because of this modeled behavior.

In line with results from the qualitative portion, results from a series of independent samples t-tests indicated that women from intact homes did model certain behaviors of their fathers, more so than women from fatherless homes. For example, women from intact homes $(M=3.24, S D=1.19)$ scored significantly higher on the item, "My style of communicating with others is similar to my father's," $t(104)=4.01, p<$ .001 , compared to women from fatherless homes $(M=2.09, S D=1.31)$. Women from intact homes $(M=3.73, S D=1.10)$ also scored higher than fatherless women $(M=2.39$, $S D=1.41)$ on the item, "My personality is similar to my father's," $t(105)=4.84, p<$ .001. Similarly, women from intact homes $(M=2.49, S D=1.06)$ scored higher on the item, "My father has taught me everything I know about men," compared to fatherless women $(M=1.54, S D=.83), t(106)=4.03, p<.001$. Finally, women from intact homes $(M=2.70, S D=1.15)$ also scored higher than fatherless women $(M=1.71, S D=1.08)$ on 
the item, "The men I am attracted to remind me of my father," $t(106)=3.78, p<.001$. In addition, the quantitative results indicated that fatherless women tend to self disclose less frequently than women who grew up in an intact home. Hence, if a father is not around to instill security in his daughter, and does not model positive communication, she may feel insecure in her self-disclosures to her significant other, which could result in her self-silencing. Overall, the findings support that a father models to his daughter how to adapt to various social experiences, and this model is of the utmost importance when it comes to understanding causal relationships. Next, I will address the findings in accordance to the qualitative research questions, while further into this chapter I will address the findings in accordance to the quantitative research questions and hypotheses.

Qualitative research. In response to my first research question, I found that my participants struggled with insecurities about what their role should be in romantic relationships. All seven of these women claimed to be independent, and each of them felt that they typically hold a dominant role in their romantic relationships. These participants referred to being independent and not needing a man, yet many of them claimed missing out on being protected by their father, which they felt is a common male gender role. In turn I found that there was difficulty with women identifying themselves with one particular role. Some of the participants stated that they enjoy holding the role of caretaker, but not when pushed by their significant others to hold this role. Further the majority of my participants referred to being attracted to a man who is a man's man. These women described being attracted to men who are protectors of the home. As 
independent women, some of my participants found trouble in letting this man take control and reverting to traditional female roles (even submissiveness) when forced to.

In response to research questions two, three and four, there were also many tensions. Interestingly all of my participants described themselves as being open in their communication style. This meaning that they tell their significant others their thoughts, feelings, and needs typically with ease. Nonetheless, these women all explained being in at least one dysfunctional relationships (either current or previous) for long periods of time. I would argue that this is where social cognitive theory comes into play. These women had to undergo a laborious (and in some cases an abusive) trial and error process to understand how to find a solution to a problem in their romantic relationships. It is therefore likely that in the absence of not observing her parents resolve problems mutually and amicably, a fatherless woman may not have a "model" to resolve conflicts in her own romantic relationship. While it is important to talk things through, it is also important to come to a resolution that meets the needs of both parties. However, it seems that in many of my participants' cases the fear of abandonment overpowered the negative aspects of being in a dysfunctional relationship. In turn, when self-silencing occurred some participants stated that this was due to the fear of distancing her significant other. There are potentially troubling problems where these women want to be open and honest, yet are afraid of abandonment. Thus they remain in dysfunctional relationships or just hold back their thoughts, feelings and needs in order to not push their partner away regardless of the circumstances of the relationship. 
Quantitative research. Overall, results from the quantitative research were almost identical to the results from the qualitative research (specifically RQ2, 3, and 4). While fatherless women and women from intact homes did not differ significantly on a number of variables (RQs 5 through 8), relationship with father was a very important and key variable. Thus, the more positive the relationship with father, the more positive communication and esteem outcomes for the daughter. Not surprisingly, fatherlessness was significantly and negatively related to childhood upbringing. Women who are fatherless were found to have a less happy childhood upbringing than women who grew up in an intact home. Fatherlessness was also significantly and negatively associated with frequency of self-disclosure. Analyses also revealed that there was an association between having a negative relationship with a father and relational self-esteem, overall self-disclosure, and overall self-silencing. Finally partner fatherlessness also seemed to influence relationship satisfaction.

Findings from qualitative and quantitative studies. I believe the results of the thesis research are richer because of the triangulated data. Some contradictions did emerge between the two studies. In the first study my participants all claimed to have a dominant role in their romantic relationships, whereas in the quantitative study fatherless women associated themselves more so with egalitarian roles. The fatherless participants were also attracted to men who hold traditional stereotypical gender roles in the first study, whereas in the quantitative study the respondents did not associate with traditional gender role attitudes. 
Unfortunately there was a similarity between the qualitative and quantitative findings when it comes to relational length, and dysfunctional relationships. In the interviews my participants identified with being highly expressive and open to their romantic partners, yet there was a common theme of remaining in dysfunctional relationships for long periods of time. On the questionnaire, respondents were asked to describe the length of their past relationships and the reason it ended. Out of 39 fatherless participants, 36 had at least one previous romantic relationship or at least one ex-romantic partner. There were five instances where these women claimed to have been in an abusive (whether verbal, emotional, or physical) relationship. There were twelve instances where fatherless women were in relationships with unfaithful men or cheaters. There were three participants whose past relationships were with men who were both abusive and unfaithful. Other reasons why the relationship ended included: the romantic partner was non-committal, trust issues or insecurity, the romantic partner is bipolar or has issues with drugs, both partners grew apart, etc. The fatherless respondents had an average of two relationships, and the average length of these relationships was three years.

\section{Strengths and Limitations}

I agree with my participants in that as a result of being fatherless I gained a huge sense of independence. However, if someone were to ask me today what I gained as a result of being fatherless, I would answer "this study." Being a fatherless woman and conversing with other fatherless women (prior to beginning this thesis) greatly inspired me to carry out this research. I wanted to go above and beyond on my thesis and for this 
reason I chose to use a multi-method approach. In my graduate courses I became aware of the paradigmatic tensions between interpretive and positivist research. While I am drawn to the interpretive paradigm, I felt that using both methods for this research would strengthen my thesis and enhance my scholarly experience. I was extremely interested in understanding what fatherlessness meant to my participants from their perspective, however I wanted to take this a step further and research whether these stories and ideas were generalizable to other fatherless women. Further, since this is an exploratory study I wanted this research to be thorough. After completing both interpretive and positivist studies, I have encountered a profound respect for both paradigms. I have learned the dedication and diligence it takes to produce really good research. I have learned how to interpret and make meaning out of rich conversations and groundbreaking statistics. During the interviews, I felt that both my fatherless participants and I had many "ah ha" moments. My hope is that this study will provide very similar self-discovery to the fatherless women who read this. Further my hope is that since this research topic is fairly new in our discipline, that I have encouraged other scholars to conduct further research on this demographic.

Unfortunately my human subjects at CSU, Sacramento was not approved, and therefore I was not able to recruit participants from this campus for the quantitative portion of this study. Hence, I did not have as many participants as anticipated to complete the online questionnaire. In turn I also had an unbalanced number of participants who were fatherless (33.6\%) versus women who grew up with a father in the household (66.4\%). It is also important to note that all of my participants for the 
interview were minorities (very few Caucasian women participated in the study), who were either enrolled in college at the time of the interview or alumni from a four year institution. The majority of my participants for the online questionnaire were also college educated. Therefore perhaps these women were more aware of fatherless issues because they are exposed to conversations about fatherlessness, or exposed to research on fatherlessness. Future research should be inclusive to various demographics and not just college students. Since this research is scarce in the communication studies discipline, I really had to start with a blank slate. The vast majority of the research encountered on this topic derived from disciplines such as counseling and psychology. The theoretical framework used to support the study was from mass media. My hope is that as time progresses and studies are conducted on this topic, new theories will derive that are a better fit for this topic. Nonetheless I am confident that this research is thorough and a stepping stone for future research.

\section{Summary}

I am so honored and grateful to have engaged in a meaning-making process with other fatherless women, especially since these participants were my friends. I am also honored to have had the opportunity to take their unique experiences with fatherlessness and understand them from a positivist standpoint. If there is one idea that I hope the readers take away from this study, it is the importance of conducting future research on this group of women. It is clear that having a negative relationship with a father affects a woman's self-concept and her communication in romantic relationships. The findings demonstrate that fatherless women encountered tensions with their role in romantic 
relationships. This would be a theoretically rich phenomenon to investigate further perhaps using a relational dialectics framework.

My main purpose with this research is to make fatherless women aware of ways we are impacted by our father's absence. If we are aware of these issues, perhaps we will be more prone to speak up to romantic partners and not be afraid of abandonment. My hope is that this study will provide other fatherless women with the same self-reflecting experience. I dedicate this thesis to fatherless women everywhere-by telling our stories we help ourselves learn to negotiate and overcome father absence. 


\section{References}

Aquilino, W. (1996). The life course of children born to unmarried mothers: Childhood living arrangements and young adult outcomes. Journal of Marriage and the Family, 58(2), 293-310.

Atkins, C., Blumberg, E., Hofstetter, C.R., Hovell, M., Kreitner, S., \& Sipan, C. (1994). Family influences on Latino and Anglo adolescents' sexual behavior. Journal of Marriage and the Family, 56, 973-986.

Bandura, A., \& Bussey, K. (1984). Influence of gender constancy and social power on sex-linked modeling. Journal of Personality and Social Psychology, 47(6), 12921302.

Barras, J.B. (2000). Whatever happened to daddy's little girl: The impact of fatherlessness on black women. New York: The Ballantine Publishing Group.

Blankenhorn, D. (1996). The first man in every girl's life. Headway, 8(9), 10.

Botta, R.A., \& Dumlao, R. (2002). How do conflict and communication patterns between father and daughters contribute to or offset eating disorders? Health Communication, 14(2), 199-219.

Bowlby, J. (1969). Attachment and loss: Vol. 1 Attachment. New York: Basic Books.

Braithwaite, D., \& Baxter, L. (2006). "You're my parent but you're not": dialectical tensions in stepchildren's perceptions about communicating with the nonresidential parent. Journal of Applied Communication Research, 34(1), 30-48.

Bryant, J., \& Oliver, M.B. (2009). Media effects: Advances in theory and research ( $3^{\text {rd }}$ ed.). New York, NY: Routledge.

Calvin, T. (1993). Your heart belonged to daddy...and then he "abandoned" you! Cosmopolitan, 214, 161-163.

Carlson, M. J. (2006). Family structure, father involvement, and adolescent behavioral outcomes. Journal of Marriage and Family, 68,137-154.

Cheung, M. (1997). Social construction theory and the satir model: Toward a synthesis. The American Journal of Family Therapy, 25(4), 331-343.

Christiani, M. (2003). Adolescent females' strategic behavior within romantic relationships. Politics and the Life Sciences, 22(1), 36-42. 
Coontz, S. (1997). Working with what we've got: The strengths and vulnerabilities of today's families. In J. Stewart (Ed.), Bridges not walls (pp. 289-294). New York, NY: The McGraw Hill Companies, Inc.

Corey, G., \& Schneider-Corey, M. (2002). Intimate relationships. In J. Stewart (Ed.), Bridges not walls (pp. 354-364). New York, NY: The McGraw Hill Companies, Inc.

Crary, D. (2008, October 24). Researchers cite costs of teen pregnancies. Record Searchlight, p. A3.

Dail, P.W., \& Way, W.L. (1985). What do parents observe about parenting from prime time television? Family Relations, 34, 491-499.

DeBell, M. (2008). Children living without their fathers: Population estimates and indicators of educational well-being. Social Indicators Research, 87(3), 427-443.

Dumlao, R., \& Botta, R. (2000). Family communication patterns and the conflict styles young adults use with their fathers. Communication Quarterly, 48(2), 174-189.

Ellis, B.J., Bates, J.E., Dodge, K.A., Fergusson, D.M., Horwood, L.J., Pettit, G.S., \& Woodward, L. (2003). Does father absence place daughters at special risk for early sexual activity and teenage pregnancy? Child Development, 74(3), 801-821.

Endres, T. (1989). Rhetorical visions of unmarried mothers. Communication Quarterly, 37(2), 134-150.

Harp, K., Webb, L., \& Amason, P. (2007). Family communication patterns and young adults' conflict styles with romantic partners: Two alternative paths of influence. Conference Papers -- National Communication Association, 1. Retrieved from http://web.ebscohost.com.proxy.lib.csus.edu/ehost/pdfviewer/pdfviewer?vid=4\&hid=

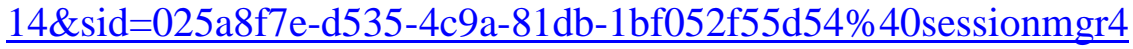

Horan, S.M., Houser, M.L., \& Cowan, R.L. (2007). Are children communicated with equally? An investigation of parent-child sex composition and gender role communication differences. Communication Research Reports, 24(4), 361-372.

Jack, D.C. (1991). Silencing the self: Women and depression. Cambridge, MA: Harvard University Press.

Johnson, D.W. (1997). Being open with and to other people. In J. Stewart (Ed.), Bridges not walls (pp. 240-247). New York, NY: The McGraw Hill Companies, Inc. 
Kline, S., ONeil, N., \& Fay, M. (2005). The influence of family communication on love attitudes of young adults. Conference Papers -- International Communication Association, 1-38. Retrieved from http://web.ebscohost.com.proxy.lib.csus.edu/ehost/pdfviewer/pdfviewer?vid=6\&hid=

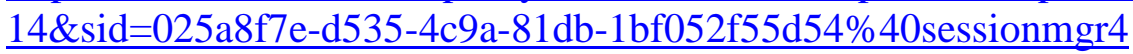

Kristol, I. (1994). Life without father. The Wall Street Journal Europe, 224(88), A18.

Krohn, F., \& Bogan, Z. (2001). The effects absent fathers have on female development and college attendance. College Student Journal, 35(4), 598.

Lindlof, T.R., \& Taylor, B.C. (2002). Qualitative communication research methods $\left(2^{\text {nd }}\right.$ ed.). Thomas Oaks, CA: Sage Publications, Inc.

Louis, K.S. (1982). Multisite/multimethod studies: An introduction. The American Behavioral Scientist, 26(1), 6-22.

Mackey, W.C., \& Coney, M.S. (2000). The enigma of father presence in relationship to sons' violence and daughters' mating strategies: Empiricism in search of a theory. Journal of Men's Studies, 8(3).

McCormick, C.B., \& Kennedy, J. H. (2000). Father-child separation, retrospective and current views of attachment relationship with father, and self-esteem in late adolescence. Psychological Reports, 86, 827-834.

McKay, M., Davis, M., \& Fanning, P. (1995). Expressing. In J. Stewart (Ed.), Bridges not walls (pp.249-260). New York, NY: The McGraw Hill Companies, Inc.

Parker, S.J. (Producer), \& King, M.P. (Director). (2008). Sex and the city [Motion picture]. USA: New Line Cinema.

Pollock, A.D., Die, A.H., \& Marriott, R. G. (2001). Relationship of communication style to egalitarian marital role expectations. The Journal of Social Psychology, 130(5), 619-624.

Punyanunt-Carter, N.M. (2007). Using attachment theory to study satisfaction in fatherdaughter relationships. Human Communication, 10(2), 103-120.

Punyanunt-Carter, N.M. (2006). Evaluating the effects of attachment styles on relationship maintenance behaviors in father-daughter relationships. The Family Journal, 14(2), 135-143.

Punyanunt-Carter, N.M. (2005). Father and daughter motives and satisfaction. Communication Research Reports, 22(4), 293-301. 
Raman, P., \& Halford, J. (2009). Television viewing and relationship outcomes. Unpublished Manuscript, University of Arizona.

Raskin, J.D. (2002). Constructivism in psychology: personal construct psychology, radical constructivism, and social constructionism. American Communication Journal, 5(3), 1-17.

Richmond, V.P., McCroskey, J.C., \& Roach, K.D. (1997). Communication and decision-making styles, power base usage, and satisfaction in marital dyads. Communication Quarterly, 45(4), 410-426.

Rindfleisch, A., Malter, A. J., Ganesan, S., \& Moorman, C. (2008). Cross-sectional versus longitudinal survey research: concepts, findings, and guidelines. Journal of Marketing Research, 45(2), 351-361.

Rubin, R.B., Palmgreen, P., \& Sypher, H.E. (2008). Communication research measures: A sourcebook. New York, NY: Routledge.

Segrin, C., \& Nabi, R. L. (2002). Does television viewing cultivate unrealistic expectations about marriage? Journal of Communication, 52(2), 247-263.

Steuber, K.R. (2005). Adult attachment, conflict style, and relationship satisfaction: A comprehensive model. Unpublished master's thesis for master's degree, University of Delaware.

Uebelacker, L.A., Courtnage, E.S., \& Whisman, M.A. (2003). Correlates of depression and marital dissatisfaction: Perceptions of marital communication style. Journal of Social and Personal Relationships, 20(6), 757-769.

Wong, W. (2002). Did how we learn affect what we learn? Methodological bias, multimethod research and the case of economic development. The Social Science Journal, 39, 247-264. 
Appendix A: Recruitment Flier 


\section{Come make history...}

- Are you 18 or older?

- Are you a female?

- Did you grow up in a fatherless household or in a house with both of your parents taking care of you?

- Have you ever been in a romantic relationship?

- Do you want the opportunity to win a $\$ 100$ gift card to the store of your choice?

Come make part of history and be involved in research conducted by a graduate student at San Jose State University (SJSU) never before done in the communication studies field!!!

For more information email LaToya Jackson at Latoya_marie_jackson@yahoo.com or log in to http://tinyurl.com/yj3spln to fill out an online survey.

Come take part in history!!!

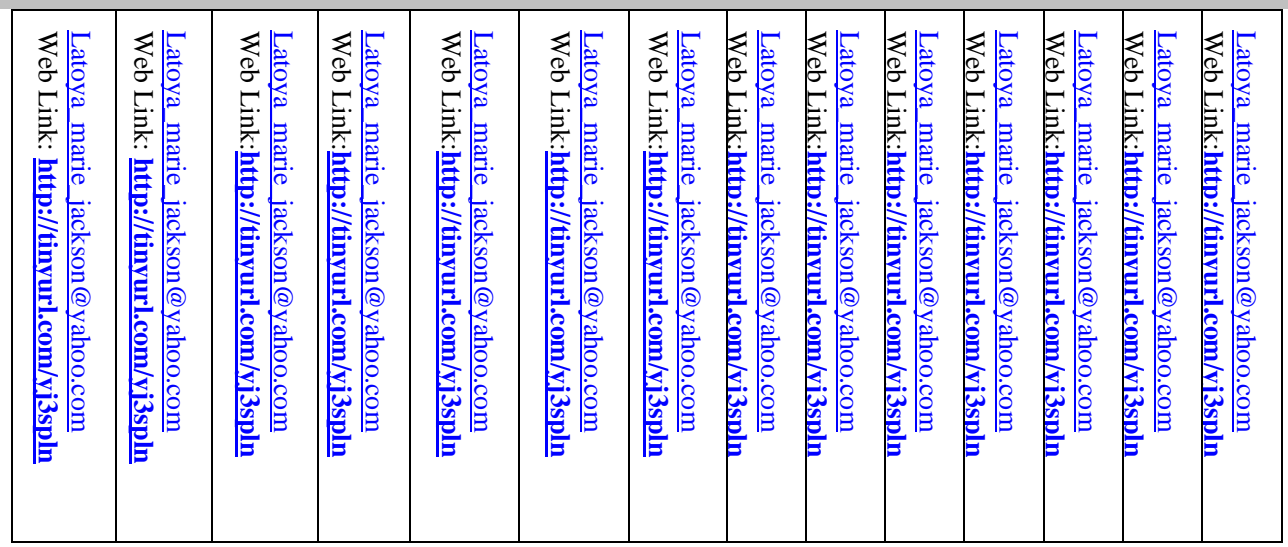


Appendix B: Recruiting Scripts 


\section{Recruiting Script A: Interview Portion of Study}

Hello, my name is LaToya Jackson, and I am a graduate student in the Communication Studies Department at San Jose State University. I am conducting research on the effects of fatherlessness on women's communication in romantic relationships, and I am inviting you to participate and to contribute your experiences as a fatherless woman.

Participation in this research includes being interviewed about your experiences as a fatherless child as well as discussion about your romantic relationships. The interview will take approximately an hour and a half. If you have any questions or would like to participate in the research, I can be reached at Latoya_marie_jackson@yahoo.com. Thank you for your time and consideration.

\section{Recruiting Script B: Online Questionnaire Portion of Study}

Hello, my name is LaToya Jackson, and I am a graduate student in the Communication Studies Department at San Jose State University. I am conducting research on the effects of fatherlessness on women's communication in romantic relationships, and I am inviting you to participate and contribute your experiences as either a fatherless woman or a woman who grew up with a father in the household.

Participation in this research includes filling out an online questionnaire about how you communicate with a significant other. The survey will take approximately 45 minutes. If you have any questions or would like to participate in the research, I can be reached at Latoya_marie_jackson@yahoo.com. Thank you for your time and consideration. 
Appendix C: Permission Letter 


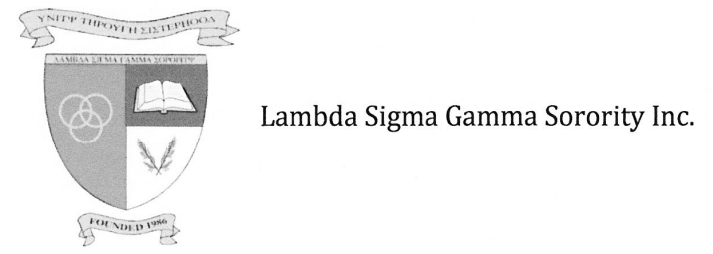

\title{
Permission Letter
}

\author{
Researcher Name: LaToya Jackson \\ M.A. Candidate \\ San Jose State University
}

Title of Research: Where's my daddy: The effects of fatherlessness on women's communication in romantic relationships

I, Danidle Nuñwational President of Lambda Sigma Gamma Sorority Inc. grant LaToya Jackson permission to recruit potential participants for her research titled Where's my daddy: The effects of fatherlessness on women's communication in romantic relationships using the sorority list serves. This includes the national list servelsg@yahoogroups.com and her local chapter list serve

lsgalpha@yahoogroups.com. Any questions can be referred me via email at drmuvioz@gmail.com
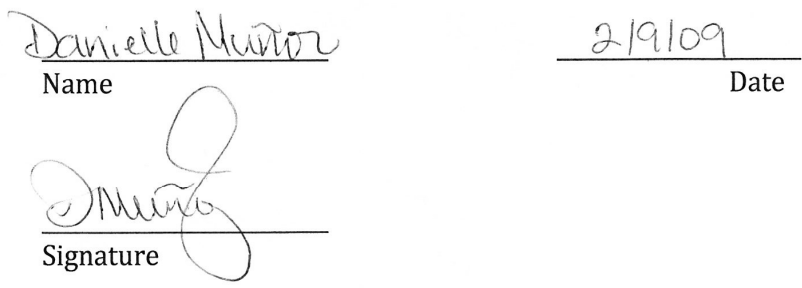
Appendix D: Consent Forms 


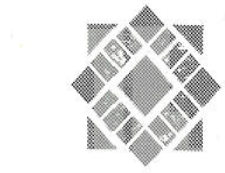

San José State UNIVERSITY

College of Social Sciences Department of Communication Studies

One Washington Square San José, CA 95192-0112 Voice: 408-924-5360 Fax: 408-924-5396 E-mail: commstud@email.sjsu.edu uww.sjsu.edu/depts/commstudies

Consent Form: Interview Portion of Study

Consent to Participate in Research Study

You are being asked to participate in a research study which is being conducted by LaToya Jackson, who is a graduate student in the Communication Studies department at San Jose State University. The purpose of this research is to understand the experiences of fatherless women from their perspective. Further, this research shall determine whether there is an association between fatherlessness and women's communication styles in romantic relationships compared to those women who grew up in a "traditional" household.

By participating in this research you will help me determine the effects of fatherlessness on women's communication styles in romantic relationships. Should you agree to participate in the study, you will be asked to first sign and date this consent form. After giving consent you will be asked to answer a set of interview questions and during this process you will be taped with a digital recorder. Please rest assured that the recorded interview tapes shall only be used for the purpose of this research and shall be destroyed upon completing this thesis. Further, the researcher shall be the only person who has access to these tapes.

As a result of participating in this project, you may be exposed to minimum risk. You will not undergo any type of harm, however discussing what it meant to grow up fatherless or recalling failed relationships could be emotionally burdensome. Therefore the risk will be the emotions that go along with discussing and recalling upsetting events. Participants may recall personal experiences that may evoke certain feelings. Should you experience distress related to participation in this study you can discuss these with professionals who are able to offer you support. For further support you may contact:

Ken Siegmann, MFT

901 Sunrise Ave. Ste. A3

Roseville, CA 95661

(916) $367-2105$

San Jose State University

Counseling Services

Administration Building, Rm. 201

One Washington Square

San Jose, CA 95192-0035

(408) 924- 5910

Note: Please be aware that the counseling services at San Jose State University and at Sacramento State University are only applicable to currently enrolled students.
Sacramento State University Psychological Counseling Services Student Health Center, $2^{\text {nd }}$ floor $6000 \mathrm{~J}$ Street

Sacramento, CA 95819-6045

(916) $278-6416$

SF Counseling Center 1801 Bush Street, Suite 215

San Francisco, CA 94109

(415) 440-0500

Page 1 of 2
The California State University: Chancellor's Office Bakersfield, Channel Islands, Chico, Dominguez Hills, Fresno, Fullerton, Los Angeles, Manitime Academy. Monterey Bay, Northridge, Pomona Sacramento, San Bernardino, San Diego, San Francisco, San José, San Luis Obispo, San Marcos, Sonoma, Stanislaus 
All information gathered in this study will be kept confidential. Information you provide on the consent form and notes from the interview will be stored separately in a locked cabinet or password protected computer in the researcher's home. Your name or any other identifying information will not be used in the study, but rather a

San José State UNIVERSITY

College of Social Sciences Department of Communication Studies

One Washington Square San José, CA 95192-0112 Voice: $408-924-5360$ Fax: 408-924-5396

E-mail: commstud@email.sjsu.edu www.sjsu.edu/depts/commstudies

(a)
pseudonym will be created to discuss any information pertinent to your identity. All documents will be destroyed upon completion of the study.

You will not receive any compensation for participating in this research. However all participants will be entered in a $\$ 100$ drawing for a gift certificate for any store of their choice. Further snacks and beverages will be provided during the interview process.

Your participation in this research is entirely voluntary. You are free to decide not to participate, or to decide at a later time to stop participating. You can decide to withdraw from the study at any time. If you have any questions about this research you may contact LaToya Jackson at (916) 203-8692 or via email at Latoya marie jackson(ayahoo.com, or Dr. Priya Raman in the Communication Studies department at San Jose State University at priva.raman@sisu.edu. Questions about a research subjects' rights, or research-related injury may be presented to Pamela Stacks, Ph.D., Associate Vice President, Graduate Studies and Research, at (408) 924-2427.

Your decision whether or not to participate in this research study will have no influence on your present or future status at San Jose State University or Sacramento State University.

By signing below, you are saying that you understand the risks involved in this research and agree to participate in it.

Signature of Participant

Signature of Witness
Date

Date

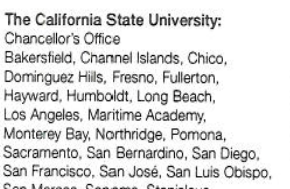

The Call lorna State University: Bakersfield, Channel Islands, Chico, Hayward, Humboldt Lo, Fullerton, Monterey Bay, Northridge, Pomon San Francisco. San José, San Luis Obispo, San Marcos, Sonoma, Stanislaus
Page 2 of 2 
Consent Form: Online Questionnaire Portion of Study

Consent to Participate in Research Study

\section{San José State UNIVERSITY}

College of Social Sciences Department of Communication Studies

One Washington Square San José, CA 95192-0112 Voice: $408-924-5360$ Fax: 408-924-5396

E-mail: commstud@email.sjsu.edu www.sjsu.edu/depts/commstudies

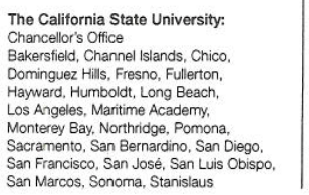

The Calitornia State University
Chancellor's Office Bakersfield, Channel Islands, Chico. Hayward, Humboldt, Long Beach, Monterey Bay, Northridge, Pomon San Francisco, San José, San Luis Obispo, San Marcos, Sonoma, Stanislaus
You are being asked to participate in a research study which is being conducted by LaToya Jackson, who is a graduate student in the Communication Studies department at San Jose State University. The purpose of this research is to understand the experiences of fatherless women from their perspective. Further, this research shall determine whether there is an association between fatherlessness and women's communication styles in romantic relationships compared to those women who grew up in a "traditional" household.

By participating in this research you will help me determine the effects of fatherlessness on women's communication styles in romantic relationships. Should you agree to participate in the study, you will be asked to first sign and date this consent form in an electronic format. After giving consent you will complete an online questionnaire/survey that will take approximately 45 minutes.

As a result of participating in this project, you may be exposed to minimum risk. You will not undergo any type of harm, however exposing what it meant to grow up fatherless or recalling failed relationships could be emotionally burdensome. Therefore the risk will be the emotions that go along with recalling upsetting events. Participants may recall personal experiences that may evoke certain feelings. Should you experience distress related to participation in this study you can discuss these with professionals who are able to offer you support. For further support you may contact:

Ken Siegmann, MFT

901 Sunrise Ave. Ste. A3

Roseville, CA 95661

(916) 367-2105

Sacramento State University Psychological Counseling Services Student Health Center, $2^{\text {nd }}$ floor 6000 J Street

Sacramento, CA 95819-6045

(916) $278-6416$

San Jose State University

Counseling Services

Administration Building, Rm. 201

One Washington Square

SF Counseling Center

1801 Bush Street, Suite 215

San Francisco, CA 94109

San Jose, CA 95192-0035

(408) 924- 5910

(415) 440-0500

Note: Please be aware that the counseling services at San Jose State University and at Sacramento State University are only applicable to currently enrolled students.

Page 1 of 2 
All information gathered in this study will be kept confidential. Information you provide on the consent form and the questionnaire will be stored separately in a locked cabinet or password protected computer in the researcher's home. Your name or any other identifying information will not be used in the study, but rather a pseudonym will be created to discuss any information pertinent to your identity. All documents and questionnaires will be destroyed upon completion of the study.

College of Social Sciences Department of Communication Studies

One Washington Square San José, CA 95192-0112 Voice: 408-924-5360

Fax: 408-924-5396

E-mail: commstud@email.sjsu.edu www.sjsu.edu/depts/commstudies

You will not receive any compensation for participating in this research. However all participants will be entered in a $\$ 100$ drawing for a gift certificate for any store of their choice.

Your participation in this research is entirely voluntary. You are free to decide not to participate, or to decide at a later time to stop participating. You can decide to withdraw from the study at any time. If you have any questions about this research you may contact LaToya Jackson at (916) 203-8692 or via email at Latova marie iackson@yahoo.com, or Dr. Priya Raman in the Communication Studies department at San Jose State University at priya.raman @ asisu.edu. Questions about a research subjects' rights, or research-related injury may be presented to Pamela Stacks, Ph.D., Associate Vice President, Graduate Studies and Research, at (408) $924-2427$.

Your decision whether or not to participate in this research study will have no influence on your present or future status at San Jose State University or Sacramento State University.

By clicking below, you are saying that you understand the risks involved in this research and agree to participate in it.

I agree to participate in the survey

I do not agree to participate in the survey.

Email Address

$\overline{\text { Date }}$ 
Appendix E: Interview Questions 
Interview Questions

\section{Interview Questionnaire}

1. When and where were you born?

2. What ethnicity are you?

3. Who is currently in your family and tell me about them? Who raised you?

4. When was the last time you had contact with your father? How was the contact? How do you feel about that?

5. What do you know about your father? Who told you that?

6. What was it like growing up in a fatherless home? Did you talk about why your father was not around?

7. Do you have a relationship with a male figure that you looked up to as if he were a father? If so, tell me about it.

8. How is your relationship with your mother? Is it a positive or negative relationship? Do you get along well with her? Do you speak to her frequently? If not, is there another female figure that you look up to as a mother?

9. Are you like your mother? Do you have similar communication styles as your mother?

10. Did your mother talk to you about relationships and men? What would she tell you? If not, who spoke to you about this and what did they tell you?

11. Are you currently in a relationship? Tell me about your current relationship or your most recent past relationships. 
12. RQ 1/3: Do you consider yourself pretty open with your romantic partners? Do you share or keep secrets from him? Do you express your observations, thoughts, feelings, and needs to your romantic partner? If not, why not? If so, how so? Can you provide me with examples?

13. RQ 2: How do you deal with arguments with romantic partners? Are you passive? Aggressive? Passive-aggressive? How so? Do you fully express your feelings in arguments or do you hold back? Are there certain topics or situations when you do hold back? How so?

14. RQ 1/3: How soon into a relationship do you reveal intimate details about your personal life with your romantic partners? Do you ever reach a point where you reveal everything about yourself?

15. What role do you play in your romantic relationships? Are you dominant or submissive? Do you and your romantic partner share egalitarian roles?

16. RQ2: Do you frequently express your feelings and needs to your romantic partners? If so, how so? If not, why not? Provide examples.

17. RQ3: Do you ever feel that you cannot tell your significant other how you're feeling or what you need? Why not? How often do you feel this way?

18. In an ideal world, what would be a perfect romantic relationship? Have you ever been in one? How would you communicate in this perfect relationship?

19. Do you have a certain "type" of male you are attracted to or date? What does he look like? What is his personality like? How does he treat you? 
20. Do you feel that you gained certain things by being fatherless? If so, what? If not, why not?

21. Do you feel that you missed out on certain things by being a fatherless child? If so, what? If not, why not?

22. Did you have any expectations about this interview?

23. If given the opportunity, would you answer any of the questions that were previously asked to you differently?

24. Is there anything else you would like to add or ask? 
Appendix F: Online Questionnaire 


\section{Online Questionnaire}

SECTION ONE: Please answer the following questions regarding your background. Please circle/check/fill in as applicable.

1. Age: years

2. Ethnic background:

___ American Indian or Alaskan Native African-American

White

Multi-racial
Asian or Pacific Islander

Hispanic/Latino

Other/Unknown

3. Sexual orientations:
___ Straight
Lesbian
Bisexual
Transgender

Other, Please specify

4. Religious background:

_ Christian

Muslim

Atheist
Hindu

Jewish

Other, Please specify

5. Highest level of education completed:

_Less than high school High School/G.E.D. Some college Bachelor's degree Graduate degree Post-graduate

6. As a child what was your family's annual household income when growing up?

$\$ 14,999$ and under

$\$ 25,000-34,999$

$\$ 45,000-59,999$
$\$ 15,000-24,999$

$\$ 35,000-44,999$

$\$ 60,000$ and over

7. Did your biological father raise you? yes no 
8. If your father was not a part of your life was it due to:

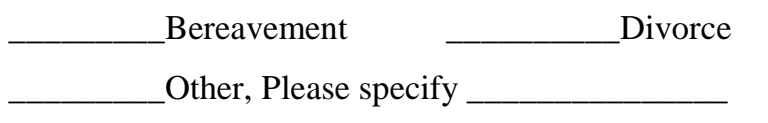
___ Abandonment
N/A My father was a part of my life

9. Did your biological mother raise you?

yes

no

10. If your mother was not a part of your life was it due to:

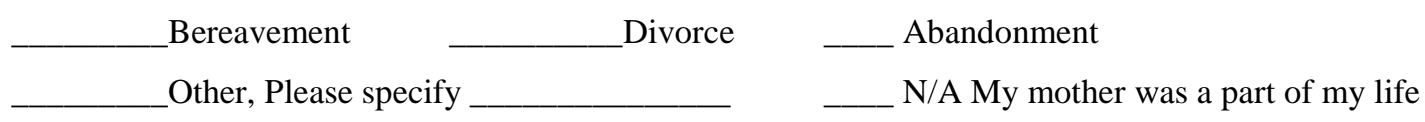

11. Were you raised by a person(s) other than your biological

father and mother?

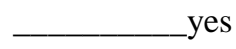

no

If so, by whom and what gender is he or she?
Gender
Relationship to you
a)
b)
c)
d)

\section{Childhood Upbringing}

Instructions: The following statements are about your childhood upbringing. Please indicate how much you agree with each statement (where $1=$ Strongly Disagree and $5=$ Strongly Agree).

1. Overall, I remember my childhood as being happy.

$\begin{array}{llllllll}\text { Strongly Disagree } & 1 & 2 & 3 & 4 & 5 & \text { Strongly Agree }\end{array}$

2. Growing up, my family members were very close to each other.
Strongly Disagree
2
4
5
Strongly Agree

3. Overall, I remember my childhood as being ordinary.
Strongly Disagree

2

3
4
5
Strongly Agree 
4. Growing up, there were never any substantial problems in my home.

$\begin{array}{llllllll}\text { Strongly Disagree } & 1 & 2 & 3 & 4 & 5 & \text { Strongly Agree }\end{array}$

5. Overall, I remember my childhood as being difficult.

$\begin{array}{llllllll}\text { Strongly Disagree } & 1 & 2 & 3 & 4 & 5 & \text { Strongly Agree }\end{array}$

6. Growing up there were many substantial problems in my home (e.g. economical difficulty, abuse in the home, or other similar obstacles).

$\begin{array}{llllllll}\text { Strongly Disagree } & 1 & 2 & 3 & 4 & 5 & \text { Strongly Agree }\end{array}$

\section{Parental Relationships}

Instructions: The following statements are about your relationship with your parents. Please indicate how much you agree with each statement (where $1=$ Strongly Disagree and $5=$ Strongly Agree).

1. I have a strong (positive) relationship with my father.

$\begin{array}{llllllll}\text { Strongly Disagree } & 1 & 2 & 3 & 4 & 5 & \text { Strongly Agree }\end{array}$

If you do not have a relationship with your father or your answer was 1 or 2 to the question above, please skip questions 2-7.

2. I communicate with my father on a daily basis.

$\begin{array}{llllllll}\text { Strongly Disagree } & 1 & 2 & 3 & 4 & 5 & \text { Strongly Agree }\end{array}$

3. My personality is similar to my father's.

$\begin{array}{llllllll}\text { Strongly Disagree } & 1 & 2 & 3 & 4 & 5 & \text { Strongly Agree }\end{array}$

4. My style of communicating with others is similar to my father's.

$\begin{array}{lllllll}\text { Strongly Disagree } & 1 & 2 & 3 & 4 & 5 & \text { Strongly Agree }\end{array}$

5. My father has taught me everything I know about men.

$\begin{array}{llllllll}\text { Strongly Disagree } & 1 & 2 & 3 & 4 & 5 & \text { Strongly Agree }\end{array}$

6. The men I am attracted to remind me of my father.

$\begin{array}{llllllll}\text { Strongly Disagree } & 1 & 2 & 3 & 4 & 5 & \text { Strongly Agree }\end{array}$


7. I am open and honest with my father about my romantic relationships.

$\begin{array}{lllllll}\text { Strongly Disagree } & 1 & 2 & 3 & 4 & 5 & \text { Strongly Agree }\end{array}$

8. I have a negative relationship with my father.

$\begin{array}{lllllll}\text { Strongly Disagree } & 1 & 2 & 3 & 4 & 5 & \text { Strongly Agree }\end{array}$

9. I do not communicate with my father.

$\begin{array}{llllllll}\text { Strongly Disagree } & 1 & 2 & 3 & 4 & 5 & \text { Strongly Agree }\end{array}$

10. Besides my biological father, there is another male figure I look up to as a father.

$\begin{array}{lllllll}\text { Strongly Disagree } & 1 & 2 & 3 & 4 & 5 & \text { Strongly Agree }\end{array}$

11. I have a strong (positive) relationship with my mother.

$\begin{array}{llllllll}\text { Strongly Disagree } & 1 & 2 & 3 & 4 & 5 & \text { Strongly Agree }\end{array}$

If you do not have a relationship with your mother or your answer was 1 or 2 to the question above, please skip questions 12-16.

12. I communicate with my mother on a daily basis.

$\begin{array}{llllllll}\text { Strongly Disagree } & 1 & 2 & 3 & 4 & 5 & \text { Strongly Agree }\end{array}$

13. My personality is similar to my mother's.

$\begin{array}{llllllll}\text { Strongly Disagree } & 1 & 2 & 3 & 4 & 5 & \text { Strongly Agree }\end{array}$

14. My style of communicating with others is similar to my mother's.
Strongly Disagree
2
34
5 Strongly Agree

15. My mother has taught me everything I know about men.

$\begin{array}{lllllll}\text { Strongly Disagree } & 1 & 2 & 3 & 4 & 5 & \text { Strongly Agree }\end{array}$

16. I am open and honest with my mother about my romantic relationships.

$\begin{array}{llllllll}\text { Strongly Disagree } & 1 & 2 & 3 & 4 & 5 & \text { Strongly Agree }\end{array}$

17. I have a negative relationship with my mother.
Strongly Disagree
2
3
4
5
Strongly Agree 
18. I do not communicate with my mother.

\section{$\begin{array}{lllllll}\text { Strongly Disagree } & 1 & 2 & 3 & 4 & 5 & \text { Strongly Agree }\end{array}$}

SECTION TWO: The following are questions about your romantic relationships. Please circle/check/fill in as applicable.

1. Relationship status

Single, not in a relationship

Single, dating one person exclusively

Married/Committed
Single, dating casually

Living with my partner

Divorced

2. If you are currently in a relationship, how long have your partner and you been married/dating?

Years and Months N/A, I am not currently in a romantic relationship

3. If you are currently in a relationship, describe your partner's family background:

N/A, I am not currently in a romantic relationship

My partner is fatherless

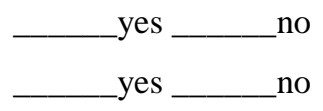

My partner is motherless

4. If you are not currently in a relationship, how long has it been since your last dating relationship or marriage?

_ Y Years and Months N/A I am currently in a romantic relationship

5. If you are not currently in a relationship, how long did your last dating relationship or marriage last? Years and Months N/A I am currently in a romantic relationship

6. Approximately how many long-term dating relationships/marriages have you been involved in? (Number)

Please list the length of the relationship and a couple of words as to why the relationship ended (i.e. unsatisfied, difference of opinions, cheating on his part, cheating on my part, verbal abuse, physical abuse, etc.)

Length of relationship Why did it end?

1)

2) 
3)

4)

7. What role do you typically play in your romantic relationships?

Dominant

Submissive

Egalitarian roles

\section{Male Attributes}

Instructions: The following statements are about the type of men you are most commonly attracted to.

These statements are about the men you are typically attracted to and not the characteristics that you would like in a man. Therefore when answering these statements you should think of men you have dated or are in a relationship with. Please indicate how much you agree with each statement (where $1=$ Strongly Disagree and $5=$ Strongly Agree).

1. I like my man to be dangerous (a bad boy).

$\begin{array}{llllllll}\text { Strongly Disagree } & 1 & 2 & 3 & 4 & 5 & \text { Strongly Agree }\end{array}$

2. I like my man to be a nice guy who always treats me well.

$\begin{array}{llllllll}\text { Strongly Disagree } & 1 & 2 & 3 & 4 & 5 & \text { Strongly Agree }\end{array}$

3. I like my man to be my protector; I should always feel safe by his side.
Strongly Disagree
2
$\begin{array}{lll}3 & 4 & 5\end{array}$
5 Strongly Agree

4. I like my man to be a nurturer, in touch with his feminine side.
Strongly Disagree
23
45
Strongly Agree

5. I like my man to be a man's man; he should hold all of the traditional male gender roles.

$\begin{array}{llllllll}\text { Strongly Disagree } & 1 & 2 & 3 & 4 & 5 & \text { Strongly Agree }\end{array}$

6. I like my man to be tall.

$\begin{array}{llllllll}\text { Strongly Disagree } & 1 & 2 & 3 & 4 & 5 & \text { Strongly Agree }\end{array}$

7. I like my man to be short.

$\begin{array}{llllllll}\text { Strongly Disagree } & 1 & 2 & 3 & 4 & 5 & \text { Strongly Agree }\end{array}$


8. I like my man to be big built

$\begin{array}{llllllll}\text { Strongly Disagree } & 1 & 2 & 3 & 4 & 5 & \text { Strongly Agree }\end{array}$

9. I like my man to be skinny.

$\begin{array}{llllllll}\text { Strongly Disagree } & 1 & 2 & 3 & 4 & 5 & \text { Strongly Agree }\end{array}$

\section{Gender Role Attitudes}

Instructions: The following statements involve your feelings about appropriate behavior for men and women. Please indicate how much you agree with each statement (where $1=$ Strongly Disagree and $5=$ Strongly Agree).

1. When a man and a woman are on a date, it is OK for the woman to pay for the date.

$\begin{array}{llllllll}\text { Strongly Disagree } & 1 & 2 & 3 & 4 & 5 & \text { Strongly Agree }\end{array}$

2. A woman should be a virgin when she marries.

$\begin{array}{llllllll}\text { Strongly Disagree } & 1 & 2 & 3 & 4 & 5 & \text { Strongly Agree }\end{array}$

3. There is something wrong with a woman who does not want to marry.

$\begin{array}{llllllll}\text { Strongly Disagree } & 1 & 2 & 3 & 4 & 5 & \text { Strongly Agree }\end{array}$

4. There is something wrong with a woman who does not want to have children.

$\begin{array}{llllllll}\text { Strongly Disagree } & 1 & 2 & 3 & 4 & 5 & \text { Strongly Agree }\end{array}$

5. A woman's children should come before her career.

$\begin{array}{llllllll}\text { Strongly Disagree } & 1 & 2 & 3 & 4 & 5 & \text { Strongly Agree }\end{array}$

6. A woman's marriage should come before her career.

$\begin{array}{llllllll}\text { Strongly Disagree } & 1 & 2 & 3 & 4 & 5 & \text { Strongly Agree }\end{array}$

7. It looks worse for a woman to be drunk than a man. *

$\begin{array}{llllllll}\text { Strongly Disagree } & 1 & 2 & 3 & 4 & 5 & \text { Strongly Agree }\end{array}$

8. Women should do more housework than men.

$\begin{array}{llllllll}\text { Strongly Disagree } & 1 & 2 & 3 & 4 & 5 & \text { Strongly Agree }\end{array}$


9. Women rather than men should do the cooking at home.

$\begin{array}{llllllll}\text { Strongly Disagree } & 1 & 2 & 3 & 4 & 5 & \text { Strongly Agree }\end{array}$

10. Women should be in charge of child rearing.

$\begin{array}{llllllll}\text { Strongly Disagree } & 1 & 2 & 3 & 4 & 5 & \text { Strongly Agree }\end{array}$

\section{Relational Satisfaction Scale}

Instructions: Please mark the following statements to reflect your satisfaction in your current heterosexual romantic relationship. If you are not currently in a romantic relationship, please skip this section. Indicate the degree to which you agree with the following statements, where (7) is Strongly agree, (6) agree, (5) moderately agree, (4) are undecided, (3) moderately disagree, (2) disagree, or (1) strongly disagree. Circle the response that you relate to. Work quickly and just record your first impressions.

1. My partner meets my needs.

$\begin{array}{lllllllll}\text { Strongly Disagree } & 1 & 2 & 3 & 4 & 5 & 6 & 7 & \text { Strongly Agree }\end{array}$

2. In general, I am very satisfied with my romantic relationship.

$\begin{array}{llllllllll}\text { Strongly Disagree } & 1 & 2 & 3 & 4 & 5 & 6 & 7 & \text { Strongly Agree }\end{array}$

3. In general, I am very unsatisfied with my romantic relationship.

$\begin{array}{llllllllll}\text { Strongly Disagree } & 1 & 2 & 3 & 4 & 5 & 6 & 7 & \text { Strongly Agree }\end{array}$

4. My romantic relationship is relatively good compared to most.

$\begin{array}{llllllllll}\text { Strongly Disagree } & 1 & 2 & 3 & 4 & 5 & 6 & 7 & \text { Strongly Agree }\end{array}$

5. My relationship is relatively bad compared to most.

$\begin{array}{lllllllll}\text { Strongly Disagree } & 1 & 2 & 3 & 4 & 5 & 6 & 7 & \text { Strongly Agree }\end{array}$

6. I often times wish I hadn't gotten into this relationship.

$\begin{array}{llllllllll}\text { Strongly Disagree } & 1 & 2 & 3 & 4 & 5 & 6 & 7 & \text { Strongly Agree }\end{array}$

7. My relationship has met my original expectations.

$\begin{array}{llllllllll}\text { Strongly Disagree } & 1 & 2 & 3 & 4 & 5 & 6 & 7 & \text { Strongly Agree }\end{array}$


8. There are many problems in my relationship.

$\begin{array}{llllllllll}\text { Strongly Disagree } & 1 & 2 & 3 & 4 & 5 & 6 & 7 & \text { Strongly Agree }\end{array}$

Instructions: Listed below are several statements regarding your perceptions of yourself in romantic relationships. Please read each item carefully and decide to what extent you agree or disagree that the item describes you. For each statement, please indicate the extent to which you agree with the statement by circling the number that best describes your level of agreement where $1=$ Strongly Disagree and $5=$ Strongly Agree.

1. I am confident about myself as a romantic partner.
Strongly Disagree
2

3
4
5
Strongly Agree

2. I am better in romantic relationships than most other people.
Strongly Disagree 1
2
3
45
Strongly Agree

3. I would rate myself pretty favorably as a romantic partner.
Strongly Disagree 1
2
3
45
Strongly Agree

4. I would be a very good partner in an intimate relationship.
Strongly Disagree
2
3
4
5
Strongly Agree

5. I feel that I have a number of positive qualities as a romantic partner.
Strongly Disagree
2
3
45
Strongly Agree

6. I worry a lot about my romantic relationships.
Strongly Disagree
2
3
45
Strongly Agree

7. I often worry that my romantic partner will not want to stay with me.
Strongly Disagree
2
3
4
5
Strongly Agree

8. I worry that I won't measure up to the ideals of my romantic other.
Strongly Disagree
2
3
4
5
Strongly Agree

9. I worry that I might not be able to be a good romantic partner.
Strongly Disagree
2
3
4
5
Strongly Agree 
10. I often worry that my partner doesn't care about me.
Strongly Disagree
23
4
5
Strongly Agree

Instructions: Listed below are several possible aspects of romantic relationships. Please read each item carefully and decide to what extent you agree or disagree that the item characterizes your expectations of romantic relationships. For each statement, please indicate the extent to which you agree with the statement by circling the number that best describes your level of agreement where $1=$ Strongly Disagree and $5=$ Strongly Agree.

1. I expect that my partner and I will remain in love forever.
Strongly Disagree
$\begin{array}{lll}1 & 2 & 3\end{array}$
45
Strongly Agree

2. I expect that my partner and I will trust each other entirely.
Strongly Disagree
1
2
3
4
5
Strongly Agree

3. I expect a lot of sexual activity with my partner.

$\begin{array}{llllllll}\text { Strongly Disagree } & 1 & 2 & 3 & 4 & 5 & \text { Strongly Agree }\end{array}$

4. I expect no jealousy between my partner and me.
Strongly Disagree
$\begin{array}{lll}1 & 2 & 3\end{array}$
4
$5 \quad$ Strongly Agree

5. I expect that my partner will be very physically attractive.
Strongly Disagree
1
2
3
45
Strongly Agree

6. I expect that my partner and I will be highly committed to each other.
Strongly Disagree
1
2
34
45
Strongly Agree

7. I expect minimal conflict over everyday decisions between my partner and me.
Strongly Disagree
$\begin{array}{lll}1 & 2 & 3\end{array}$
4
5
Strongly Agree

8. I do not expect my partner and I to have compatible lifestyles/interests.
Strongly Disagree
1
23
4
$5 \quad$ Strongly Agree

9. I expect that my partner and I will be each other's best friend.
Strongly Disagree
1
2
3
4
5
Strongly Agree 
10. I expect that my partner and I will NOT verbally abuse one another.

$\begin{array}{lllllll}\text { Strongly Disagree } & 1 & 2 & 3 & 4 & 5 & \text { Strongly Agree }\end{array}$

11. I expect that my partner and I will argue very frequently.

$\begin{array}{llllllll}\text { Strongly Disagree } & 1 & 2 & 3 & 4 & 5 & \text { Strongly Agree }\end{array}$

12. I expect that my partner and I will be faithful to each other.

$\begin{array}{llllllll}\text { Strongly Disagree } & 1 & 2 & 3 & 4 & 5 & \text { Strongly Agree }\end{array}$

\section{Ease of Expression Scale}

Instructions: Please mark the following statements to reflect how easily you express your thoughts, feelings, needs and observations to your significant other. Please consider your most recent or previous discussions and interactions with your romantic partner or immediate past romantic partner when answering this section. Indicate the degree to which the following statements reflect how comfortable you are expressing yourself to him by marking whether you $1=$ Strongly Disagree or $5=$ Strongly Agree

1. I frequently let my significant other know when I notice something in the relationship that I do not like.

$\begin{array}{llllllll}\text { Strongly Disagree } & 1 & 2 & 3 & 4 & 5 & \text { Strongly Agree }\end{array}$

2. I frequently praise my significant other know when I notice something in the relationship that I do like.

$\begin{array}{llllllll}\text { Strongly Disagree } & 1 & 2 & 3 & 4 & 5 & \text { Strongly Agree }\end{array}$

3. I frequently let my significant other know when I notice a behavior from him that I do not like.
Strongly Disagree
2
45
Strongly Agree

4. I frequently praise my significant other know when I notice a behavior from him that I do like.

$\begin{array}{lllllll}\text { Strongly Disagree } & 1 & 2 & 3 & 4 & 5 & \text { Strongly Agree }\end{array}$

5. I frequently tell my significant other what I am thinking.

$\begin{array}{llllllll}\text { Strongly Disagree } & 1 & 2 & 3 & 4 & 5 & \text { Strongly Agree }\end{array}$

6. I never let my significant other know my negative thoughts.
Strongly Disagree
2
3
45
Strongly Agree 
7. I am not afraid to voice my needs to my significant other.

$\begin{array}{llllllll}\text { Strongly Disagree } & 1 & 2 & 3 & 4 & 5 & \text { Strongly Agree }\end{array}$

8. I do not hesitate to tell my significant other what I need out of the relationship.

$\begin{array}{llllllll}\text { Strongly Disagree } & 1 & 2 & 3 & 4 & 5 & \text { Strongly Agree }\end{array}$

9. I rarely tell my significant other what I need out of the relationship.
Strongly Disagree
2
45
Strongly Agree

10. I am not afraid to voice my feelings to my significant other.
Strongly Disagree
2

3
4
5

\section{Strongly Agree}

11. I rarely tell my significant other how I feel.
Strongly Disagree

23
45
Strongly Agree

Revised Self-Disclosure Scale (Rubin, et al., 2008, p. 325)

Instructions: Please mark the following statements to reflect how you communicate/communicated with your significant other. Please consider your most recent or previous discussions and interactions with your romantic partner or immediate past romantic partner when answering this section. Indicate the degree to which the following statements reflect how you communicate/communicated with this person by marking whether you (7) Strongly agree, (6) agree, (5) moderately agree, (4) are undecided, (3) moderately disagree, (2) disagree, or (1) strongly disagree. Circle the response that you relate to. Work quickly and just record your first impressions.

1. When I express my personal feelings, I am always aware of what I am doing and saying.
Strongly Disagree
23
4
5
6
7
Strongly Agree

2. I do not often talk about myself.

$\begin{array}{llllllllll}\text { Strongly Disagree } & 1 & 2 & 3 & 4 & 5 & 6 & 7 & \text { Strongly Agree }\end{array}$

3. My statements of my feelings are usually brief.

$\begin{array}{llllllllll}\text { Strongly Disagree } & 1 & 2 & 3 & 4 & 5 & 6 & 7 & \text { Strongly Agree }\end{array}$

4. I usually talk about myself for fairly long periods at a time.

$\begin{array}{llllllllll}\text { Strongly Disagree } & 1 & 2 & 3 & 4 & 5 & 6 & 7 & \text { Strongly Agree }\end{array}$


5. My conversations do not last long when I am talking about myself.

$\begin{array}{lllllllll}\text { Strongly Disagree } & 1 & 2 & 3 & 4 & 5 & 6 & 7 & \text { Strongly Agree }\end{array}$

6. I often talk about myself.

$\begin{array}{llllllllll}\text { Strongly Disagree } & 1 & 2 & 3 & 4 & 5 & 6 & 7 & \text { Strongly Agree }\end{array}$

7. I often talk about my feelings.

$\begin{array}{lllllllll}\text { Strongly Disagree } & 1 & 2 & 3 & 4 & 5 & 6 & 7 & \text { Strongly Agree }\end{array}$

8. I rarely express my personal beliefs and opinions.

$\begin{array}{llllllllll}\text { Strongly Disagree } & 1 & 2 & 3 & 4 & 5 & 6 & 7 & \text { Strongly Agree }\end{array}$

9. On the whole, my disclosures about myself are more negative than positive.

$\begin{array}{lllllllll}\text { Strongly Disagree } & 1 & 2 & 3 & 4 & 5 & 6 & 7 & \text { Strongly Agree }\end{array}$

10. I normally reveal "bad" feelings I have about myself.

$\begin{array}{lllllllll}\text { Strongly Disagree } & 1 & 2 & 3 & 4 & 5 & 6 & 7 & \text { Strongly Agree }\end{array}$

11. I normally "express" positive or good feelings I have about myself.

$\begin{array}{lllllllll}\text { Strongly Disagree } & 1 & 2 & 3 & 4 & 5 & 6 & 7 & \text { Strongly Agree }\end{array}$

12. I usually disclose negative things about myself.

$\begin{array}{lllllllll}\text { Strongly Disagree } & 1 & 2 & 3 & 4 & 5 & 6 & 7 & \text { Strongly Agree }\end{array}$

13. On the whole, my disclosures about myself are more positive than negative.

$\begin{array}{lllllllll}\text { Strongly Disagree } & 1 & 2 & 3 & 4 & 5 & 6 & 7 & \text { Strongly Agree }\end{array}$

14. I intimately disclose who I really am, openly and fully in my conversation.

$\begin{array}{lllllllll}\text { Strongly Disagree } & 1 & 2 & 3 & 4 & 5 & 6 & 7 & \text { Strongly Agree }\end{array}$

15. I often disclose intimate, personal things about myself without hesitation.

$\begin{array}{llllllllll}\text { Strongly Disagree } & 1 & 2 & 3 & 4 & 5 & 6 & 7 & \text { Strongly Agree }\end{array}$

16. I feel that I sometimes do not control my self-disclosure of personal or intimate things I tell about myself.

$\begin{array}{lllllllll}\text { Strongly Disagree } & 1 & 2 & 3 & 4 & 5 & 6 & 7 & \text { Strongly Agree }\end{array}$

17. Once I get started, I intimately and fully self-disclose my thoughts, feelings and needs to my partner.
Strongly Disagree
23
5
6
7
Strongly Agree

4 
18. I always feel completely sincere when I reveal my own feelings and experiences.

$\begin{array}{llllllllll}\text { Strongly Disagree } & 1 & 2 & 3 & 4 & 5 & 6 & 7 & \text { Strongly Agree }\end{array}$

19. I am not always honest in my self-disclosures.

$\begin{array}{llllllllll}\text { Strongly Disagree } & 1 & 2 & 3 & 4 & 5 & 6 & 7 & \text { Strongly Agree }\end{array}$

20. I am always honest in my self-disclosures.

$\begin{array}{llllllllll}\text { Strongly Disagree } & 1 & 2 & 3 & 4 & 5 & 6 & 7 & \text { Strongly Agree }\end{array}$

21. I do not always feel completely sincere when I reveal my own feelings, emotions, behaviors or experiences.

$\begin{array}{llllllllll}\text { Strongly Disagree } & 1 & 2 & 3 & 4 & 5 & 6 & 7 & \text { Strongly Agree }\end{array}$

22. I willingly disclose a great deal of positive and negative things about myself to my significant other, honestly, and fully (in depth).

$\begin{array}{llllllllll}\text { Strongly Disagree } & 1 & 2 & 3 & 4 & 5 & 6 & 7 & \text { Strongly Agree }\end{array}$

The Silencing the Self Scale (by Dana Crowley Jack)

Instructions: Please indicate the number that best describes how you feel about each of the statements listed below (where 1 = Strongly Disagree, $3=$ Neutral-neither Agree or Disagree, and $5=$ Strongly Agree). Please answer regarding your feelings and behavior in relation to an intimate partner. If you are not currently in a romantic relationship, answer according to how you felt and behaved in your last intimate relationship.

1. I think it is best to put myself first because no one else will look out for me.

$\begin{array}{llllllll}\text { Strongly Disagree } & 1 & 2 & 3 & 4 & 5 & \text { Strongly Agree }\end{array}$

2. I don't speak [about] my feelings in an intimate relationship when I know they will cause disagreement.

$\begin{array}{llllllll}\text { Strongly Disagree } & 1 & 2 & 3 & 4 & 5 & \text { Strongly Agree }\end{array}$

3. Caring means putting the other person's needs in front of my own.
Strongly Disagree
1
$2 \quad 3$
34
5
Strongly Agree

4. Considering my needs to be as important as those of the people I love is selfish.

$\begin{array}{llllllll}\text { Strongly Disagree } & 1 & 2 & 3 & 4 & 5 & \text { Strongly Agree }\end{array}$

5. I find it is harder to be myself when I am in a close relationship than when I am on my own.
Strongly Disagree
1
23
34
45
Strongly Agree 
6. I tend to judge myself by how I think other people see me.

$\begin{array}{llllllll}\text { Strongly Disagree } & 1 & 2 & 3 & 4 & 5 & \text { Strongly Agree }\end{array}$

7. I feel dissatisfied with myself because I should be able to do all the things people are supposed to be able to do these days.

$\begin{array}{llllllll}\text { Strongly Disagree } & 1 & 2 & 3 & 4 & 5 & \text { Strongly Agree }\end{array}$

8. When my partner's needs and feelings conflict with my own, I always state mine clearly.

$\begin{array}{llllllll}\text { Strongly Disagree } & 1 & 2 & 3 & 4 & 5 & \text { Strongly Agree }\end{array}$

9. In a close relationship, my responsibility is to make the other person happy.

$\begin{array}{llllllll}\text { Strongly Disagree } & 1 & 2 & 3 & 4 & 5 & \text { Strongly Agree }\end{array}$

10. Caring means choosing to do what the other person wants, even when I want to do something different.

$\begin{array}{lllllll}\text { Strongly Disagree } & 1 & 2 & 3 & 4 & 5 & \text { Strongly Agree }\end{array}$

11. In order to feel good about myself, I need to feel independent.

$\begin{array}{llllllll}\text { Strongly Disagree } & 1 & 2 & 3 & 4 & 5 & \text { Strongly Agree }\end{array}$

12. In order to feel good about myself, I need to feel self-sufficient.

$\begin{array}{llllllll}\text { Strongly Disagree } & 1 & 2 & 3 & 4 & 5 & \text { Strongly Agree }\end{array}$

13. One of the worst things I can do is be selfish.

$\begin{array}{lllllll}\text { Strongly Disagree } & 1 & 2 & 3 & 4 & 5 & \text { Strongly Agree }\end{array}$

14. I feel I have to act in a certain way to please my partner.
Strongly Disagree
1
$\begin{array}{lll}2 & 3 & 4\end{array}$
$5 \quad$ Strongly Agree

15. Instead of risking confrontations in close relationships, I would rather not rock the boat. $\begin{array}{llllllll}\text { Strongly Disagree } & 1 & 2 & 3 & 4 & 5 & \text { Strongly Agree }\end{array}$

16. I speak my feelings with my partner, even when it leads to problems or disagreements.
Strongly Disagree

1
345
5 Strongly Agree

17. Often I look happy enough on the outside, but inwardly I feel angry.
Strongly Disagree
$\begin{array}{llll}1 & 2 & 3\end{array}$
45
Strongly Agree

18. Often I look happy enough on the outside, but inwardly I feel rebellious.
Strongly Disagree
1
2
3
45
Strongly Agree

19. In order for my partner to love me, I cannot reveal certain things about myself to him/her. $\begin{array}{llllllll}\text { Strongly Disagree } & 1 & 2 & 3 & 4 & 5 & \text { Strongly Agree }\end{array}$

20. When my partner's needs or opinions conflict with mine, rather than asserting my own point of view I usually end up agreeing with him/her.
Strongly Disagree
1
2
34
45
Strongly Agree 
21. When I am in a close relationship I lose my sense of who I am.

$\begin{array}{llllllll}\text { Strongly Disagree } & 1 & 2 & 3 & 4 & 5 & \text { Strongly Agree }\end{array}$

22. When it looks as though certain of my needs can't be met in a relationship, I usually realize that they weren't very important anyway.
Strongly Disagree
1

2
3
5
Strongly Agree

4

23. My partner loves and appreciates me for who I am.

$\begin{array}{llllllll}\text { Strongly Disagree } & 1 & 2 & 3 & 4 & 5 & \text { Strongly Agree }\end{array}$

24. Doing things just for myself is selfish.
Strongly Disagree
12
3
4
5
Strongly Agree

25. When I make decisions, other people's thoughts and opinions influence me more than my own thoughts and opinions.
Strongly Disagree

$\begin{array}{lll}1 & 2 & 3\end{array}$
4
5 Strongly Agree

26. I rarely express my anger at those close to me.
Strongly Disagree
$\begin{array}{lll}1 & 2 & 3\end{array}$
45
Strongly Agree

27. I feel that my partner does not know my real self.
Strongly Disagree
12
3

45
Strongly Agree

28. I think it's better to keep my feelings to myself when they do conflict with my partner's.
Strongly Disagree
1
3
4
5
Strongly Agree

2

29. I often feel responsible for other people's feelings.

$\begin{array}{lllllllll}\text { Strongly Disagree } & 1 & 2 & 3 & 4 & 5 & \text { Strongly Agree }\end{array}$

30. I find it hard to know what I think and feel because I spend a lot of time thinking about how other people are feeling.

$\begin{array}{llllllll}\text { Strongly Disagree } & 1 & 2 & 3 & 4 & 5 & \text { Strongly Agree }\end{array}$

31. In a close relationship I don't usually care what we do, as long as the other person is happy.
Strongly Disagree
12
3
4
5
Strongly Agree

32. I try to bury my feelings when I think they will cause trouble in my close relationship(s).

$\begin{array}{llllllll}\text { Strongly Disagree } & 1 & 2 & 3 & 4 & 5 & \text { Strongly Agree }\end{array}$


Appendix G: IRB Approval 


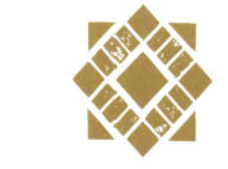

San José State UNIVERSITY

Office of the Provost Associated Vice President Graduate Studies \& Research

One Washington Square San Jose, CA 95192-0025 Voice: 408-924-2427 Fax: 408-924-2612

E-mail: gradstudies@sjsu.edu

http://www.sjsu.edu
To: LaToya M. Jackson

From: Pamela Stacks, Ph.D. Associate Vice President Graduate Studies and Research

Date: March 3, 2009

The Human Subjects-Institutional Review Board has approved your request to use human subjects in the study entitled:

"Where's My Daddy? The Effects of Fatherlessness on Women's Communication Styles in Romantic Relationships"

This approval is contingent upon the subjects participating in your research project being appropriately protected from risk. This includes the protection of the anonymity of the subjects' identity when they participate in your research project, and with regard to all data that may be collected from the subjects. The approval includes continued monitoring of your research by the Board to assure that the subjects are being adequately and properly protected from such risks. If at any time a subject becomes injured or complains of injury, you must notify Dr. Pamela Stacks, Ph.D. immediately. Injury includes but is not limited to bodily harm, psychological trauma, and release of potentially damaging personal information. This approval for the human subject's portion of your project is in effect for one year, and data collection beyond March 3, 2010 requires an extension request.

Please also be advised that all subjects need to be fully informed and aware that their participation in your research project is voluntary, and that he or she may withdraw from the project at any time. Further, a subject's participation, refusal to participate, or withdrawal will not affect any services that the subject is receiving or will receive at the institution in which the research is being conducted.

If you have any questions, please contact me at (408) 924-2427.

Protocol \#S0902031

cc. Priya Raman, 0112
The Calitornia State University Chancellor's Office Bakerstield, Channel Islands, Chico, Fullerton, Humboldt, Long Beach, Los Angeles, Maritime Academy. Monterey Bay, Northridge, Pomona Sactantento, San Bernardino, San Diego, San Marcos. Sonoma, Stanistays 